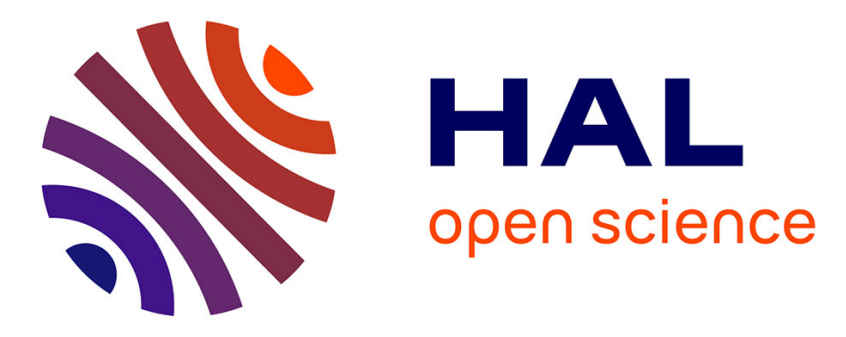

\title{
Subcellular specificity of cannabinoid effects in striatonigral circuits
}

Edgar Soria-Gomez, Antonio Pagano Zottola, Yamuna Mariani, Tifany

Desprez, Massimo Barresi, Itziar Bonilla-del Río, Carolina Muguruza, Morgane Le Bon-Jego, Francisca Julio-Kalajzić, Robyn Flynn, et al.

\section{To cite this version:}

Edgar Soria-Gomez, Antonio Pagano Zottola, Yamuna Mariani, Tifany Desprez, Massimo Barresi, et al.. Subcellular specificity of cannabinoid effects in striatonigral circuits. Neuron, 2021, 109 (9), pp.1513-1526.e11. 10.1016/j.neuron.2021.03.007 . hal-03375577

\section{HAL Id: hal-03375577 \\ https://hal.science/hal-03375577}

Submitted on 15 Oct 2021

HAL is a multi-disciplinary open access archive for the deposit and dissemination of scientific research documents, whether they are published or not. The documents may come from teaching and research institutions in France or abroad, or from public or private research centers.
L'archive ouverte pluridisciplinaire $\mathbf{H A L}$, est destinée au dépôt et à la diffusion de documents scientifiques de niveau recherche, publiés ou non, émanant des établissements d'enseignement et de recherche français ou étrangers, des laboratoires publics ou privés. 


\section{SUBCELLULAR SPECIFICITY OF CANNABINOID EFFECTS IN STRIATONIGRAL}

\section{CIRCUITS}

Edgar Soria-Gomez ${ }^{1,2,3,4,5,15,16^{*}}$, Antonio C. Pagano Zottola ${ }^{1,2,15}$, Yamuna Mariani $^{1,2,15}$, Tifany Desprez ${ }^{1,2}$, Massimo Barresi ${ }^{2,6}$, Itziar Bonilla-del-Río ${ }^{3,4}$, Carolina Muguruza ${ }^{7}$, Morgane Le Bon-Jego ${ }^{2,6}$, Francisca Julio-Kalajzić ${ }^{1,2}$, Robyn Flynn ${ }^{8,9}$, Geoffrey Terral ${ }^{1,2}$, Ignacio Fernández-Moncada ${ }^{1,2}$, Laurie M. Robin $^{1,2}$, Jose F. Olivera da Cruz ${ }^{1,2}$, Simone Corinti ${ }^{1,2}$, Yasmine Ould Amer ${ }^{10}$, Julia Goncalves ${ }^{1,2}$, Marjorie Varilh ${ }^{1,2}$, Astrid Cannich ${ }^{1,2}$, Bastien Redon ${ }^{1,2}$, Zhe Zhao $^{1,2}$, Thierry Lesté-Lasserre ${ }^{1,2}$, Peggy Vincent ${ }^{1,2}$, Tarson Tolentino-Cortes ${ }^{11}$, Arnau Busquets-García ${ }^{1,2}$, Nagore Puente ${ }^{3,4}$, Jaideep S. Bains ${ }^{9}$, Etienne Hebert-Chatelain $^{10}$, Gabriel Barreda-Gómez ${ }^{11}$, Francis Chaouloff ${ }^{1,2}$, Alexander W. Lohman ${ }^{8,9,12}$, Luis F. Callado ${ }^{7,13}$, Pedro Grandes ${ }^{3,4,14}$, Jerome Baufreton ${ }^{2,6}$, Giovanni Marsicano $0^{1,2,16,17^{*}}$, Luigi Bellocchio ${ }^{1,2,16^{*}}$

${ }^{1}$ INSERM, U1215 NeuroCentre Magendie, Endocannabinoids and Neuroadaptation, Bordeaux, France; ${ }^{2}$ University of Bordeaux; ${ }^{3}$ Dept. of Neurosciences, Faculty of Medicine and Nursing, University of the Basque Country UPV/EHU, Leioa, Spain; ${ }^{4}$ Achucarro Basque Center for Neuroscience, Leioa, Spain; ${ }^{5}$ IKERBASQUE, Basque Foundation for Science; ${ }^{6} \mathrm{IMN}-U \mathrm{MR}$ CNRS 5293 Neurodegenerative Diseases Institute, Bordeaux, France; ${ }^{7}$ Dept. of Pharmacology, University of the Basque Country UPV/EHU, Leioa, and Centro de Investigación Biomédica en Red de Salud Mental (CIBERSAM), Spain. ${ }^{8}$ Department of Cell Biology and Anatomy, Cumming School of Medicine, University of Calgary, Calgary, $A B$ Canada; ${ }^{9}$ Hotchkiss Brain Institute, University of Calgary, Calgary, AB Canada; ${ }^{10}$ Canada Research Chair in Mitochondrial Signaling and Physiopathology, Department of Biology, University of Moncton, NB Canada; ${ }^{11}$ Department of Research and Development, IMG Pharma Biotech S.L., Derio, Spain; ${ }^{12}$ Alberta Children's Hospital Research Institute, University of Calgary, Calgary, AB Canada; ${ }^{13}$ Biocruces Bizkaia Health Research Institute, Barakaldo, Spain; ${ }^{14}$ Division of Medical Sciences, University of Victoria, Victoria, BC, Canada.

${ }^{15}$ These authors contributed equally

${ }^{16}$ Senior Authors

${ }^{17}$ Lead Contact 


\section{SUMMARY}

5 Recent advances in neuroscience positioned brain circuits as the key units

6 controlling behavior, implying that their positive or negative modulation

7 necessarily leads to specific behavioral outcomes. However, emerging evidence

8 suggests that activation or inhibition of specific brain circuits can actually

9 produce multimodal behavioral outcomes. Here we show that, in the same

10 neuronal circuit, activation of a receptor at different subcellular locations can

11 determine distinct specific behaviors. Pharmacological activation of type-1

12 cannabinoid receptors $\left(\mathrm{CB}_{1}\right)$ in the striatonigral circuit elicits both antinociception and

13 catalepsy in mice. The reduction of nociception depends on the activation of plasma

14 membrane-residing $\mathrm{CB}_{1}$ receptors $\left(\mathrm{pmCB}_{1}\right)$, leading to inhibition of PKA activity and

15 Substance-P release. Conversely, mitochondrial-associated $\mathrm{CB}_{1}$ receptors $\left(\mathrm{mtCB}_{1}\right)$

16 located at the same terminals mediate cannabinoid-induced catalepsy through decrease

17 of intra-mitochondrial PKA-dependent cellular respiration and synaptic transmission.

18 Thus, subcellular-specific $\mathrm{CB}_{1}$ receptor signaling within striatonigral circuits

19 determines multimodal control of behavior.

20 KEYWORDS: $\mathrm{CB}_{1}$ receptor, catalepsy, antinociception, THC, mitochondria, 21 substantia nigra, PKA, Substance-P. 


\section{INTRODUCTION}

2 The cannabinoid receptor type-1 $\left(\mathrm{CB}_{1}\right)$ is the main target of cannabinoid

3 compounds. Cannabinoids possess high therapeutic potentials (Cohen et al.,

4 2019), particularly in the management of pain sensitivity (Donvito et al., 2018).

5 However, because of significant side-effects (e.g., cognitive and motor

6 dysfunctions; Borgelt et al., 2013; Prashad and Filbey, 2017) their medical and

7 recreational use is under intense scrutiny (Cohen et al., 2019). In particular,

8 activation of $\mathrm{CB}_{1}$ receptors impairs motor control (Giuffrida and Seillier, 2012;

9 Monory et al., 2007) and cataleptic-like effects are considered the leading

10 cause of vehicle accidents caused by human cannabis consumption (Martin et 11 al., 2017).

12 Basal ganglia circuits, classically associated with motor control, are now studied 13 in different contexts, including cognition and nociception. In particular, 14 striatonigral circuits formed by dopamine receptor type-1 $\left(D_{1}\right)$-positive striatal 15 medium spiny neurons projecting to the substantia nigra pars reticulata ( $\mathrm{SNr}$ ) 16 play crucial roles in motor regulation (Freeze et al., 2013) and participate in 17 nociception (Taylor et al., 2016). Indeed the SNr represents the ideal hub 18 coordinating voluntary movement and nociceptive responses according to the 19 different inputs received (Zhou et al., 2016), and displays one of the highest 20 levels of $\mathrm{CB}_{1}$ receptor protein expression in the brain (Marsicano and Kuner, 21 2008).

22 Neuronal $\mathrm{CB}_{1}$ receptors are predominantly associated with presynaptic terminal 23 plasma membranes $\left(\mathrm{pmCB}_{1}\right.$; Ibsen et al., 2017) and their activation mainly 
1 results in the fine-tuned regulation of neurotransmitter and neuropeptide release

2 (Busquets-Garcia et al., 2018). However, recent data indicate that functional

$3 \quad \mathrm{CB}_{1}$ receptors are also present in intracellular compartments, particularly in

4 association with mitochondria ( $\mathrm{mtCB}_{1}$; Benard et al., 2010; Busquets-Garcia et

5 al., 2018; Hebert-Chatelain et al., 2016; Jimenez-Blasco et al., 2020; Koch et

6 al., 2015), where they modulate bioenergetic and memory processes (Hebert-

7 Chatelain et al., 2016). Indeed, normal mitochondrial functions are required for

8 proper synaptic transmission underlying behavioral control (Francisco et al.,

9 2020; Kanellopoulos et al., 2020; Rangaraju et al., 2014).

10 The double subcellular functional localization of $\mathrm{CB}_{1}$ receptors in striatonigral 11 circuits suggests that cannabinoids might exert different effects not only by 12 altering the functions of different cell types and brain circuits, but also by 13 impacting different subcellular processes within the same circuits. Thus, here 14 we used the diverse distribution of $\mathrm{CB}_{1}$ receptors as a tool to investigate 15 whether subcellular constraints in the same neuronal circuit can determine 16 multimodal behavioral control.

\section{RESULTS}

18 Striatonigral $\mathrm{CB}_{1}$ receptors mediate cannabinoid-induced motor 19 impairments and antinociception

20 Cannabinoid agonists dose-dependently decrease motor activity and induce 21 antinociception through the activation of central $\mathrm{CB}_{1}$ receptors (Metna-Laurent 22 et al., 2017; Monory et al., 2007). To test whether $\mathrm{CB}_{1}$ receptor signaling in the $23 \mathrm{SNr}$ is responsible for these effects, we locally infused (Figure S1A) the $\mathrm{CB}_{1}$ 
1 receptor-selective antagonist AM251 in mice systemically treated

2 (intraperitoneal, i.p.) with the plant-derived $\mathrm{CB}_{1}$ receptor agonist $\Delta^{9}$ -

3 tetrahydrocannabinol (THC, $10 \mathrm{mg} / \mathrm{kg}$ ). AM251 fully blocked the THC-induced

4 reduction in locomotor activity in the open field (Figure S1B), catalepsy in the

5 horizontal-bar test (Figure 1A) and antinociception in the hot-plate test (Figure

6 1B), indicating that activation of $\mathrm{CB}_{1}$ receptors in this brain region is necessary

7 for these effects. As a control, voluntary or accidental misplacement of the

8 cannulas to brain areas just adjacent to the SNr (Figure S1A) eliminated any

9 impact of AM251 on THC-induced catalepsy, antinociception or hypolocomotion

10 (Figure 1A, 1B and S1B), clearly indicating the local specificity of the effect.

11 The SNr receives direct (striatonigral) and indirect (striatopallidal - pallidonigral)

12 information from striatal medium spiny neurons (MSNs). MSNs belonging to the

13 direct pathway preferentially express dopamine $D_{1} R$ receptor, whereas the

14 indirect pathway ones are identified by the expression of dopamine $D_{2} R$ 15 receptor, although in the external segment of the Glubus Pallidus (GPe) there 16 are some collateral $D_{1} R$-positive projections (Freeze et al., 2013). Interestingly, $17 \quad \mathrm{CB}_{1}$ receptors are abundantly expressed by both neuronal populations 18 (Fernandez-Ruiz et al., 2011). To identify which subpopulation of $\mathrm{CB}_{1}$ receptors 19 are responsible for the antinociceptive and motor effects of THC, we used an 20 intersectional recombinase approach (Zhao et al., 2020). We injected a 21 recombinant adeno-associated virus (rAAV) expressing the Cre recombinase 22 protein in a flipase (FLP)-dependent manner (AAV-FRT-iCre-EGFP) in the 23 striatum of mice carrying a "floxed" $\mathrm{CB}_{1}$ gene ( $C B_{1}$-flox; Marsicano et al., 2003).

24 Simultaneously, a retrograde rAAV expressing flipase (AAV-retro-FLP-BLFP) 
1 was administered into either the GPe or the SNr (Figure S1C). Thus, we

2 obtained the expression of the Cre recombinase in striatopallidal or striatonigral

3 neurons of $C B_{1}$-flox mice, leading to the generation of ST-GP-CB - KO or ST-

$4 \mathrm{SN}-\mathrm{CB}_{1}-\mathrm{KO}$ mutants that carrying the deletion of the receptor gene in either

5 populations, respectively (Figure S1C). In situ hybridization coupled to GFP

6 immunostaining for Cre detection showed that the recombinase was

7 preferentially expressed in $D_{1} R$ neurons over $D_{2} R$ in ST-SN-CB $-K O\left(D_{1} R / C r e\right.$

8 cells $68.5 \pm 2.8 \% ; D_{2} R /$ Cre cells $9 \pm 1 \%$ ) with an opposite situation in ST-GP-CB ${ }^{-}$

$9 \mathrm{KO}\left(\mathrm{D}_{1} \mathrm{R} /\right.$ Cre cells $21.7 \pm 1.9 \% ; \mathrm{D}_{2} \mathrm{R} /$ Cre cells $\left.42.5 \pm 5.1 \%\right)$.

10 Deletion of $\mathrm{CB}_{1}$ receptor gene in these models was confirmed by double in situ 11 hybridization experiments, which showed preferential loss of $\mathrm{CB}_{1}$ receptor 12 expression by $\mathrm{D}_{1} \mathrm{R}$-expressing striatal neurons in ST-SN-CB$B_{1}-\mathrm{KO}$ mice and by $13 \mathrm{D}_{2} \mathrm{R}$ expressing neurons in the ST-GP-CB$B_{1} \mathrm{KO}$ mice (Figure S1D). Accordingly, 14 ST-SN-CB $-\mathrm{KO}$ showed a consistent reduction of $\mathrm{CB}_{1}$ immunoreactivity in the $15 \mathrm{SNr}$ whereas in ST-GP-CB$-\mathrm{KO}, \mathrm{CB}_{1}$ protein was selectively reduced in the 16 GPe (Figure 1C).

17 Whereas ST-GP-CB $-\mathrm{KO}$ mice responded to THC treatment similar to control 18 animals, ST-SN-CB $-\mathrm{KO}$ littermates did not display either catalepsy or 19 antinociception upon THC administration (Figure 1D and 1E). On the other 20 hand, the hypolocomotor effect of THC was maintained upon both 21 manipulations (Figure S1E), suggesting that other subpopulations of $\mathrm{SNr} \mathrm{CB}_{1}$ 22 receptors are likely involved in this effect. These data indicate that activation of $23 \mathrm{CB}_{1}$ receptors expressed at striatonigral, but not striatopallidal, terminals is 
1 necessary for THC-induced antinociception and catalepsy, revealing a common

2 anatomical target for these effects.

4 Cannabinoid-induced antinociception relies on activation of 5 striatonigral $\mathrm{pmCB}_{1}$ and regulation of Substance-P/NK 6 receptor activity

7 THC and AM251 are lipophilic molecules, which easily cross biological

8 membranes, thereby potentially acting at both plasma membrane and

9 intracellular $\mathrm{CB}_{1}$ receptors. To distinguish between the contributions of these 10 two pools of $\mathrm{CB}_{1}$ receptors to the $\mathrm{THC}$ effects in the $\mathrm{SNr}$, we locally 11 administered the $\mathrm{CB}_{1}$ receptor antagonist Hemopressin (Hp; Heimann et al., 12 2007). $\mathrm{Hp}$ is a peptide compound, which is unable to cross the plasma 13 membrane (Benard et al., 2012) and, thereby, antagonizes only $\mathrm{pmCB}_{1}$ 14 receptors but not intracellular ones (Benard et al., 2012; Rozenfeld and Devi, 15 2008). Intra-SNr administration of $\mathrm{Hp}$ did not exert any effect by itself and it was 16 not able to reverse THC-induced catalepsy (Figure 1F), but it strongly reduced 17 the antinociceptive effect of THC (Figure 1G). Striatonigral neurons are known 18 to release several neuropeptides, including Substance-P (Deniau et al., 2007; 19 Johnson et al., 2016), which promotes pain perception via central activation of 20 its main target, the type-1 neurokinin receptor ( $\mathrm{NK}_{1}$; Steinhoff et al., 2014).

21 Interestingly, inhibition of $\mathrm{NK}_{1}$ signaling can decrease pain reactions induced by 22 systemic $\mathrm{CB}_{1}$ receptor blockade (Darmani and Pandya, 2000), and some 23 evidence suggests a negative role of $\mathrm{CB}_{1}$ receptor signaling in Substance-P 
1 production and release in the spinal cord and the striatum (Lever and

2 Malcangio, 2002; Steiner et al., 1999). To test whether Substance-P signaling in

3 the SNr might underlie THC-induced antinociception, we systemically

4 administered the selective $\mathrm{NK}_{1}$ receptor agonist GR73632 (Ray et al., 2009), in

5 combination with THC. GR73632 $(75 \mu \mathrm{g} / \mathrm{kg})$ alone had no effect in any test, and

6 it did not alter the cataleptic effect of THC (Figure S1F). However, this

7 treatment blocked the antinociceptive effect of the cannabinoid (Figure S1G).

8 Then, in order to verify that the interaction between $\mathrm{CB}_{1}$ and $\mathrm{NK}_{1}$ receptors

9 occurs in the SNr, GR73632 was locally injected before systemic THC

10 treatment. This treatment did not alter THC-induced catalepsy (Figure 1H), but,

11 strikingly, it fully abolished the antinociceptive effect of THC (Figure 1I). These

12 data show that cannabinoid-induced antinociception involves Substance-P

13 signaling, suggesting that activation of $C_{1}$ receptors might reduce the release

14 of the neuropeptide at striatonigral terminals. To test this hypothesis, we

15 established an ex vivo "sniffer cells" approach (Figure $\mathbf{S 1 H}$ ), which has been

16 already successfully used to detect the release of other neuropeptides in real

17 time (Zaelzer et al., 2018). We transfected HEK-293T cells with 2 plasmids for

18 co-expression of $\mathrm{NK}_{1}$ receptor together with the calcium indicator GCaMP6s

19 (Figure $\mathbf{S 1 H}$ ) to obtain cells capable of detecting exogenously applied

20 Substance-P in a very sensitive (EC50, $5.1 \mathrm{nM})$ and specific way (Figure S1H

21 and S1I). These cells were then seeded over acute sagittal brain slices

22 containing the striatonigral pathway (Figure 1J). After 2-hour rest to allow

23 cellular adhesion to the slices, GCaMP6s fluorescence was imaged (Zaelzer et

24 al., 2018) (Figure 1J) before and after electrical stimulation of the striatonigral

25 afferents. This manipulation elicited a marked increase in GCaMP6s 
1 fluorescence in cells placed above the $\mathrm{SNr}$ (Figure 1K, S1J, S1K, S1L, S1M),

2 indicating an increase in Substance-P release. The increase in fluorescence is

3 specific for the peptide, since is absent when slices are treated with cells only

4 expressing GCaMP6s (Figure S1J and S1L) and it was blocked by the $\mathrm{NK}_{1}$

5 selective antagonist CP122721 (Figure S1K and S1L). Strikingly, application of

6 the cannabinoid agonist WIN55,212-2 (WIN) dramatically reduced electrically

7 evoked Substance-P release in wild type mice (Figure $1 \mathrm{~K}$ and $\mathrm{S1M}$ ), but not in

$8 \quad C B_{1}-\mathrm{KO}$ littermates (Figure 1K). WIN did not affect the response to exogenous

9 peptide (Figure $\mathbf{S 1 N}$ ), showing that its effect in slices was due to a $\mathrm{CB}_{1}$

10 receptor-mediated decrease of Substance-P release.

11 To further confirm the striatonigral origin of Substance-P release as well as its 12 modulation by cannabinoids, we coupled the sniffer cells approach to 13 optogenetic stimulation (Zaelzer et al., 2018). For this aim, we virally expressed 14 the red-activated channelrhodopsin ChrimsonR (Klapoetke et al., 2014) in $D_{1} R$ 15 Cre positive cells (Lemberger et al., 2007) of the striatum and then we 16 conducted sniffer experiments in $\mathrm{SNr}$ slices (Figure 1L). As technical 17 validations of the approach, we also performed patch clamp experiments in $\mathrm{SNr}$ 18 neurons upon light stimulations. As expected based on the partial spectrum 19 overlapping of the used light wavelength (Klapoetke et al., 2014), the 20 application of the blue light to record calcium levels in the sniffer cells induced a 21 slight activation of Chrimson and triggered-GABAergic currents which, however, 22 had a much lower amplitude than the ones triggered by the red light (Figure 23 S10). Thus, some experiments had to be discarded because the blue-light 24 stimulation was able to saturate the subsequent red-light-induced Substance-P 
1 release. Nevertheless, Chrimson activation by red-light triggered above-

2 baseline calcium responses in sniffer cells in approximately $50 \%$ of the

3 experiments. In these conditions, calcium responses indicating Substance-P

4 release were drastically reduced by the application of WIN (Figure 1M),

5 similarly as previously observed with electrical stimulation.

6 Altogether, these data indicate that $\mathrm{pmCB}_{1}$ receptors at $\mathrm{D}_{1} \mathrm{R}$-positive

7 striatonigral terminals are responsible for THC-induced antinociception,

8 involving the modulation of Substance- $\mathrm{P} / \mathrm{NK}_{1}$ signaling. Additionally, these

9 results point out a different mechanism for the cataleptic effect, which likely

10 involves intracellular $\mathrm{CB}_{1}$ receptors in the $\mathrm{SNr}$.

\section{Subcellular localization of $\mathrm{CB}_{1}$ receptors in the $\mathbf{S N r}$}

12 To investigate the intracellular distribution of the $\mathrm{CB}_{1}$ receptor in the $\mathrm{SNr}$, we

13 used immunogold electron microscopy (Puente, 2019). The majority of $\mathrm{CB}_{1}$ 14 receptor protein in the $\mathrm{SNr}$ of WT mice was associated to the plasma 15 membrane $\left(\mathrm{pmCB}_{1}\right)$ of synaptic terminals (Figure 2A-C and S2A). 16 Quantifications of gold particles using stringent parameters to identify 17 mitochondrial-localized immunoreactivity (Puente, 2019) revealed that $\mathrm{CB}_{1}$ 18 receptors in the $\mathrm{SNr}$ are anatomically associated to mitochondrial membranes $19\left(\mathrm{mtCB}_{1}\right)$ with a density of approximately 3 particles per $20 \mu \mathrm{m}^{2}$ (Figure 2A-D 20 and S2A). Moreover, approximately $10 \%$ of total mitochondria analyzed were 21 labeled with $\mathrm{CB}_{1}$ receptor in WT mice (Figure 2A-E and S2A). Conversely, only 22 background levels of $\mathrm{CB}_{1}$ immunoreactivity was detected in any analyzed 23 compartment of $C B_{1}-\mathrm{KO}$ mice (Figure 2A-E and S2A), clearly demonstrating 24 the existence of $\mathrm{mtCB}_{1}$ in striatonigral terminals. 


\section{Generation of $\mathrm{DN22}-\mathrm{CB}_{1}-\mathrm{KI}$ mutant mice, lacking $\mathrm{mtCB}_{1}$ receptors}

2 We previously showed that a mutant version of the $\mathrm{CB}_{1}$ protein lacking the first

322 amino acids (called DN22-CB ${ }_{1}$ ) is neither anatomically nor functionally

4 associated to mitochondrial membranes, nevertheless maintaining its other

5 functions (e.g. at plasma membrane; Hebert-Chatelain et al., 2016). Thus, we

6 generated a new knock-in mutant mouse line (called DN22-CB,-KI; Pagano

7 Zottola et al., 2020), in which the wild-type $C B_{1}$ receptor gene is replaced by the

8 coding sequence of the DN22-CB 1 protein (Figure S2B). Quantifications of $\mathrm{CB}_{1}$

9 receptor mRNA (by qRT-PCR) and protein (by immunofluorescence) revealed no significant differences between WT and DN22- $C B_{1}-\mathrm{KI}$ mice in many different

11 brain regions (Figure S2C and S2D). Counting of gold particles in immunoelectron microscopy experiments indicated that the total amount of $\mathrm{CB}_{1}$ receptor protein in the SNr was not significantly different between DN22-CB $-\mathrm{KI}$ and WT littermates (Figure 2F, 2G and S2D). Similarly, the levels of $\mathrm{pmCB}_{1}$ were not impacted by the mutation (Figure $\mathbf{2 F}, \mathbf{2 H}$ and $\mathbf{S 2 D}$ ). However, the density of mitochondrial-associated $\mathrm{mtCB}_{1}$ receptors and the percentage of $\mathrm{CB}_{1}$-positive

17 mitochondria were significantly lower in DN22- $\mathrm{CB}_{1}-\mathrm{KI}$ mice as compared to WT 18 littermates, reaching levels undistinguishable from global $C B_{1}-\mathrm{KO}$ mice (Figure $\mathbf{2 F}, \mathbf{2 I}, \mathbf{2} \mathbf{J}$ and $\mathbf{S 2 D}$ ). To test the ability of $\mathrm{DN22}-\mathrm{CB}_{1}$ receptors to activate $\mathrm{G}$ protein signaling, we performed $\left[{ }^{35}\right.$ S GTPy binding assays upon stimulation with

21 the cannabinoid agonist WIN in cortical, hippocampal and midbrain extracts

22 from WT, $C B_{1}-\mathrm{KO}$, and DN22- $C B_{1}-\mathrm{KI}$ mice (Figure $2 \mathrm{~K}$ ). The DN22-CB ${ }_{1}$ mutant 23 was as efficient as its wild-type cognate in triggering $G$ protein activation

24 (Figure 2K). These results were also confirmed by in situ $\left[{ }^{35} \mathrm{~S}\right] \mathrm{GTPY}$ binding 25 assays in other brain regions (Figure S2E and S2F). Moreover, 
1 autoradiographic analyses of $\left[{ }^{3 \mathrm{H}}\right]$ CP55.940 cannabinoid agonist binding in

2 parallel sections did not identify any significant difference between the two

3 genotypes (Figure $\mathbf{S} 2 \mathrm{G}$ and $\mathbf{S 2 H}$ ). Thus, DN22- $C B_{1}-\mathrm{KI}$ mice display normal

4 binding of cannabinoid ligands and subsequent activation of G-protein 5 signaling.

6 Oxygen consumption assays in substantia nigra (SN) homogenates revealed

7 that WIN lowered ADP-stimulated mitochondrial respiration in WT but not in

$8 \mathrm{CB}_{1}$-KO mice (Figure $\mathbf{2} \mathbf{L}$ and $\mathbf{S 2 I}$ ), indicating a specific $\mathrm{CB}_{1}$-mediated control of

9 mitochondrial activity. Notably, this effect was also abolished in SN

10 homogenates from $\mathrm{DN22}-\mathrm{CB}_{1}-\mathrm{KI}$ mice, showing its dependency on mtCB${ }_{1}$

11 receptors (Figure $\mathbf{2 L}$ and $\mathbf{S 2 I}$ ). The $\mathrm{DN22}-\mathrm{CB}_{1}-\mathrm{KI}$ mutant strain was viable,

12 fertile and presented normal body weight, muscular strength and locomotion

13 (Figure S3A and S3B). Interestingly, DN22-CB,-KI mice did not display any 14 alteration in voluntary running wheel activity (Figure S3C), where global $C B_{1^{-}}$ $15 \mathrm{KO}$ mice are impaired (Dubreucq et al., 2010), showing that certain $\mathrm{CB}_{1}$ 16 receptor-dependent behavioral functions are maintained in these mutants.

17 Previous evidence suggests that $\mathrm{mtCB}_{1}$ receptors might be partly responsible 18 for electrophysiological depolarization-induced suppression of inhibition in the 19 hippocampus (DSI; Benard et al., 2012), which is known to depend on 20 endocannabinoid signaling (Wilson et al., 2001). Interestingly, DN22-CB${ }_{1}-\mathrm{KI}$ 21 mice displayed DSI, but its amplitude was slightly decreased as compared to 22 WT littermates (Figure S3D and S3E), confirming the participation of $\mathrm{mtCB}_{1}$ 23 receptors in this form of synaptic plasticity (Benard et al., 2012). Altogether, 24 these observations indicate that the constitutive deletion of the first 22 amino 
1 acids of the $\mathrm{CB}_{1}$ protein specifically impacts the effects of cannabinoids

2 involving mitochondrial activity, but leave other functions of $\mathrm{CB}_{1}$ receptors

3 unchanged. Therefore, DN22-CB $-\mathrm{Cl}$ mutant mice represent a novel and

4 suitable tool to untangle the roles of $\mathrm{mtCB}_{1}$ receptors.

6 Activation of $\mathrm{mtCB}_{1}$ receptors decreases synaptic transmission

7 at striatonigral terminals and induces catalepsy, but not

\section{8 antinociception}

9 To explore if $\mathrm{mtCB}_{1}$ receptors participate in the well-known cannabinoid control

10 of synaptic transmission in the SNr (Sales-Carbonell et al., 2013; Szabo et al.,

11 2000), we performed optogenetic-coupled electrophysiological recordings of

12 striatonigral neurotransmission in slices. The rAAV expressing

13 channelrhodopsin (Chr2) under the neuronal synapsin promoter (AAV-synP-

14 Chr2-mCherry) was injected into the dorsal striatum (Figure 3A) of DN22- $C B_{1^{-}}$

$15 \mathrm{KI}, C B_{1}-\mathrm{KO}$ mice and WT littermates. Non-dopaminergic neurons receiving

16 Chr2-expressing fibers from striatonigral projecting neurons were recorded

17 using whole-cell patch clamp in SNr slices (Figure 3B). Delivery of brief light-

18 pulses on striatonigral terminals triggered reliable optically-induced inhibitory

19 post-synaptic currents (olPSCs) in SNr neurons, which were sensitive to $\mathrm{GABA}_{A}$

20 blockade (Figure 3C). Treatment with WIN $(5 \mu \mathrm{M})$ reduced olPSCs in WT but

21 not in $C B_{1}-\mathrm{KO}$ mice (Figure $\mathbf{3 D}$ and $\mathbf{3 E}$ ), suggesting a $\mathrm{CB}_{1}$-dependendent

22 mechanism. Interestingly, WIN-mediated reduction of oIPSCs was absent in

23 slices from DN22- $C B_{1}-\mathrm{KI}$ mice (Figure 3D and 3E). Furthermore, no changes 
1 were observed in the paired-pulse ratio during baseline, indicating a normal

2 synaptic efficiency in DN22-CB $-\mathrm{KI}$ mice as compared to their WT littermates

3 (Figure S3F). These data indicate that $\mathrm{mtCB}_{1}$ receptors are necessary for the

4 cannabinoid-induced inhibition of synaptic transmission in the striatonigral

5 pathway, which has been proposed as a potential mechanism for cannabinoid-

6 induced catalepsy (Garcia et al., 2016). Accordingly, THC or WIN

7 administrations induced strong catalepsy in WT mice, but not in DN22-CB ${ }_{1}-\mathrm{KI}$

8 littermates (Figure 3F). Conversely, both genotypes displayed normal

9 cannabinoid-induced antinociception (Figure 3G). Interestingly, WIN application

10 reduced Substance-P release in DN22- $C B_{1}-\mathrm{KI}$ SNr slices (Figure S3G) to a

11 similar extent as observed in WT slices (Figure 1K). Furthermore, both intra-

$12 \mathrm{SNr}$ hemopressin infusion (Figure $\mathbf{S 3 H}$ ), as well as systemic administration of

13 the $\mathrm{NK}_{1}$ receptor agonist GR73632 (Figure S3I) strongly reduced THC-induced

14 antinociception in DN22- $C B_{1}-\mathrm{KI}$ mice. Therefore, the $\mathrm{CB}_{1}$-dependent control of

15 Substance-P release in the $\mathrm{SNr}$, and subsequent antinociceptive effect, do not

16 require $\mathrm{mtCB}_{1}$ receptors. These data show that the activation of $\mathrm{mtCB}_{1}$

17 receptors is necessary for cannabinoid-induced synaptic depression in the $\mathrm{SNr}$

18 and catalepsy. Conversely, $\mathrm{mtCB}_{1}$ receptors are dispensable for the local

19 cannabinoid-induced signaling leading to antinociception. Thus, a mechanistic

20 double dissociation of these effects of cannabinoids seems to exist in the SNr. 


\section{Cannabinoid-induced catalepsy relies on activation of}

\section{2 striatonigral $\mathrm{mtCB}_{1}$ receptors and mitochondrial inhibition}

3 Striatal dopamine receptor type-1 $\left(D_{1}\right)$-positive cells are one of the major

4 components of striatonigral circuits (Freeze et al., 2013). Notably, mice lacking

5 the $C B_{1}$ gene in $D_{1}$-positive cells $\left(D_{1}-C B_{1}-K O\right)$ do not display cannabinoid-

6 induced catalepsy (Monory et al., 2007). We took advantage of this phenotype

7 to investigate the specific impact of striatonigral $\mathrm{mtCB}_{1}$ receptor activation on

8 the cataleptic effect of cannabinoids. For this purpose, we adopted a $\mathrm{CB}_{1}$

9 rescue approach (Figure $\mathbf{4 A}$ ) by injecting Cre-dependent viral vectors

10 expressing $\mathrm{CB}_{1}$ or $\mathrm{DN}_{22}-\mathrm{CB}_{1}$ (AAV-DIO-CB $\mathrm{B}_{1}$ or $\mathrm{AAV}-\mathrm{DIO}-\mathrm{DN} 22-\mathrm{CB}_{1}$,

11 respectively) directly into the dorsal striatum of $D_{1}-C B_{1}-K O$ mice (expressing

12 Cre specifically in $D_{1}$ positive cells) to specifically target striatonigral neurons

13 (Figure 4B and 4C). Oxygen consumption assays revealed that WIN failed to 14 decrease mitochondrial respiration in $\mathrm{SN}$ extracts from $\mathrm{D}_{1}-\mathrm{CB}_{1}-\mathrm{KO}$ mice 15 injected with a control virus (Figure 4D). The re-expression of $\mathrm{CB}_{1}$ receptors in 16 striatal $D_{1}$-positive cells of mutant mice fully rescued the cannabinoid-induced 17 decrease of oxygen consumption in the SN (Figure 4D), whereas the injection 18 of $A A V-D I O-D N 22-B_{1}$ was not able to restore this effect (Figure 4D). The 19 rescue of $\mathrm{CB}_{1}$ receptors in striatonigral cells was sufficient to restore the 20 cataleptic effect of $\mathrm{THC}$ in $\mathrm{D}_{1}-\mathrm{CB}_{1}-\mathrm{KO}$ mice (Figure $4 \mathrm{E}$ ). In contrast, no 21 catalepsy was observed after DN22-CB ${ }_{1}$ expression in THC-treated $\mathrm{D}_{1}-\mathrm{CB}_{1}-\mathrm{KO}$ 22 mice (Figure 4E). Additionally, we performed correlation analysis between the 23 levels of $\mathrm{CB}_{1}$ expression (Figure $4 \mathrm{C}$ ) and THC-induced catalepsy (Figure 4E) 24 in mice with rescue of $\mathrm{CB}_{1}$ or $\mathrm{DN22}-\mathrm{CB}_{1}$. The absence of positive correlation 
1 (Figure S3J) between the parameters, indicates that the subcellular localization

2 rather than the expression levels of $\mathrm{CB}_{1}$ determines the cataleptic effect of

3 cannabinoids.

4 Thus, $\mathrm{mtCB}_{1}$ receptor signaling in the striatonigral circuit is responsible for the

5 local reduction of mitochondrial respiration and the cataleptic effect induced by

6 cannabinoids.

8 Cannabinoid-induced catalepsy involves striatonigral

\section{9 mitochondrial sAC activity}

10 To identify the molecular machinery linking the effects of cannabinoids on SN

11 mitochondrial respiration and catalepsy, we aimed at dissecting the

12 intramitochondrial signaling pathways involved. Stimulation of $\mathrm{mtCB}_{1}$ receptors

13 activates intra-mitochondrial $\mathrm{G} \alpha_{i}$ proteins, thereby inhibiting soluble adenylyl

14 cyclase (SAC) and protein kinase-A (PKA) activities (Hebert-Chatelain et al.,

15 2016). The cannabinoid-induced reduction of mitochondrial respiration in SN

16 extracts was abolished by pretreatment with the sAC inhibitor KH7 (Figure 4F),

17 suggesting that $\mathrm{sAC}$ activity is involved in $\mathrm{mtCB}_{1}$ receptor-dependent effects in

18 this brain region. On the other hand, pre-treatment with the $N K_{1} R$ agonist

19 GR73632 did not impact the effect of WIN on SN respiration (Figure S3K),

20 suggesting dissociation between the two pathways. To investigate whether the

21 intra-mitochondrial SAC pathway participates in the SNr-dependent behavioral

22 effects of $\mathrm{THC}$, we first locally injected $\mathrm{KH} 7$ before systemic $\mathrm{THC}$ treatment.

23 The SAC inhibitor blocked the cataleptic effect of THC (Figure 4G), without 
1 impacting the behavior of mice in the hot-plate test (Figure $\mathbf{4 H}$ ). Thus, similarly

2 to the impact on mitochondrial respiration, the cataleptic effect of THC requires

3 SAC activity in the SNr. However, these results do not show that the $\mathrm{CB}_{1}$

4 signaling involved in catalepsy is specific of striatonigral neurons. Since sAC

5 expression is not limited to mitochondria and $\mathrm{KH} 7$ can have additional targets

6 (Valsecchi et al., 2014), pharmacological experiments cannot provide definitive

7 information about the subcellular location and the molecular specificity of the

8 observed effects. To address these issues, we used a Cre-dependent viral

9 approach to overexpress a mitochondrial-targeted version of sAC (mt-sAC-HA;

10 Hebert-Chatelain et al., 2016; Valsecchi et al., 2014) that was previously

11 reported to be targeted to mitochondria (Figure S3L, Pearson's coefficient

$120.70 \pm 0.04$; Hebert-Chatelain et al., 2016) and block respiratory effects of

13 cannabinoids in cell cultures (Hebert-Chatelain et al., 2016). Striatonigral

14 overexpression of mt-sAC obtained by injecting AAV-DIO-mt-sAC-HA into the

15 dorsal striatum of $D_{1}$-Cre mice (Lemberger et al., 2007) (Figure S3M and N)

16 fully blocked the cannabinoid effect on mitochondrial respiration in SN extracts

17 (Figure $4 \mathrm{I}$ and S3O). Strikingly, these mice did not present any cataleptic effect 18 upon THC administration as compared to control mice (Figure 4J), whereas 19 they displayed a normal THC-induced antinociception (Figure 4K). These data 20 show that inhibition of intra-mitochondrial SAC signaling in striatonigral terminals 21 is not involved in antinociception, but it underlies the cannabinoid-induced 22 decrease of mitochondrial respiration and the subsequent cataleptic effect. 


\section{PKA signaling mediates both cannabinoid-induced catalepsy}

2 and antinociception, but in different subcellular compartments

3 Adenylyl cyclase activity triggers several signaling pathways and the activation

4 of PKA is one of the most prominent (Dwivedi and Pandey, 2008). Inhibition of

5 PKA is one of the best characterized signaling mechanisms of $\mathrm{CB}_{1}$ receptor

6 activation throughout the brain (Ibsen et al., 2017), including in striatal neurons

7 (Borgkvist and Fisone, 2007; Martinez et al., 2012). For instance, the activity of

8 this kinase is necessary for the stimulation of Substance-P release in spinal

9 cord and cultured dorsal root ganglion neurons, and this mechanism is

10 modulated by $\mathrm{CB}_{1}$ receptors (Chen et al., 2018; Oshita et al., 2005). Within

11 mitochondria, PKA signaling following mt-sAC activation is a target for $\mathrm{mtCB}_{1}$ -

12 induced reduction of mitochondrial functions (Hebert-Chatelain et al., 2016).

13 Thus, PKA inhibition at different subcellular locations might mediate $\mathrm{pmCB}_{1}$ -

14 dependent antinociception and $\mathrm{mtCB}_{1}$-dependent catalepsy, by reducing

15 Substance-P release and inhibiting mitochondrial respiration, respectively. To

16 test this hypothesis, we used constructs expressing constitutively active mutant

17 forms of PKA (Niswender et al., 2005) targeted either to the cytosol (PKA-CA,

18 myc tagged) or to the mitochondria (MLS-PKA-CA, myc-tagged, Figure S3P;

19 Hebert-Chatelain et al., 2016). These constructs were used to generate rAAVs

20 for Cre-dependent expression, which were injected into the dorsal striatum of

$21 D_{1}$-Cre mice. By this way, we obtained expression of these two different forms

22 of constitutively active PKA in striatonigral neurons (Figure S3Q). Expression of

23 PKA-CA did not alter catalepsy, but it blocked the antinociceptive effect of THC

24 (Figure 4L and 4M). Conversely, the expression of MLS-PKA-CA dampened 
1 the cataleptic effect of THC, without changing the antinociception (Figure 4L

2 and 4M). Importantly, the expression of PKA-CA did not alter cannabinoid-

3 induced decrease of mitochondrial respiration in SN extracts, whereas MLS-

4 PKA-CA abolished this effect (Figure $\mathbf{4 N}$ and S3R). These data show that

5 inhibition of PKA activity in striatonigral neurons mediates both cataleptic and

6 antinociceptive effects of cannabinoids. However, the specific subcellular

7 location of the activity of this kinase is differentially involved in these effects.

8 Whereas intra-mitochondrial SAC-PKA signaling mediates cannabinoid-induced

9 decrease of mitochondrial respiration and catalepsy, the antinociceptive effect

10 of these drugs relies on the inhibition of cytoplasmic PKA.

\section{DISCUSSION}

12 This study reveals that the differential subcellular localization of a receptor can

13 bias the behavioral consequences of its activation in the same brain circuit. Via

14 the regulation of specific subcellular molecular pathways, striatonigral neurons 15 are the substrate of both adverse cataleptic and clinically-relevant 16 antinociceptive effects of cannabinoids. While stimulation of $\mathrm{pmCB}_{1}$ receptors at 17 striatonigral terminals induces inhibition of nociceptive responses, presynaptic $18 \mathrm{mtCB}_{1}$ receptors in the same location are responsible for cataleptic effects of 19 cannabinoids (Figure S4). Mechanistically, cannabinoid-induced catalepsy 20 relies on $\mathrm{mtCB}_{1}$ receptor-dependent regulation of intramitochondrial sAC/PKA 21 signaling, inhibition of mitochondrial respiration and decrease of inhibitory 22 synaptic transmission at striatonigral terminals. Conversely, antinociception 23 requires $\mathrm{pmCB}_{1}$ receptor-dependent reduction of cytosolic PKA activity and 24 decrease of Substance-P/NK ${ }_{1}$ receptor signaling (Figure S4). 
1 The SNr, being a key part of the basal ganglia loop (Freeze et al., 2013), is

2 classically considered to provide mainly motor regulation, integrating striatal

3 pathways and regulating the activity of motor cortex through thalamic

4 projections (Borsook et al., 2010). However, the SNr also, directly and indirectly,

5 modulates the activity of several brain regions involved in pain processing such

6 as the superior and inferior colliculus, pedunculopontine nucleus (PPN), rostral

7 ventral medulla and dorsal root ganglia (Borzook et al., 2010; Zhou, 2016).

8 Moreover, several electrical and optogenetic stimulation studies revealed a

9 novel nociceptive network, e.g Subthalamic Nucleus - SNr - superior colliculus

10 and parabrachial nucleus (Luan et al., 2020; Pautrat et al., 2018). Thus, the SNr

11 is ideally placed to control voluntary movement, as wells as nociceptive

12 responses. There could be two different sets of striatonigral neurons, one

13 dedicated to nociception control (as indicated by the presence of different

14 nociceptive neurons in the $\mathrm{SNr}$ and the other to movement control (as already

15 extensively studied (Borzook et al., 2010). Alternatively the same neurons could

16 be involved in both effects according to the different inputs received and

17 possibly differential molecular mechanisms triggered by those inputs (Chudler

18 and Dong, 1995). In this scenario, the subcellular localization of $\mathrm{CB}_{1}$ receptors

19 could serve as a molecular switch regulating motor control and pain perception.

20 More recently, an emerging idea started to grow in brain research about the 21 possibility that specific subcellular locations of a molecular process could trigger 22 different cellular effects (Creighton, 2011; llouz et al., 2017). For instance, 23 although their relative impact on behavior has not been investigated so far, 24 specific subcellular locations of targeted molecules have been proposed to 
1 differentially modulate cellular processes in the same brain cells (Bucko et al.,

2 2019; Qi et al., 2019; Skalhegg and Tasken, 2000). The recent evidence that

3 certain GPCRs, including $\mathrm{CB}_{1}$, can functionally localize to different organelles

4 (Benard et al., 2012; Eichel and von Zastrow, 2018; Hebert-Chatelain et al.,

5 2016; Lahuna and Jockers, 2018) indicates that they might be directly involved

6 in these subcellular-specific signaling pathways and their behavioral

7 consequences. Moreover, given the crucial role of proper GPCRs trafficking

8 for their activity (Lobingier and von Zastrow, 2019), one might speculate that

9 a transient mitochondrial passage might be a determinant of certain $\mathrm{CB}_{1}$

10 functions at plasma membranes. Although not yet possible to be directly

11 addressed experimentally, this interesting hypothesis might change the current

12 view of receptor trafficking and will be for sure the subject of future studies.

13 The activation of $\mathrm{mtCB}_{1}$ receptors in striatonigral terminals is responsible for the

14 effects of cannabinoids on cellular respiration, synaptic transmission and 15 behavioral catalepsy. A growing body of evidence highlights the importance

16 of mitochondrial functions for the regulation of synaptic transmission (Garcia

17 et al., 2019; Vos et al., 2010), but little is known concerning the detailed 18 molecular mechanisms linking the organelle to the synaptic machinery. The 19 constant supply of ATP produced by mitochondria is considered to be a key 20 element for sustaining synaptic transmission (Rangaraju et al., 2014). By 21 regulating mitochondrial respiration at synaptic terminals, $\mathrm{mtCB}_{1}$ receptors 22 are therefore perfectly placed to potentially dampen inhibitory striatonigral 23 neurotransmission and, thereby, induce catalepsy upon pharmacological 24 activation. This suggests that similar mechanisms might occur during 
1 physiological fine-tuned control of movements, thereby establishing a link

2 between mitochondrial activity, synaptic transmission and motor control.

3 The assessment of nociception in animal models necessarily relies on the

4 observation of motor responses. Thus, it has been proposed that cannabinoid-

5 induced decrease of pain reactions might be secondary to motor impairments,

6 such as catalepsy, rather than reflecting proper antinociception (Giuffrida and

7 Seillier, 2012; Pertwee, 2001). However, analgesic and antinociceptive effects

8 of cannabinoids have been observed at several supraspinal and spinal

9 locations, in the absence of motor alterations, indicating that these two effects

10 can be discriminated at the level of different brain and spinal cord regions

11 (Woodhams et al., 2017). Our data show that both behavioral outputs can be

12 mediated by activation of $\mathrm{CB}_{1}$ receptors located in different subcellular

13 organelles in striatonigral neurons, triggering distinct molecular mechanisms.

14 This does not only add a new location for cannabinoid effects, but it also shows

15 that $\mathrm{CB}_{1}$ receptor-dependent catalepsy and antinociception rely on a true

16 intracellular mechanistic dichotomy, likely involved in the physiological

17 regulation of complex processes, such as motor and pain control. This

18 dichotomy, observed after acute pharmacological activation of $\mathrm{CB}_{1}$ receptor,

19 might be also underlying the physiological role of endogenous cannabinoids in

20 motor regulation and pain processing. Indeed, pharmacological and/or genetic

$21 \mathrm{CB}_{1}$ receptor blockade increases the sensitivity to pain perception (Clapper et 22 al., 2010; Nadal et al., 2013) and also have been often reported to increase 23 locomotor reactivity (Griebel et al., 2005; Häring et al., 2011). On the other 24 hand, like THC and other cannabinoid agonists, inhibitors of endocannabinoids 
1 degradation are able to induce antinociception and catalepsy via $\mathrm{CB}_{1}$ receptor

2 activation (Long et al., 2009), further confirming the endogenous role of the

3 receptor in regulating these two physiological processes.

4 Cannabinoids induce antinociception through the $\mathrm{pmCB}_{1}$ receptor-dependent

5 reduction of Substance- $P$ release in striatonigral neurons and the consequent

6 decrease of local $\mathrm{NK}_{1}$ receptor signaling. Interestingly, Substance-P in the $\mathrm{SNr}$

7 participates in pain processing, possibly through the modulation of the activity of

8 rostral ventral medulla and dorsal root ganglia(Boccella et al., 2020; Borsook et

9 al., 2010; Taylor et al., 2016). Therefore, the $\mathrm{CB}_{1}$ receptor-dependent

10 modulation of Substance- $\mathrm{P} / \mathrm{NK}_{1}$ signaling in the striatonigral neurons is a novel

11 mechanism that likely participates in larger circuits modulating nociceptive

12 responses.

13 To conclude, $\mathrm{CB}_{1}$ receptors in the striatonigral circuit mediate cannabinoid-

14 induced catalepsy and antinociception. This regulation clearly involves distinct

15 subcellular and molecular mechanisms in the same neuronal circuit, resulting in

16 the respective control of neurotransmitter and neuropeptide release. Thus,

17 selective subcellular manipulations of $\mathrm{CB}_{1}$ receptors represent a potential

18 therapeutic strategy to avoid undesirable effects of cannabinoid drugs, and to

19 promote their beneficial pain treatment. The unforeseen dichotomy between

20 cannabinoid-induced mitochondrial catalepsy and non-mitochondrial

21 antinociception in the same cellular population introduces the concept of

22 subcellular specificity of behavioral control. 


\section{ACKNOWLEDGMENTS}

2 We thank Delphine Gonzales, Nathalie Aubailly, and all the personnel of the

3 Animal Facility of the NeuroCentre Magendie for mouse care. We also thank all

4 the members of the Marsicano lab for useful discussions, Virginie Morales for

5 invaluable help with administrative work. We thank the Histology and

6 Biochemistry platforms of the NeuroCentre Magendie, as well as the Bordeaux

7 Imaging Center (BIC) for help in the experiments. We thank G. Manfredi

8 (Cornell University) for the mt-sAC-HA. We thank Su Melser for helpful

9 suggestions regarding the mitochondrial respiration and Roman Serrat for help

10 in imaging. We also thank Daniela Cota, Manuel Guzman, Pavel E. Rueda-

11 Orozco, and Guillaume Ferreira for their useful and critical reading on the

12 manuscript. This work was supported by INSERM (to G.M. and L.B.), EU-FP7

13 (PAINCAGE, HEALTH-603191 to G.M.), European Research Council

14 (Endofood, ERC-2010-StG-260515; CannaPreg, ERC-2014-PoC-640923,

15 Micabra to G.M.), Fondation pour la Recherche Medicale (DRM20101220445 to

16 G.M. and ARF20140129235 to L.B.). Human Frontiers Science Program (to

17 G.M.), Region Aquitaine (to G.M.), French State/Agence Nationale de la

18 Recherche (LABEX BRAIN ANR-10-LABX-43 to G.M., JCJC MitoCB1-fat to

19 L.B.), Marie Skłodowska-Curie Actions Individual Fellowships (H2020-MSCA-IF-

20 2016, ID747487 to C.M.), the Basque Government (IT1211/19 to L.F.C.),

21 Fyssen Foundation, CONACyT, Ikerbasque and MINECO (Ministerio de

22 Economía y Competitividad) PGC2018-093990-A-I00 (MICIU/AEI/FEDER, UE)

23 (to E.S.-G.). NSERC Discovery Grant - RGPIN-2019-06274 (to A.W.H. and

24 R.F.). The Basque Government (IT1230-19 to P.G.), Red de Trastornos 
1 Adictivos, Instituto de Salud Carlos III (ISC-III) and European Regional

2 Development Funds-European Union (ERDF-EU; RD16/0017/0012 to P.G.),

3 MINECO/FEDER, UE (SAF2015-65034-R to P.G.) and MINECO/FEDER, UE

4 (POP contract BES-2016-076766 to I.B.-D.R.

\section{AUTHOR CONTRIBUTIONS}

6 E.S-G., and L.B., performed and analyzed behavioral, biochemical and 7 anatomical experiments. A.C.P.Z., C.M., M.L.B-J., R.F., I.M.M., Y.O.A., A.C., 8 T.L-L., P.V., T.T-C., J.S.B., E.H-C., G.B-G., A.W.L., and L.F.C. performed and 9 analyzed biochemical experiments. Y.M., T.D., L.M.R., J.F.C.O., S.C., J.C., 10 L.M., B.R., A.B-G., and F.C., performed and analyzed behavioral experiments. 11 M.B., G.T., and J.B., performed and analyzed electrophysiological experiments. 12 Y.M., I.B-d-R., M.V., Z.Z., F.J-K., N.P., and P.G., performed and analyzed 13 anatomical experiments. E.S-G., G.M., and L.B., conceived and supervised the 14 whole project and wrote the manuscript. All authors edited and approved the 15 manuscript.

\section{DECLARATION OF INTERESTS}

17 The authors declare no competing interests. 


\section{STAR METHODS}

\section{Animals}

3 Experiments were approved by the Committee on Animal Health and Care of

4 INSERM, and the French Ministry of Agriculture and Forestry (authorization

5 number 3306369). Mice were maintained under standard conditions (food and

6 water ad libitum; 12h/12h light/dark cycle, light on 7 a.m.; experiments were

7 performed between 9 a.m. and 5 p.m.). C57BL/6-N male mice (2-4 months old)

8 were purchased from Janvier (France). $\mathrm{D}_{1}-C B_{1}-\mathrm{KO}$ mice and their WTs

9 littermates were generated and maintained as previously described(Monory et

10 al., 2007). $D_{1}$-Cre mice(Lemberger et al., 2007) were kindly provided by

11 Günther Schütz, (German Cancer Research Center). DN22-CB - KI mice were

12 generated using a flox-stop strategy as previously described(Ruehle et al.,

13 2013). Stop cassette was excised via a Cre deleter mouse strain and knock-in

14 mice were maintained over a C57BL6/N background for several generations

15 before experiments.

\section{Drugs}

17 THC was obtained from THC Pharm GmbH (Frankfurt, Germany). AM251, 18 Hemopressin and GR73632 were purchased from Tocris (France). WIN 55,212-

192 mesylate salt and $\mathrm{KH} 7$ were obtained from Sigma Aldrich (France). THC $20(10 \mathrm{mg} / \mathrm{kg})$ was dissolved in a mixture of saline $(0.9 \% \mathrm{NaCl})$ with $5 \%$ ethanol 21 and 4\% cremophor. WIN 55,212-2 was dissolved in DMSO for in vitro 22 experiments and in mixture of DMSO, Tween80 (1.25-1.25-97.5) and saline for 23 in vivo treatments. Hemopressin (22 ng in $0.5 \mu \mathrm{l})$ and GR73632 (100ng in $0.5 \mu \mathrm{l})$ 24 were dissolved in saline. AM251 (4 $\mu \mathrm{g}$ in $0.5 \mu \mathrm{l})$ and $\mathrm{KH} 7(2 \mu \mathrm{g}$ in $0.5 \mu \mathrm{l})$ were 
1 dissolved in $10 \%$ DMSO, 10\% cremophor and $80 \%$ saline. Vehicles contained

2 the same amounts of solvents respectively to the drug. All drugs were prepared

3 fresh before the experiments.

4 Viral vectors

5 To generate AAV-DIO-CB 1 , AAV-DIO-DN22, AAV-DIO-mt-SAC-HA, AAV-DIO-

6 PKA-CA and AAV-DIO-MLS-PKA-CA the coding sequences for the 5

7 proteins(Hebert-Chatelain et al., 2016) were subcloned in pAAV-CAG-flex

8 plasmid (kindly gifted by Matthias Klugmann, UNSW, Australia) by using

9 standard molecular cloning techniques. The same pAAV-CAG-flex plasmid was

10 used as empty control (AAV-DIO-ctr). AAVs were generated by PEI transfection

11 of HEK 293T cells and purified by iodixanol-gradient ultracentrifugation as

12 previously described(Hebert-Chatelain et al., 2016). Virus titers were $5.43^{\star} 10^{11}$

13 for AAV-DIO-CB $1,3.34^{*} 10^{11}$ for AAV-DIO-DN22, $2.36^{*} 10^{11}$ for AAV-DIO-mt14 SAC-HA, $3.87^{*} 10^{11}$ for AAV-DIO-PKA-CA, $3.96{ }^{*} 10^{11}$ for AAV-DIO-MLS-PKA-CA 15 and $4.51 * 10^{11}$ for AAV-DIO-ctr, expressed as genomic copies (GC) $\times$ ml.

16 For optogenetic experiments, rAAV2-hSyn-ChR2(H134R)-mCherry $\left(10^{13}\right.$ 17 GCxml) and rAAV-hSyn-DIO-ChrimsonR-tdTomato $\left(5.2^{*} 10^{12}\right.$ GCxml) were 18 purchased from UNC vector core (USA) and Viral Vector Facility (VVF) of the 19 Neuroscience Center Zurich (Zentrum für Neurowissenschaften Zürich, ZNZ) 20 respectively.

21 The viral vectors used for $\mathrm{CB}_{1}$ deletion experiment (see next section) were 22 purchased from the VVF. Titres were: $6.4^{*} 10^{12}$ for AAV-retro-hSyn1-EBFP223 FLPo, $4.1^{*} 10^{12}$ for AAV-retro-hSyn1-EBFP2 and $6.3^{*} 10^{12}$ for AAV-hEF1a-dFRT24 iCre-EGFP. 


\section{Surgery and drug/virus administration}

2 For intra-SNr injections of drugs mice were anesthetized by intraperitoneal

3 injection of a mixture of ketamine $(100 \mathrm{mg} / \mathrm{kg}$, Imalgene $500 \AA$, Merial) and

4 Xylazine $(10 \mathrm{mg} / \mathrm{kg}$, Rompun, Bayer) and placed into a stereotaxic apparatus

5 (David Kopf Instruments) with mouse adapter and lateral ear bars. Mice were

6 allowed to recover for at least one week in individual cages before the

7 beginning of the experiments. Mice were weighed daily and individuals that

8 failed to regain the pre-surgery body weight were excluded from the following

9 experiments. Mice were bilaterally implanted with $3.5 \mathrm{~mm}$ stainless steel guide

10 cannulae (Plastics One, USA) targeting the SNr with the following coordinates:

11 AP $-3.2, \mathrm{~L} \pm 1.3$, DV -3.5 , according to Paxinos and Franklin(Paxinos and

12 Franklin, 2001). Guide cannulae were secured with cement anchored to the

13 skull by screws. The drug injections for intra-SNr were performed by using

14 injectors protruding $1 \mathrm{~mm}$ from the tip of the cannula. The correct placement of

15 the SNr cannulas was verified by injection of sky-blue toluidine followed by

16 neutral red staining(Soria-Gomez et al., 2014) (Figure S1A).

17 AAV injections of AAV-DIO-CB ${ }_{1}$ or AAV-DIO-DN22 in the dorsal striatum of $D_{1}$ $18 C B_{1}$-KO mice, or AAV-DIO-mt-SAC-HA, AAV-DIO-PKA-CA and AAV-DIO-MLS-

19 PKA-CA in $\mathrm{D}_{1}$-Cre mice, with respective AAV-DIO-Ctr, were performed with the 20 following coordinates: AP $+0,5 \quad \mathrm{~L} \pm 2,0$, DV -3.0 as previously 21 described(Bellocchio et al., 2016).

22 For the specific deletion of $\mathrm{CB} 1$ in the striatopallidal or striatonigral neurons, 23 mice were anesthetized by inhalation of isofluorane $5 \%$ and placed into the 24 stereotaxic apparatus with the anesthesia maintained at $2 \%$ during the entire 
1 surgery. AAV vectors were injected with the help of a microinjector (Nanoject III,

2 Drummond Scientific, PA, USA). The deletion was performed injecting the viral

3 vectors AAV-hEF1a-dFRT-iCre-EGFP in the dorsal striatum, STR (2 injections

4 of $1 \mu$ l per side) with the following coordinates: $\mathrm{AP}+0,8 \mathrm{ML} \pm 2,0 \mathrm{DV}-3,0$ and -

5 3,5; and the retrogade vector AAV-retro-hSyn1-EBFP2-FLPo or AAV-retro-

6 hSyn1-EBFP2 as control in one of its target external Globus Pallidus, GPe or

7 Substantia nigra pars reticulata, $\mathrm{SNr}$ (respectively AP $-0,5 \mathrm{ML} \pm 1,8 \mathrm{DV}-4,25$;

8 volume $350 \mathrm{nl}$ per side and AP - 3,25 ML \pm 1,35 DV - 4,5; volume $750 \mathrm{nl}$ per 9 side).

10 Animals were allowed to recover for at least four weeks before the beginning of 11 biochemical (see after) or behavioral experiments. Mice that underwent 12 behavioral experiments were fixed by transcardial perfusion of $4 \%$ PFA and 13 their brain were processed for imaging (to detect BFLP and EGFP) and double 14 fluorescent in-situ hybridization (see below), or for immunofluorescence as 15 previously described (Hebert-Chatelain et al., 2016), with primary antibodies 16 directed against $\mathrm{CB}_{1}$ receptor $\left(\mathrm{CB}_{1}\right.$-Go-Af450-1; $2 \mu \mathrm{g} / \mathrm{ml}$; Frontier Science Co. 17 Ltd), to detect $\mathrm{CB}_{1}$ rescue and $\mathrm{CB}_{1}$ deletion, or against HA-tag (\#3724; Cell 18 Signaling Technology Danvers, MA) to confirm overexpression of mt-sAC. Mice 19 that did not fulfill histological positive criteria were excluded from the study.

Double fluorescent in-situ hybridization coupled to GFP immunodetection

21 Double FISH/GFP immunofluorescence experiments to measure the number of $22 \quad \mathrm{CB}_{1} / \mathrm{D}_{1} \mathrm{R}$ vs $\mathrm{CB}_{1} / \mathrm{D}_{2} \mathrm{R}$ positive striatal neurons in the deletion experiments, were 23 carried out as previously described (Oliveira da Cruz et al., 2020; Terral et al., 24 2019). Briefly, free-floating frozen coronal sections were cut out with a cryostat 
1 (30 $\mu \mathrm{m}$, Microm HM 500M Microm Microtech) and collected in an antifreeze

2 solution and conserved at $-20^{\circ} \mathrm{C}$. After inactivation of endogenous peroxidases

3 and blocking with Avidin/Biotin Blocking Kit (Vector Labs, USA), sections were

4 processed with a combination of FITCH coupled riboprobe against mouse CB1

5 receptor (1:1000, prepared as described in Marsicano and Lutz, 1999) together

6 with Digoxigenin (DIG)-labeled riboprope against D1R or D2R (1:1000 Monory

7 et al., 2007). Signals were revealed with a TSA reaction using fluorescein

8 isothiocyanate (FITC)-labeled tyramide (1:80 for 12 minutes, Perkin Elmer) for

$9 \mathrm{CB}_{1}$ receptor, or with Streptavidin-Texas Red (1:400, PerkinElmer) for D1R or

10 D2R receptor. Sense control probes were used to establish background signal.

11 After processing for FISH, anti-GFP immunofluorescence was carried out as

12 previously described (Oliveira da Cruz et al., 2020; Terral et al., 2019). Counting

13 of co-expressing cells was performed manually over $20 x$ objective fluorescent

14 microscope as previously described (Bellocchio et al., 2010, Oliveira da Cruz et

15 al., 2020; Terral et al., 2019). Image analyses and counting was performed in at

16 least 6 striatal slice per mouse averaging results from 3-4 mice. This resulted in

17 counting 1300-1600 neurons in average per each condition/analysis.

18 Quantitative real-time PCR (qRT-PCR).

19 Samples from WT, DN22- $C B_{1}-\mathrm{KI}$ and $C B_{1}-\mathrm{KO}$ mice were homogenized in Tri-

20 reagent (Euromedex, France) and RNA was isolated using a standard 21 chloroform/isopropanol protocol(Chomczynski and Sacchi, 1987). RNA was 22 processed and analyzed following an adaptation of published methods. cDNA 23 was synthesized from $1 \mu \mathrm{g}$ of total RNA using Maxima Reverse Transcriptase 24 (Thermo Scientific, USA) and primed with oligo-dT primers (Thermo Scientific, 
1 USA) and random primers (Thermo Scientific, USA). qRT-PCR was perfomed

2 using a LightCycler® 480 Real-Time PCR System (Roche, Switzerland). qRT-

3 PCR reactions were done in duplicate for each sample, using transcript-specific

4 primers, cDNA (4 ng) and LightCycler 480 SYBR Green I Master (Roche,

5 Switzerland) in a final volume of $10 \mu \mathrm{l}$. The PCR data were exported and

6 analyzed in an informatics tool (Gene Expression Analysis Software

7 Environment) developed at the NeuroCentre Magendie. For the determination

8 of the reference gene, the Genorm method was used(Livak and Schmittgen,

9 2001). Relative expression analysis was corrected for PCR efficiency and

10 normalized against two reference genes. Valosin containing protein $(\mathrm{V} c p)$ and

11 succinate dehydrogenase complex subunit (Sdha) genes were used as

12 reference genes for Amygdala. Glyceraldehyde-3-phosphate dehydrogenase

13 (Gapdh) and Sdha genes were used as reference genes for Hippocampus.

14 Tubulin alpha 4 a (Tuba4a) and tyrosine 3 mono oxygenase tryptophan 5 mono

15 oxygenase activation protein zeta (Ywhaz) genes were used as reference

16 genes for Anterior Olfactory Nucleus. Sdha and tubulin alpha 4 a (Tuba4a)

17 genes were used as reference genes for Prefrontal Cortex. Actin, beta (Actb)

18 and tTubulin alpha 4 a (Tuba4a) genes were used as reference genes for STR.

19 Glyceraldehyde-3-phosphate dehydrogenase (Gapdh) and peptidylprolyl

20 isomerase A (Ppia) genes were used as reference genes for Hypothalamus.

21 The relative level of expression was calculated using the comparative $\left(2^{-\triangle C T}\right)$

22 method(Livak and Schmittgen, 2001). Primers sequences are reported in the

23 following table: 


\begin{tabular}{|l|l|l|l|}
\hline Gene & GenBank ID & Forward Sequence (5'-3') & Reverse Sequence (5'-3') \\
\hline Vcp & NM_009503 & TGGCCGTCTAGATCAGCTCAT & TTTCGCAGATTGGCTTTTAGG \\
\hline Sdha & NM_023281 & TACAAAGTGCGGGTCGATGA & TGTTCCCCAAACGGCTTCT \\
\hline Gapdh & NM_008084 & TCAAGAAGGTGGTGAAGCAG & TGGGAGTTGCTGTTGAAGTC \\
\hline Tuba4a & NM_009447 & CCACTTCCCCTTGGCTACCTA & CCACTGACAGCTGCTCATGGT \\
\hline Ywhaz & NM_011740 & CTTGTGAGGCTGTGACACAAAC & CAAGAGTGTGCACGCAGACA \\
\hline Actb & NM_007393 & TGACCGAGCGTGGCTACA & CATAGCACAGCTTCTCTTTGATGTC \\
\hline Ppia & NM_008907 & CAAATGCTGGACCAAACACAA & GCCATCCAGCCATTCAGTCT \\
\hline Cnr1 & NM_007726 & GTCGATCTTAGACGGCCTTGC & TTGAGCCCACGTAGAGGAGGT \\
\hline Cnr1 & NM_007726 & GTGCTGTTGCTGTTCATTGTG & CTTGCCATCTTCTGAGGTGTG \\
\hline
\end{tabular}

\section{Mitochondrial respiration}

3 Mitochondrial respiration in substantia nigra extracts was measured as

4 previously described(Hebert-Chatelain et al., 2016) with some modification.

5 Briefly, immediately after cervical dislocation, the mouse brain was extracted

6 and the substantia nigra was rapidly dissected using the coronal brain

7 matrix(Vallee et al., 2014) and was homogenized in $450 \mu$ of Miro5 buffer

8 without taurine supplementation (Makrecka-Kuka et al., 2015) using a Politron

9 homogenizer (11.000 rpm 3-5 sec). After brief centrifugation the supernatant

10 was treated with saponin at a final concentration of $12.5 \mu \mathrm{g} / \mathrm{ml}$. Respiration

11 analyses were carried out using a 2K Oroboros device(Makrecka-Kuka et al., 12 2015). $100 \mu$ of lysate were put in each chamber and complex I-dependent 
1 respiration was triggered by adding malate $(2 \mathrm{mM})$, pyruvate $(5 \mathrm{mM})$ and 2 glutamate (10 mM) (MPG)(Makrecka-Kuka et al., 2015). Then we applied

3 DMSO or WIN 55,212-2 at final concentration of $1 \mu \mathrm{M}$ and 5 minutes after we

4 injected $1.25 \mathrm{mM}$ ADP. Each measure of OCR in ADP condition was

5 normalized to the values before ADP injection and the effect of WIN 55,212-2

6 was expressed as percentage of vehicle conditions. Only samples for which the

7 ratio of $A D P / M P G$ in the vehicle was equal or superior to 1.5 were retained for

8 the analyses. In the experiments of $\mathrm{KH} 7$ pre-treatment, the drug was dissolved

9 in DMSO (used as vehicle) and injected together with the lysates at a final 10 concentration of $5 \mu \mathrm{M}$.

11 In a previous set of experiments we validated the quality of mitochondria in the 12 preparation by measuring the $\mathrm{O}_{2}$ consumption after the MPG and ADP 13 administration. We added the complex II substrate Succinate at the final 14 concentration of $10 \mathrm{mM}, 10 \mu \mathrm{M}$ Cytochrome $\mathrm{C}$, to check mitochondrial 15 membrane integrity, and finally Rotenone $(0.5 \mu \mathrm{M})$ and Antimycin $\mathrm{A}(2.5 \mu \mathrm{M})$ 16 inhibitors of complex I and III, respectively(Makrecka-Kuka et al., 2015) (Table 17 S1). When using homogenates from virus-injected mice (see above) 40ul of 18 samples were processed for western blotting against sAC, HA-tag and myc-tag 19 to confirm overexpression of mt-sAC and the different forms of PKA-CA in the $20 \mathrm{SNr}$ of $\mathrm{D}_{1}$-Cre mice respectively.

\section{Mitochondrial isolation from mouse striatum}

22 In this set of experiments, $D_{1}$-Cre mice were injected with control AAV vector, 23 AAV-DIO-mt-sAC-HA, AAV-DIO-PKA-CA and AAV-DIO-MLS-PKA-CA as 24 described above. Mice were sacrificed by cervical dislocation, brains were 
1 rapidly extracted and the striatum dissected on ice. Mitochondria were extracted

2 by immuno-magnetic isolation using the Mitochondrial Extraction and Isolation

3 Kits (Milteny Biotech, FRANCE) according to manufacturer instructions. After

4 tissue lysis in $1.5 \mathrm{ml}$ of protease inhibition buffer provided by the manufacturer,

5 one small fraction was collected as total cell lysate (TCL). Extracted

6 mitochondria and their respective TCL were re-suspended in the same buffer,

7 quantified for their protein content and loaded on polyacrylamide gel $(12 \mu \mathrm{g}$ per

8 sample) for western blotting as described below.

\section{$9 \quad$ Western Blotting}

10 Protein homogenates in Miro5, added with protease inhibitors (Complete 11 protease inhibitor cocktail, Sigma-Aldrich, France) have been mixed with 12 denaturing 4x Laemmli loading buffer (250 mM Tris- $\mathrm{HCl}$, 40\% Glycerol, 8\% 13 SDS, $5 \%$-Mercaptoethanol, $0.2 \%$ Bromophenol blue) and boiled at $95^{\circ} \mathrm{C}$ for 5 14 minutes. Samples were analyzed on $4-20 \%$ precast polyacrylamide gels (Bio15 Rad, Hercules, California) and transferred onto PVDF membranes $0.45 \mu \mathrm{m}$ 16 (Merk Millipore, Burlington, MA). Membranes were blocked in a mixture of Tris17 buffered saline and polysorbate $20(20 \mathrm{mM}$ Tris- $\mathrm{HCl} p H \quad 7.6,150 \mathrm{mM} \mathrm{NaCl}$, $18 \quad 0.05 \%$ Tween 20 ) containing $5 \%$ of non-fat dry milk for $1 \mathrm{~h}$ at room temperature. 19 For immunoblotting have been used antibodies against HA-Tag (\#3724; 1:1000, 20 Cell Signaling Technology Danvers, MA or \#PA1-985; 1:1000, Thermo Fisher 21 Scientific, Waltham, MA), myc-tag (\#11667149001; 1:500, Merk, Darmstadt, 22 Germany), SAC (ADCY10 PA-543049; 1:1000, Thermo Fisher Scientific, 23 Waltham, MA), TOMM20 (\#sc-111415, 1:1000, Santa Cruz Biotechnology, 24 Dallas, Texas), PKA catalytic subunit (\#Ab76238, 1:2000, Abcam, Cambridge, 
1 UK) and Tubulin (sc-69969; 1:5000, Santa Cruz Biotechnology, Dallas, Texas) .

2 Bound primary antibodies were detected with HRP-linked antibodies (1:2000,

3 Cell Signaling Technology, Danvers, MA) and visualized by enhanced

4 chemiluminescence detection (Clarity Western ECL Substrate, Bio-Rad,

5 Hercules, California or Super Signal West Femto Maximum Sensitivity

6 Substrate, Thermo Fisher Scientific, Waltham, MA) The images have been

7 acquired on ChemiDoc Touch (Bio-Rad, Hercules, California and analysed

8 using the Image Lab software (Bio-Rad, Hercules, California)

$9 \quad\left[\begin{array}{ll}35 \\ \text { S }\end{array}\right]$ TPYS binding assay on brain homogenates

10 Brains from 8 mice of each genotype (WT, $C B_{1}-\mathrm{KO}$ and DN22- $\left.C B_{1}-\mathrm{KI}\right)$ were 11 obtained. Midbrain, cortex and hippocampus were dissected and immediately 12 stored at $-70^{\circ} \mathrm{C}$ until assay. For each brain region, tissue samples from each 13 genotype were pooled to obtain the enriched fractions of plasma membranes. 14 Tissue samples were homogenized using an a Teflon-glass grinder (IKA 15 Labortechnik, Satufen, Germany) at $1500 \mathrm{rpm}$ (10 up-and-down strokes) in 30 16 volumes of homogenization buffer ( $1 \mathrm{mM}$ EGTA, $3 \mathrm{mM} \mathrm{MgCl}_{2}, 1 \mathrm{mM}$ DTT, and $1750 \mathrm{mM}$ Tris- $\mathrm{HCl}, \mathrm{pH}$ 7.4) supplemented with $0.25 \mathrm{M}$ sucrose. The crude 18 homogenate was centrifuged for 5 minutes at $1,000 \times \mathrm{g}$ at $4{ }^{\circ} \mathrm{C}$ and the 19 supernatant layer was re-centrifuged for 10 minutes at $40,000 \times \mathrm{g}\left(4^{\circ} \mathrm{C}\right)$. The 20 resultant pellet (P2 fraction) was washed twice in 10 and 5 volumes of 21 homogenization buffer respectively, and re-centrifuged in similar conditions. 22 Protein content was measured according to Bradford's method using BSA as 23 standard. Samples were aliquoted in order to have a protein content of $1 \mathrm{mg}$ 24 and then centrifuged in a benchtop centrifuge (EBA 12 R, Hettich Instruments, 
1 Tuttlingen, Germany) at highest speed (14,000 rpm) during 15 minutes at $4{ }^{\circ} \mathrm{C}$.

2 The supernatant layer was carefully discarded and the pellets stored at $-70 \stackrel{\circ}{\circ} \mathrm{C}$

3 until assay. The tissue samples of the nine experimental conditions (3

4 genotypes and 3 brain regions, 1 pool for each region-genotype) were

5 processed in parallel on the same day. The day of the experiment the

6 membrane pellets were defrosted $\left(4^{\circ} \mathrm{C}\right)$, thawed and re-suspended in $11 \mathrm{ml}$ of

7 incubation buffer containing $1 \mathrm{mM}$ EGTA, $3 \mathrm{mM} \mathrm{MgCl} 2,100 \mathrm{mM} \mathrm{NaCl}$, and 50

$8 \mathrm{mM}$ Tris- $\mathrm{HCl}, \mathrm{pH} 7.4$, reaching a final protein concentration of $0.09 \mathrm{mg} / \mathrm{ml}$

9 approximately. The real final protein content was measured after the experiment

10 according to Bradford's method.

11 WIN $55,212-2$ stimulated $\left[{ }^{35}\right.$ S]GTPYS binding assays were carried out in a final

12 volume of $250 \mu \mathrm{l}$ in 96 well plates, containing $1 \mathrm{mM}$ EGTA, $3 \mathrm{mM} \mathrm{MgCl}_{2}, 100$

$13 \mathrm{mM} \mathrm{NaCl}, 0.2 \mathrm{mM}$ DTT, $50 \mu \mathrm{M}$ GDP, $50 \mathrm{mM}$ Tris- $\mathrm{HCl}$ at $\mathrm{pH} 7.4$ and $0.5 \mathrm{nM}$

$14\left[{ }^{35}\right.$ S]GTPYS. Stimulation curves were carried out by incubating increasing 15 concentrations of WIN 55,212-2 $\left(10^{-12}-10-{ }^{4} \mathrm{M}\right.$; 9 concentrations by duplicate;

16 three independent experiments). The incubation was started by addition of the

17 membrane suspension (18 $\mu \mathrm{g}$ of membrane proteins per well) and was

18 performed at $30^{\circ} \mathrm{C}$ for 120 minutes with shaking (450 rpm). Incubation was

19 terminated by rapid filtration under vacuum (1450 FilterMate Harvester,

20 PerkinElmer) through GF/C glass fiber filters (Printed Filtermat A) pre-soaked in

21 ice-cold incubation buffer. The filters were then rinsed three times with $300 \mu \mathrm{l}$

22 ice-cold incubation buffer, air dried $\left(20^{\circ} \mathrm{C}, 120\right.$ minutes), and counted for

23 radioactivity (4 minutes) by liquid scintillation spectrometry using a MicroBeta

24 TriLux counter (PerkinElmer). Non-specific binding of the radioligand was 
1 defined as the remaining $\left[{ }^{35}\right.$ S]GTPYS binding in the presence of $10 \mu \mathrm{M}$

2 unlabelled GTPYS, and the basal binding, as the signal in the absence of

3 agonist. The pharmacological parameters of the stimulation curves of the

$4 \quad\left[{ }^{35}\right.$ S $]$ GTPYS binding, the maximal effect (Emax) and the concentration of the

5 drug that determines the half maximal effect (EC50), were obtained by non-

6 linear analysis using GraphPad Prism ${ }^{\mathrm{TM}}$ software version 5.0. The points fit to a

7 concentration-response curve (standard slope). The pharmacological

8 parameters Emax and EC50 are expressed as means \pm SEM. The statistical

9 comparison of the data sets was performed in GraphPad Prism ${ }^{\mathrm{TM}}$ software

10 version 5.0 , by a co-analysis of the curves.

$11 \quad\left[{ }^{35} \mathrm{~S}\right] \mathrm{GTPYS}$ and $\left[{ }^{3} \mathrm{H}\right] \mathrm{CP} 55,940$ binding assay on brain slices

$12\left[{ }^{35} \mathrm{~S}\right] \mathrm{GTP} \gamma \mathrm{S}(1250 \mathrm{Ci} / \mathrm{mmol})$ and $\left[{ }^{3} \mathrm{H}\right] \mathrm{CP} 55,940(149 \mathrm{Ci} / \mathrm{mmol})$ were purchased

13 from PerkinElmer (Boston MA, USA). The $\left[{ }^{14} \mathrm{C}\right]$ and $\left[{ }^{3} \mathrm{H}\right]$ standards were 14 supplied by American Radiolabelled Chemicals (St. Louis, MO, USA). DL15 dithiothreitol (DTT), guanosine-5'-diphosphate (GDP), and guanosine-5'- $\gamma-3$ 16 thiotriphosphate (GTP $\gamma$ S) were acquired from Sigma-Aldrich (St. Louis, MO, 17 USA). WIN 55,212-2 was purchased from Tocris Bioscience (Bristol, UK). All 18 other chemicals were obtained from standard sources and were of the highest 19 purity commercially available.

20 In order to test the ability of $\mathrm{CB}_{1}$ receptor to stimulate GTP $\gamma \mathrm{S}$ conversion after 21 WIN 55,212-2 administration or to bind the CP55,940 agonist, 5-6 WT and $22 \mathrm{DN} 22-C B_{1}-\mathrm{KI}$ mice, and $1 C B_{1}-\mathrm{KO}$ mouse as control, were sacrificed by cervical 23 dislocation and their brain rapidly frozen at $-80^{\circ} \mathrm{C}$. $20 \mu \mathrm{m}$ slices were cut with a 24 cryostat and mounted on superflost (Thermo Scientific, FRANCE) slides. 
$1 \quad I^{35}$ SJGTP $\gamma$ S binding assay. Brain sections were thawed for $15 \mathrm{~min}$ and then

2 incubated in $50 \mathrm{mM}$ Tris- $\mathrm{HCl}$ buffer with $3 \mathrm{mM} \mathrm{MgCl}_{2}, 0.2 \mathrm{mM}$ EGTA, $100 \mathrm{mM}$

$3 \mathrm{NaCl}, 2 \mathrm{mM}$ GDP and $1 \mathrm{mM}$ DTT $(\mathrm{pH}=7.4)$ for $20 \mathrm{~min}$ at room temperature.

4 Afterwards, the slices were incubated with $0.04 \mathrm{nM}\left[{ }^{35} \mathrm{~S}\right] \mathrm{GTP} \gamma \mathrm{S}$ in absence and

5 in presence of WIN 55,212-2 $\mu \mathrm{M}(1$ and $10 \mu \mathrm{M})$ for $2 \mathrm{~h}$ at $30^{\circ} \mathrm{C}$. The non-

6 specific binding was determined with $10 \mu \mathrm{M}$ GTP $\gamma$ S. Finally, the sections were

7 washed twice in $50 \mathrm{mM}$ Tris- $\mathrm{HCl}(\mathrm{pH}=7.4)$ for $15 \mathrm{~min}$ at $4^{\circ} \mathrm{C}$, dried and exposed

8 to a Kodak Biomax MR film with ${ }^{14} \mathrm{C}$ standards. The films were scanned and

9 quantified by transforming the optical densities into $\mathrm{nCi} / \mathrm{mg}$ using the ${ }^{14} \mathrm{C}$

10 standards (NIH-IMAGE, Bethesda, MA, USA). The background and the non-

11 specific densities were subtracted. The percentages of stimulation were

12 calculated from the basal and agonist-stimulated $\left[{ }^{35}\right.$ S $]$ GTP $\gamma S$ binding densities

13 according to the formula (stimulated $\times 100 /$ basal) -100 .

$\left.14 \quad{ }^{3} H\right] C P 55,940$ binding assay. Tissue sections were dried and incubated in 50 $15 \mathrm{mM}$ Tris- $\mathrm{HCl}$ buffer containing $1 \%$ of $\mathrm{BSA}(\mathrm{pH}=7.4)$ for $30 \mathrm{~min}$ at room 16 temperature. Later, the brain sections were incubated again in the same buffer 17 supplemented with $3 \mathrm{nM}\left[{ }^{3} \mathrm{H}\right] \mathrm{CP} 55,940$ for $2 \mathrm{~h}$ at $37^{\circ} \mathrm{C}$. Non-specific binding was 18 determined with $10 \mu \mathrm{M}$ WIN 55,212-2. Finally, sections were washed in ice-cold $1950 \mathrm{mM}$ Tris- $\mathrm{HCl}$ buffer supplemented with 1\% BSA followed by dipping in 20 distilled water at $4^{\circ} \mathrm{C}$. After drying, the brain slides were exposed to a radiation 21 sensitive film for 21 days at $4^{\circ} \mathrm{C}$ together with tritium standards. The films were 22 scanned and quantified by transforming the optical densities into $\mathrm{nCi} / \mathrm{mg}$ using 23 the tritium standards (NIH-IMAGE, Bethesda, MA, USA). The background and 24 the non-specific densities were subtracted to determine the specific binding. 


\section{Behavioral tests}

$2 \quad$ Wire hang test. Wild type and DN22-CB $-\mathrm{KI}$ mice were tested for their muscular

3 strength in the wire hang test(Redon et al., 2020). All tests were conducted

4 during the dark phase of the cycle under dim red light. Each cage, housing one

5 mouse, was placed on a bench in a room adjacent to the one housing the mice.

6 Thereafter, each mouse was removed from its cage, placed on the cage grid,

7 the latter being then slowly inverted as to be suspended $90 \mathrm{~cm}$ above a big

8 cage filled with polystyrene beads. The latency to fall was then recorded.

9 Basal locomotion. The basal locomotor activity of WT and DN22-CB $-\mathrm{KI}$ mice 10 was measure during seven days using the TSE PhenoMaster system (TSE

11 Systems $\mathrm{GmbH}$ ). Mice were placed individually in a plexiglass cage $[45 \mathrm{~cm}$

12 (length) $\times 34 \mathrm{~cm}$ (width) $\times 20 \mathrm{~cm}$ (height)] surrounded with the ActiMot module 13 containing IR light beams recognizing locomotor activity. Food and water were 14 available ad libitum.

15 Catalepsy, locomotion and antinociception. AM251 and Hemopressin were bilaterally injected into the SNr in a volume of $0.5 \mu \mathrm{l}$ per side. Immediately after,

17 THC (10 mg/kg) was injected i.p. Mice were tested, $30 \mathrm{~min}$ post-injections, 18 successively for catalepsy, locomotion and antinociception. Locomotor activity 19 was tested by placing the mouse in a novel environment and the number of 20 squares crossed was counted for 5 minutes. For seek of clarity, given the fact 21 that striatonigral $\mathrm{CB}_{1}$ receptor deletion did not affect the hypo-locomotor effects 22 of THC (Figure S1B and S1E), we did not show results for this behavioral 23 paradigm for the other experimental sets. The catalepsy was determined by the 24 time of immobility on a bar. To this aim, mice were positioned in a new plastic 
1 cage (identical to their home cage) without bedding with on a horizontal

2 cylindrical bar $(0.7 \mathrm{~cm}$ Diameter) placed at $4.5 \mathrm{~cm}$ high with their forepaws

3 gripping and its hind paws in the plastic box. The time spent in its initial position

4 on the bar was scored for two minutes. Immediately after, mice were placed in

5 a Hot Plate (BIOSEB) to measure antinociception. The plate was pre-heated at

$652^{\circ}$. The escape latency, defined as the time until the mice showed signs of

7 discomfort (paw licking, jumping), was recorded. All equipment was cleaned

8 with ethanol $25 \%$ and dried with paper towels between all the trials. For AAVs

9 injected mice the procedure was identical but mice were tested 5 weeks after

10 viral injections.

11 Immuno-electron microscopy

12 The experiments were performed as described previously(Puente, 2019). $C B_{1^{-}}$

$13 \mathrm{KO}$, DN22- $C B_{1}-\mathrm{Kl}$, and respective WT littermates mice ( $\mathrm{n}=3$ per genotype)

14 were deeply anesthetized by intraperitoneal injection of ketamine/xylazine

$15(80 / 10 \mathrm{mg} / \mathrm{kg}$ body weight i.p.) and were transcardially perfused at room

16 temperature $\left(\mathrm{RT}, 20-25^{\circ} \mathrm{C}\right)$ with phosphate buffered saline (0.1 M PBS, $\mathrm{pH}$ 7.4)

17 for $20 \mathrm{~s}$, followed by the fixative solution made up of $4 \%$ formaldehyde (freshly 18 depolymerized from paraformaldehyde), $0.2 \%$ picric acid, and $0.1 \%$ 19 glutaraldehyde in phosphate buffer (0.1 M PB, pH 7.4) for 10-15 min. Once the 20 animals were perfused, the brains were numbered by a different experimenter 21 to conduct the protocol blindly. Then, brains were removed from the skull and 22 post-fixed in the fixative solution for approximately 1 week at $4^{\circ} \mathrm{C}$. Afterwards, 23 brains were stored at $4^{\circ} \mathrm{C}$ in $1: 10$ diluted fixative solution until used. 
1 Pre-embedding silver-intensified immunogold method. The method applied was

2 already described(Puente, 2019). Coronal midbrain vibratome sections

3 containing the substantia nigra pars reticulata were cut at $50 \mu \mathrm{m}$ and collected

4 in $0.1 \mathrm{M} \mathrm{PB}(\mathrm{pH}$ 7.4) with $0.1 \%$ sodium azide at RT. Sections were

5 preincubated in a blocking solution of $10 \%$ bovine serum albumin (BSA), $0.1 \%$

6 sodium azide, and $0.02 \%$ saponin prepared in Tris-HCl buffered saline (TBS

$7 \quad 1 \mathrm{X}, \mathrm{pH}$ 7.4) for $30 \mathrm{~min}$ at $\mathrm{RT}$. Then, sections were incubated with a primary goat

8 anti-CB 1 antibody binding to a 31 amino acids sequence of the $\mathrm{C}$-terminus $\left(\mathrm{CB}_{1}\right.$

9 C-ter ${ }^{31} ; 2 \mu \mathrm{g} / \mathrm{ml}$; Cat. N.: CB $_{1}$-Go-Af450-1; Frontier Institute; Japan) in the

10 blocking solution but with $0.004 \%$ saponin on a shaker for 1 day at RT. After

11 several washes in $1 \% \mathrm{BSA} / \mathrm{TBS}$, tissue sections were incubated in a secondary

12 anti-goat $1.4 \mathrm{~nm}$ gold-labeled Immunoglobulin-G antibody (Fab' fragment,

$131: 100$, Nanoprobes Inc.) in 1\% BSA/TBS with $0.004 \%$ saponin on a shaker for 4

$14 \mathrm{~h}$ at RT. Thereafter, the tissue was washed in $1 \% \mathrm{BSA} / \mathrm{TBS}$ overnight at $4^{\circ} \mathrm{C}$ 15 and post-fixed in 1\% glutaraldehyde in TBS for $10 \mathrm{~min}$ at RT. Following washes 16 in double distilled water, gold particles were silver-intensified with a HQ Silver 17 kit (Nanoprobes Inc., Yaphank, NY, USA) for about 12 min in the dark and then 18 washed in $0.1 \mathrm{M} \mathrm{PB}(\mathrm{pH}$ 7.4). Stained sections were osmicated (1\% osmium 19 tetroxide, $\mathrm{OsO}_{4}$, in $0.1 \mathrm{M} \mathrm{PB} \mathrm{pH} \mathrm{7.4,} 20 \mathrm{~min}$ ), dehydrated in graded alcohols to 20 propylene oxide, and plastic-embedded flat in Epon 812. To localize the region 21 of interest, immunolabeled resin-embedded vibratome sections were first 22 visualized by light microscopy to select the portion of the $\mathrm{SN}$ and to ensure that 23 the slices have the appropriate antibody labeling. Then, semithin $(700 \mathrm{~nm})$ 24 sections are mainly extracted to remove the resin and reach the tissue. 25 Afterwards, we started to collect ultrathin sections of $50 \mathrm{~nm}$ on mesh nickel 
1 grids, stained with $2.5 \%$ lead citrate for $20 \mathrm{~min}$, and examined in a Philips

2 EM208S electron microscope. Photographs are always taken in the area of

3 interest and close to the resin; in this way we know that we are a few

4 nanometers from the surface, and that the immunelabeling is complete.

5 Furthermore, we photographed in a range of 0 to at most $950 \mathrm{~nm}$ from the

6 surface, because the first 5 ultrathin sections of $50 \mathrm{~nm}$ are collected. Tissue

7 preparations were photographed by using a digital camera coupled to the

8 electron microscope. Figure compositions were made at 300 dots per inch (dpi).

9 Labeling and minor adjustments in contrast and brightness were made using

10 Adobe Photoshop (CS, Adobe Systems, San Jose, CA, USA).

11 Semi-quantification of $m t C B_{1}$ receptor immunostaining using immunogold

12 method. Analyses were carried out according to previous publications

13 (Gutierrez-Rodriguez et al., 2018; Hebert-Chatelain et al., 2016; Puente et al., 14 2019). 2-3 of $50 \mu \mathrm{m}$-thick sections containing the substantia nigra pars 15 reticulata and hippocampus from each animal genotype ( $n=3$ each) showing 16 good and reproducible silver-intensified gold particles were cut at $50 \mathrm{~nm}$. To 17 minimize differences between groups, all sections were processed 18 simultaneously. Three separate experiments were performed for each animal.

19 Electron micrographs were taken from grids with similar labeling intensity 20 indicating that selected areas were at the same depth. To avoid false negatives, 21 only ultrathin sections in the first $1.5 \mu \mathrm{m}$ from the surface were examined. Total $22 \mathrm{CB}_{1}$ receptor labeling and total $\mathrm{CB}_{1}$ particles in plasma and mitochondrial 23 membranes were counted per area. The proportion of $\mathrm{CB}_{1}$ receptor-positive 24 mitochondria was calculated for each mouse counting only particles (at least 25 one) on mitochondrial membrane segments far away from other membranes 
1 (distance $\geq 80 \mathrm{~nm}$ ). Image-J (version 1.36) was used to measure the distance.

2 Graphs and statistical analyses were performed using GraphPad software

3 (version 5.0).

$4 \quad$ In vitro characterization of mt-sAC and PKA mutants

5 Confocal Microscopy Imaging. HeLa cells seeded on 12-mm round glass

6 coverslips and transfected as indicated, were placed on the stage of the

7 Olympus FV3000 confocal fluorescence microscope (Tokyo, Japan) and

8 imaged using a $60 \mathrm{X}$ oil objective (UPLAN $60 \times$ oil, 1.35 NA, Olympus), and

9 appropriate excitation laser and filters. For each experiment, 15 cells were

10 randomly selected and analyzed. Stacks of 30 images separated by $0.2 \mu \mathrm{m}$

11 along the $\mathbf{Z}$ axis were acquired. Three-dimensional reconstruction and volume

12 rendering of the stacks were carried out with the appropriate plug-in of ImageJ

13 (NIH, Bethesda, MD, USA). Pearson's correlation coefficient for TOM20

14 fluorescence colocalization with Myc or $\mathrm{HA}$, was calculated with the

15 Colocalization threshold tool of ImageJ.

16 Trypsin Sensitivity Assay. The trypsin sensitivity assay was carried out as 17 described previously (Choo, 2004) with minor modifications. Isolation of 18 mitochondrial fractions was performed as described previously (Guedouari et 19 al., 2017). Briefly, HeLa cells were harvested and resuspended in mitochondrial 20 isolation buffer (250 mM sucrose, $1 \mathrm{mM}$ EDTA, $5 \mathrm{mM}$ HEPES, pH 7.4) 21 supplemented with $1 \%$ protease inhibitor cocktail (Bioshop, ON, Canada), 2 mM 22 sodium orthovanadate and $1 \mathrm{mM}$ sodium fluoride. Cells were lysed with 15 23 strokes using a 25-gauge syringe on ice and centrifuged at $1500 \times \mathrm{g}$ for 5 min (4 $\left.24{ }^{\circ} \mathrm{C}\right)$. The resulting supernatant was centrifuged at $12,500 \times \mathrm{g}$ for $10 \min \left(4^{\circ} \mathrm{C}\right)$. 25 pellet was resuspended in the mitochondrial buffer and a cycle of centrifugation 
1 at $1500 \times g$ and $12,500 \times g$ was repeated. The final pellet was considered as the

2 mitochondria-enriched fraction. Protein concentration was determined by

3 Bradford assay (Bradford, 1976). Isolated mitochondria were suspended in

4 mitochondrial isolation buffer and incubated at $37^{\circ} \mathrm{C}$ for $10 \mathrm{~min}$ in presence or

5 absence of trypsin (0.5\%) and triton X-100 (1\%). Reaction was stopped by the

6 addition of $1 \%$ of the protease inhibitor cocktail. Mitochondria were then

7 centrifuged at $12,500 \times \mathrm{g}$ at $4{ }^{\circ} \mathrm{C}$ for $10 \mathrm{~min}$. The pellets were processed for

8 SDS-PAGE and subsequent western blotting.

9 Sniffer cells detection of Substance-P release

10 cDNA for human $\mathrm{NK}_{1}$ was purchased from the cDNA resource center

11 (www.cdna.org). $\mathrm{NK}_{1}$-mCherry plasmid was created by cloning the mCherry

12 coding sequence in frame with the $\mathrm{C}$-terminus of $\mathrm{NK}_{1}$ with its stop codon

13 removed by PCR.

14 System validation in vitro. $\mathrm{NK}_{1}$-mCherry was co-transfected with GCaMP6s 15 (Addgene) into HEK293 cells (Cedarlane) seeded on coverslips using 16 Lipofectamine 2000 (Invitrogen). 24-48 hours later, coverslips were transferred 17 to a perfusion chamber containing $\mathrm{EBS}$ (in $\mathrm{mM}$ : $\mathrm{NaCl} 140, \mathrm{KCl} 5.4, \mathrm{CaCl}_{2} 1.3$, 18 HEPES 10, glucose 33, $\mathrm{pH} 7.35$ ) and allowed to equilibrate for 10-15 minutes at 19 room temperature with a flow rate of $\sim 1 \mathrm{ml} / \mathrm{min}$. Baseline GCaMP6s 20 fluorescence was recorded for 60 seconds. Then Substance-P (Tocris) was 21 added to the chamber using a micropipette to achieve final concentrations of $2210^{-11} \mathrm{M}-10^{-6} \mathrm{M}$. 16-bit Images were collected at $1 \mathrm{~Hz}$ on an Olympus BX-61 23 microscope with a 20X water immersion objective and a Hamamatsu ORCA24 Flash4 CCD camera. Using ImageJ, the change in fluorescence normalized to 25 baseline fluorescence $(\Delta \mathrm{F} / \mathrm{F} 0)$ was calculated following background subtraction 
1 by binning the 30 frames prior to Substance-P stimulation (F0) and 30 frames

2 surrounding the peak response following Substance-P stimulation. The

3 perfusion chamber was washed with $50 \mathrm{~mL}$ of EBS over 15 minutes between

4 coverslips. When necessary, rundown was corrected using the Bleach

5 Correction algorithm in ImageJ and the occasional flicker of the microscope

6 bulb was corrected manually.

7 Substance-P and WIN 55,212-2 effect in vitro. HEK cells were seeded on glass

8 coverslips coated with poly-lysine and transfected with plasmid DNA for $\mathrm{NK}_{1}$ -

9 mCherry and GCaMP6s or Empty vector and GCaMP6s with PEI (Figure S1I).

10 Cells were imaged 24-48 hrs after transfection on epifluorescence mode with an

11 inverted spinning-disk microscope equipped with 40X objective (NA 1.4), a 12 multi-LED illumination system and a CDD camera. Coverslips were mounted on 13 a open chamber and superfused with a buffer solution of (in $\mathrm{mM}$ ): $112 \mathrm{NaCl}, 5$ $14 \mathrm{KCl}, 24 \mathrm{NaHCO}, 10 \mathrm{HEPES}, 1.25 \mathrm{CaCl}_{2}, 1.25 \mathrm{MgCl}_{2}, 5$ glucose, bubbled with 15 air $/ 5 \% \mathrm{CO}_{2}(\mathrm{pH} 7.4)$ at $36^{\circ} \mathrm{C}$. For experiments on cells expressing $\mathrm{NK}_{1}$ 16 mCherry/ GCaMP6s, cells expressing $\mathrm{NK}_{1}$ were first selected by $570 \mathrm{~nm}$ 17 illumination and emission collection at $617 / 36 \mathrm{~nm}$ before starting $\mathrm{Ca}^{2+}$ imaging. 18 Cells expressing GCaMP6s were excited at $490 \mathrm{~nm}$ for $0.05-0.1 \mathrm{~s}$ and emission 19 collected at 524/16 $\mathrm{nm}$. Data was background corrected and represented as 20 normalized fluorescence. Substance-P and WIN55.212-2 were applied for 1 21 minute and recording were performed for the next 5 minutes (Figure S1L).

22 Substance- $P$ release from striatonigral terminals. Sagittal sections containing $23 \mathrm{SNr}$ were prepared from 6 to 12 weeks-old mice. For electrical stimulation, 24 naive $C B_{1}-\mathrm{KO}$, DN22- $C B_{1}-\mathrm{KI}$, and respective WT littermates were used. For 25 optogenetic activation of striatonigral terminals 6 weeks-old D1-Cre mice were 
1 used to target striatal neurons with injection of a rAAV-hSyn-DIO-ChrimsonR-

2 tdTomato into the dorsal Striatum (in mm relative to bregma: $A P=+0.8, L= \pm 2.0$,

$3 \quad \mathrm{DV}=-2.7) 6$ weeks before experiments.

4 Mice were first sedated by inhaling isoflurane (4\%) for approximately $30 \mathrm{~s}$ and

5 then deeply anesthetized with a mixture of ketamine and xylazine (100 and 20

$6 \mathrm{mg} / \mathrm{kg}$, i.p., respectively). After the disappearance of the reflexes, a thoracotomy

7 was performed to allow transcardial perfusion of a saturated $\left(95 \% \mathrm{O}_{2} / 5 \% \mathrm{CO}_{2}\right)$

8 ice-cold solution containing $250 \mathrm{mM}$ sucrose, $10 \mathrm{mM} \mathrm{MgSO}_{4} \cdot 7 \mathrm{H}_{2} \mathrm{O}, 2.5 \mathrm{mM}$

$9 \mathrm{KCl}, 1.25 \mathrm{mM} \mathrm{NaH} \mathrm{PO}_{4} \cdot \mathrm{H}_{2} \mathrm{O}, 0.5 \mathrm{mM} \mathrm{CaCl} \cdot \mathrm{H}_{2} \mathrm{O}, 1.3 \mathrm{mM} \mathrm{MgCl}, 26 \mathrm{mM}$

$10 \mathrm{NaHCO}_{3}$ and $10 \mathrm{mM}$ D-glucose. After decapitation, each brain was quickly

11 removed and cut into sagittal slices $(300 \mu \mathrm{m})$ using a vibratome (VT-1200S;

12 Leica Microsystems, Germany). The slices were then incubated at $34^{\circ} \mathrm{C}$ for 10

13 min in a standard artificial cerebrospinal fluid (ACSF) saturated by bubbling $1495 \% \mathrm{O}_{2} / 5 \% \mathrm{CO}_{2}$ and containing $126 \mathrm{mM} \mathrm{NaCl}, 2.5 \mathrm{mM} \mathrm{KCl}, 1.25 \mathrm{mM}$ $15 \mathrm{NaH}_{2} \mathrm{PO}_{4} \cdot \mathrm{H}_{2} \mathrm{O}, 2 \mathrm{mM} \mathrm{CaCl} \cdot \mathrm{H}_{2} \mathrm{O}, 2 \mathrm{mM} \mathrm{MgSO}{ }_{4} \cdot 7 \mathrm{H}_{2} \mathrm{O}, 26 \mathrm{mM} \mathrm{NaHCO} 3$ and 10 $16 \mathrm{mM}$ D-glucose, supplemented with $5 \mu \mathrm{M}$ glutathion and $1 \mathrm{mM}$ sodium pyruvate.

17 Transfected HEK cells (see above) re-suspended in ACSF were gently 18 deposited over the slices that were placed in a small petri-dish. Slices were 19 allowed to rest for $2 \mathrm{~h}$ to allow the sniffer cells to attach to the tissue before 20 starting the recording. Slices were then transferred in a recording chamber 21 under an upright microscope (Ni-E, Nikon Instruments). For electrical 22 stimulation experiments, a bipolar stimulating electrode was placed in proximity 23 of capsula interna and trains of electrical stimulation were applied. For 24 optogentic activation, an optic fiber was placed above the SNr and trains of $25570 \mathrm{nM}$ light pulses (5s $20 \mathrm{~Hz}$ ) were applied. The presence of the receptor and 
1 the fluorescence of GCaMP6s in HEK cells were observed and measured with

2 an infrared differential interference system using a $60 \mathrm{x}$ immersion lens. The

3 image detection was done with a camera (Zyla, Andor technology). GCaMP6s

4 was excited using $470 \mathrm{~nm}$ light supplied by a LED device (Lumencor). Images

5 were collected at $10 \mathrm{~Hz}$. Image stacks were imported into Image $\mathrm{J}$ software

6 where changes in fluorescence in HEK cell were measured over time. Imaged

7 were post-processed to calculate $\Delta \mathrm{F}$. Regions of interest (ROI) corresponded to

8 HEK cell visually identifiable and expressing both GCaMP6s and Substance-P

9 Receptor were delimited. The fluorescence time course $F$ of each ROI was

10 measuring by averaging all pixels within the ROI. Background fluorescence was

11 subtracted from all values. Fluorescence at various time points was expressed

12 relative to baseline. Stimulus-induced changes in fluorescence were calculated

13 from the maximum value observed during a $30 \mathrm{~s}$ period following the onset of

14 the response and expressed relative to baseline (average of values collected 10

$15 \mathrm{~s}$ before the electrical stimulation or $3 \mathrm{~s}$ before red-light stimulation). Negative

16 controls on brain slices were performed either by using HEK cells transfected

17 only with GCaMP6s and not NK1-R (see above) or by GCaMP6s/NK1-R

18 expressing HEK cells in presence of the selective Substance-P Receptor

19 blocker CP122721. Control experiments for whole-cell voltage-clamp recordings

20 of oIPSCs were performed as described in the next session.

\section{Electrophysiology}

22 Optogenetic activation of striatonigral terminals. Male DN22- $C B_{1}-\mathrm{KI}$ mice, $C B_{1-}$

23 KO mice and their WT littermates were used to target striatal neurons with

24 injection of a AAV2-hSyn-ChR2(H134R)-mCherry into the dorsal Striatum (in 
$1 \mathrm{~mm}$ relative to bregma: $\mathrm{AP}=+0.8, \mathrm{~L}= \pm 2.0, \mathrm{DV}=-2.7)$ 8-9 weeks before

2 electrophysiological recordings. Mice were sedated with isoflurane, deeply

3 anesthetized with ketamine/xylazine $(75 / 10 \mathrm{mg} / \mathrm{Kg})$ and perfused transcardially

4 with ice-cold modified artificial cerebrospinal fluid (ACSF), equilibrated with $95 \%$

$5 \mathrm{O}_{2}$ and $5 \% \mathrm{CO}_{2}$, and containing (in $\mathrm{mM}$ ): 230 sucrose, $26 \mathrm{NaHCO}_{3}, 2.5 \mathrm{KCl}$,

$61.25 \mathrm{NaH}_{2} \mathrm{PO}_{4}, 0.5 \mathrm{CaCl}_{2}, 10 \mathrm{MgSO}_{4}$ and 10 glucose. Brains were rapidly

7 removed and sectioned into $300 \mu \mathrm{m}$-thick parasagittal slices with a vibrating

8 blade microtome (VT1200S; Leica Microsystems, Germany). Slices containing

9 the SNr were then left to equilibrate for $1 \mathrm{~h}\left(\right.$ at $\left.35^{\circ} \mathrm{C}\right)$ in ACSF of the following

10 composition (in $\mathrm{mM}$ except otherwise specified): $126 \mathrm{NaCl}, 26 \mathrm{NaHCO}_{3}, 2.5$

$11 \mathrm{KCl}, 1.25 \mathrm{NaH}_{2} \mathrm{PO}_{4}, 2 \mathrm{CaCl}_{2}, 2 \mathrm{MgSO}_{4}, 10$ glucose, 1 sodium pyruvate and

$124.9 \mu \mathrm{M} \mathrm{L}$-gluthathione reduced (gassed with $95 \% \mathrm{O}_{2}$ and $5 \% \mathrm{CO}_{2}$ ). Single slices

13 were transferred to a recording chamber, perfused continuously with modified

14 oxygenated $\mathrm{ACSF}$ at $32-34^{\circ} \mathrm{C}$ containing (in $\mathrm{mM}$ ): $126 \mathrm{NaCl}, 26 \mathrm{NaHCO}_{3}, 3$

$15 \mathrm{KCl}, 1.25 \mathrm{NaH}_{2} \mathrm{PO}_{4}, 1.6 \mathrm{CaCl}_{2}, 1.5 \mathrm{MgSO}_{4}, 10$ glucose, and visualized using

16 infrared gradient contrast video microscopy and a 60X water-immersion

17 objective (Fluor 60X/1.00 W, Nikon). Recordings from individual SNr neurons

18 were made using pipettes (impedance, 6-8 $\mathrm{M} \Omega$ ) prepared from borosilicate

19 glass capillaries (G150-4; Warner Instruments, Hamden, CT, USA) with a

20 micropipette puller (P-97; Sutter Instruments, Novato, CA, USA). For whole-cell

21 voltage-clamp recordings, pipettes were filled with (in $\mathrm{mM}$ ): $130 \mathrm{~K}$-gluconate,

226.6 Na-gluconate, $1 \mathrm{MgCl}_{2} .6 \mathrm{H}_{2} \mathrm{O}, 10$ HEPES, 5 QX-314, $0.1 \mathrm{Na}_{4} \mathrm{EGTA}, 0.4$

$23 \mathrm{Na}_{3}$ GTP, $2 \mathrm{Mg}_{1.5}$ ATP and 5.4 biocytin. The pipette solution had a $\mathrm{pH}$ of 7.2 and

24 an osmolarity of 292 mOsm. Recordings were obtained using a Multiclamp

$25700 \mathrm{~B}$ amplifier and Digidata 1440 digitizer controlled by Clampex 10.3 
1 (Molecular Devices, Sunnyvale, CA, USA). Signals were low-pass filtered at 4

$2 \mathrm{kHz}$ and sampled at $20 \mathrm{kHz}$. Whole-cell voltage clamp recordings with

3 Kgluconate-filled electrodes were corrected for a junction potential of $13 \mathrm{mV}$. In

4 voltage clamp experiments, series resistance was monitored by a step of $-5 \mathrm{mV}$

5 at the end of each recording. Optogenetic activation of SNr terminals was

6 performed via optic fiber as previously described (Froux et al., 2018)

7 After 5 minutes baseline, $\mathrm{CB}_{1}$ receptor was activated with $5 \mu \mathrm{M}$ WIN 55,212-2

8 dissolved in DMSO. This concentration has been previously showed to reduce

9 hippocampal EPSCs in a $\mathrm{CB}_{1}$ dependent manner(Hebert-Chatelain et al., 10 2016). The glutamatergic synaptic transmission was not blocked for all 11 electrophysiological experiments. Levels of drug-induced depression in 12 response to WIN 55,212-2 are reported as averaged IPSC amplitudes for $5 \mathrm{~min}$ 13 just before bath application compared with averaged IPSC amplitudes during 14 the 15-min period after the application. Data were discarded when the series 15 resistance varied by $>20 \%$. After electrophysiological recordings, slices were 16 fixed overnight in a solution of paraformaldehyde at $4 \%$ and maintained in PBS17 azide at $0.3 \%$ at $4^{\circ} \mathrm{C}$ until histological processing for mCherry visualization or $18 \mathrm{TH} /$ biocytin immunostaining(Chazalon et al., 2018).

19 Hippocampal depolarization-induced suppression of inhibition. Male DN22-CB 1- $^{-}$ $20 \mathrm{KI}$ mice and their WT littermates were sacrificed by dislocation and the brain 21 was immediately immerged in ice-cold oxygenated cutting solution containing in $22 \mathrm{mM}$ : 180 Sucrose, $26 \mathrm{NaHCO}_{3}, 12 \mathrm{MgSO}_{4}, 11$ Glucose, $2.5 \mathrm{KCl}, 1.25$ $23 \mathrm{NaH}_{2} \mathrm{PO}_{4}$, and $0.2 \mathrm{CaCl}_{2}$, oxygenated with $95 \% \quad \mathrm{O}_{2}-5 \% \mathrm{CO}_{2} \approx 300 \mathrm{mOsm}$. 24 Parasagittal hippocampal slices $(300 \mu m$ thick) were obtained using a vibratome 25 (VT1200S, Leica, Germany) and transferred for $30 \mathrm{~min}$ into a $34^{\circ} \mathrm{C}$ bath of 
1 oxygenated ACSF containing in mM: $123 \mathrm{NaCl}, 26 \mathrm{NaHCO}_{3}, 11$ Glucose, 2.5

$2 \mathrm{KCl}, 2.5 \mathrm{CaCl}_{2}, 1.3 \mathrm{MgCl}_{2}, 1.25 \mathrm{NaH}_{2} \mathrm{PO}_{4} \approx 305$ mOsm. After a minimum of $1 \mathrm{~h}$

3 recovery at room temperature $\left(22-25^{\circ} \mathrm{C}\right)$, slices were transferred to a recording

4 chamber in ACSF at $32^{\circ} \mathrm{C}$. Whole-cell recordings of IPSCs were made using a

5 MultiClamp 700B amplifier (Molecular devices, UK) in CA1 pyramidal neurons

6 voltage clamped at $-70 \mathrm{mV}$ with a pipette $(3-5 \mathrm{M} \Omega)$ containing in $\mathrm{mM}: 130 \mathrm{KCl}$,

710 HEPES, 1 EGTA, $2 \mathrm{MgCl}_{2}, 0.3 \mathrm{CaCl}_{2}, 7$ Phosphocreatin, $3 \mathrm{Mg}-\mathrm{ATP}, 0.3 \mathrm{Na}-$

8 GTP; $\mathrm{pH}=7.2 ; 290 \mathrm{mOsm}$. Evoked IPSCs were performed by a monopolar

9 stimulating patch pipette filled with ACSF in stratum radiatum in presence of

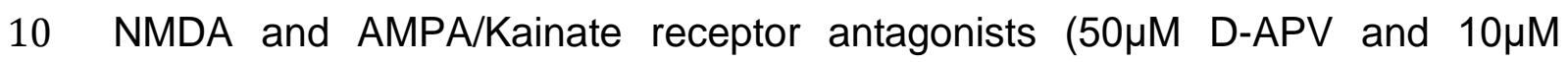

11 NBQX).

12 DSIs were performed by depolarizing pyramidal neurons from $-70 \mathrm{mV}$ to $0 \mathrm{mV}$

13 for $3 \mathrm{~s}$. DSIs' magnitude were measured as the average of 3 DSIs with $2 \mathrm{~min}$ 14 apart and represented the percentage of change between the mean of the 5 15 consecutive IPSCs preceding the depolarization and the first three IPSCs 16 following the depolarization, with IPSCs evoked every $3 \mathrm{~s}$. Currents were 17 filtered at $4 \mathrm{kHz}$ by a Digidata $1440 \mathrm{~A}$ (Molecular devices, UK) and were 18 analyzed using either Clampfit software (pClamp10).

\section{Data collection and statistical analyses}

20 No statistical methods were used to pre-determine sample sizes, but they are 21 similar to those reported in previous publications. Data collection and analysis 22 were performed blind to the conditions of the experiment. All mice were 23 assigned randomly to the different experimental conditions. 
1 All graphs and statistical analyses were performed using GraphPad software

2 (version 5.0, 6.0 or 8.0). Results were expressed as means of independent data

3 points \pm s.e.m. Behavioral data where checked for normality distribution with the

4 D'Agostino\&Pearson test. When all groups of an experiment passed the

5 normality test, ANOVA (One-way or Two-way, where appropriate) analysis was

6 performed and when interaction was significant Tukey's post hoc analysis was

7 used. When the normality was rejected, non-parametric One-way ANOVA

8 (Kruskal-Wallis) was used (Table S2 and S3). Biochemical, anatomical,

9 imaging and electrophysiological data were analyzed using Student's $t$-test

10 (unpaired or paired, where appropriate) or Wilcoxon test as appropriate (Table

11 S2 and S3). Post hoc significances were expressed as follow: * $p<0.05$, ** $12 p<0.01,{ }^{* * *} p<0.001$. 


\section{FIGURE LEGENDS}

2 Figure 1. Striatonigral $\mathrm{CB}_{1}$ receptors mediate catalepsy and 3 antinociception.

4 (A and B) Effects of correct "hit" or misplaced "no-hit" intra-SNr administration

5 of the cell permeable $\mathrm{CB}_{1}$ antagonist AM251 on the $(\mathbf{A})$ cataleptic, and $(\mathbf{B})$

6 antinociceptive $\mathrm{THC}$ effect $(10 \mathrm{mg} / \mathrm{kg}$ i.p.) respect to vehicle treated mice.

7 (C) Representative micrograph (left) and relative quantification (right) of $\mathrm{CB}_{1}$

8 immunoreactivity in the GPe (white bars) and the SNr (black bars) of mice with

9 striatopallidal (ST-GP-CB $-\mathrm{KO}$ ) or striatonigral (ST-SN-CB $-\mathrm{KO}$ ) $\mathrm{CB}_{1}$ receptor

10 deletion compared to control littermates. Target regions are indicated by yellow

11 dotted lines.

12 (D) Cataleptic and (E) antinociceptive effects of THC (10mg/kg i.p.) in mice with 13 striatopallidal (ST-GP-CB $-\mathrm{KO}$ ) or striatonigral (ST-SN-CB $B_{1} \mathrm{KO}$ ) $\mathrm{CB}_{1}$ receptor 14 deletion compared to control littermates.

15 ( $\mathbf{F}$ and $\mathbf{G})$ Effects of intra-SNr administration of the cell impermeable $\mathrm{CB}_{1}$ 16 antagonist Hemopressin ( $\mathrm{Hp}$ ) on the (F) cataleptic, and (G) antinociceptive 17 effect of systemic THC (10mg/kg i.p.) respect to vehicle treated mice.

18 ( $\mathbf{H}$ and $\mathbf{l})$ Effects of intra-SNr administration of the $\mathrm{NK}_{1}$ receptor agonist 19 GR73632 on the $(\mathbf{H})$ cataleptic, and (I) antinociceptive effect of THC $(10 \mathrm{mg} / \mathrm{kg}$ 20 i.p.) respect to vehicle treated mice.

21 (J) Schematic representation of the Substance-P sniffer strategy, and 22 representative picture of sniffers cells [HEK cell expressing $\mathrm{NK}_{1}$ receptor 
$1 \quad\left(\mathrm{NK}_{1} \mathrm{R}\right)$ (red) and GCaMP6 (green)] deposited over slices (IR). Stim: electrical

2 stimulation, STR: striatum, SNr: Substantia nigra pars reticulata, GPe: external

3 globus pallidus. Scale bars: $50 \mu \mathrm{m}$.

4 (K) Left: Representative GCaMP6 fluorescence in the SNr before and after

5 electrical stimulation, in presence of vehicle or WIN $(5 \mu \mathrm{M})$. Middle: traces of

6 GCaMP6 fluorescence variation $(\Delta \mathrm{F} / \mathrm{F} 0)$ from sniffer cells overlying the area

7 shown in (K) (right panel, white square) in the absence (Vehicle) and in the

8 presence of WIN when electrical stimulation (gray bars) of the striatonigral

9 pathway is applied in both WT and $C B_{1}-\mathrm{KO}$ littermates. Plots are from the same

10 cells in both conditions. Right: summary graphs comparing $\Delta \mathrm{F}$ induced by

11 electrical stimulation in all sniffer cells responding and imaged over the $\mathrm{SNr}$ in

12 Vehicle and WIN conditions, comparing WT vs $C B_{1}-\mathrm{KO}$ littermates.

13 (L) Schematic representation of the Substance-P sniffer strategy coupled to 14 optogenetic stimulation of striatonigral terminals. SNr: Substantia nigra pars 15 reticulata, GPe: external globus pallidus.

16 (M) Left: traces of GCaMP6 fluorescence variation $(\Delta F / F 0)$ from sniffer cells 17 overlying the $\mathrm{SNr}$ in the absence (Vehicle) and in the presence of WIN when 18 light stimulation (red bars) of the striatonigral pathway is applied. Plots are from 19 the same cells in both conditions. Right: summary graphs comparing $\Delta \mathrm{F}$ 20 induced by light stimulation in all sniffer cells responding and imaged over the 21 SNr in Vehicle and WIN conditions. 


\section{Figure 2. $\mathrm{CB}_{1}$ receptor subcellular localization in the $\mathrm{SNr}$.}

2 (A - E) Immunogold detection of $\mathrm{CB}_{1}$ receptor by electron microscopy in WT 3 and $C B_{1}-\mathrm{KO}$ mice in SNr. White arrows, plasma membrane gold particles; pink 4 arrows, mitochondrial gold particles; scale bar: $500 \mathrm{~nm}$. Den, dendrites; ter, 5 synaptic terminal, m, mitochondrion; red arrowheads, synapses. Relative 6 quantifications of total $\mathrm{CB}_{1}$ receptor labeling $(\mathrm{B})$, plasma membrane $\mathrm{CB}_{1}$ $7 \quad\left(\mathrm{pmCB}_{1}\right)$ receptor labeling $(\mathbf{C})$, mitochondrial-associated $\mathrm{CB}_{1}\left(\mathrm{mtCB}_{1}\right)$ receptor

8 labeling (D) and proportion of $\mathrm{CB}_{1}$ receptor-positive mitochondria (E).

9 (F - J) Immunogold detection of $\mathrm{CB}_{1}$ receptor by electron microscopy in WT and 10 DN22-CB $-\mathrm{KI}$ mice in SNr. White arrows, plasma membrane gold particles; pink 11 arrows, mitochondrial gold particles; scale bar: $500 \mathrm{~nm}$. Den, dendrites; ter, 12 synaptic terminal, m, mitochondrion; red arrowheads, synapses. Relative 13 quantifications of total $\mathrm{CB}_{1}$ receptor labeling $(\mathbf{G})$, plasma membrane $\mathrm{CB}_{1}$ $14\left(\mathrm{pmCB}_{1}\right)$ receptor labeling $(\mathrm{H})$, mitochondrial-associated $\mathrm{CB}_{1}\left(\mathrm{mtCB}_{1}\right)$ receptor 15 labeling (I) and proportion of $\mathrm{CB}_{1}$ receptor-positive mitochondria (J).

(K) Concentration-response curves of the effect of WIN on $\left[{ }^{35}\right.$ S]GTPYS binding 17 in membranes isolated from cortex, hippocampus and midbrain of WT, $C B_{1}-\mathrm{KO}$ 18 and $\mathrm{DN} 22-\mathrm{CB}_{1}-\mathrm{KI}$ mice.

19 (L) The effect of WIN $(1 \mu \mathrm{M})$ on mitochondrial respiration (oxygen consumption 20 rate, $\mathrm{OCR}$ ) in $\mathrm{SNr}$ homogenates from $\mathrm{WT}, C B_{1}-\mathrm{KO}$, and $\mathrm{DN22}-\mathrm{C} B_{1}-\mathrm{KI}$ mice. 21 Data are expressed as percentage of vehicle values. 


\section{Figure 3. Striatonigral $\mathrm{mtCB}_{1}$ receptor functions.}

2 (A) Representative picture of the striatonigral pathway targeted with optogenetic

3 tools. STR, striatum; GPe, external globus pallidus; STN, subthalamic nucleus;

$4 \mathrm{TH}$, thalamus; HP, hippocampus; SNr substantia nigra pars reticulata. Scale bar $5500 \mu \mathrm{M}$.

6 (B) Representative post-hoc characterization of the analyzed cells (white arrow) 7 by immunofluorescence for biocytin, mCherry (ChR2) and thyroxine8 hydroxylase (TH). Scale bar: $50 \mu \mathrm{M}$.

9 (C) Representative traces of light evoked inhibitory post-synaptic currents 10 (oIPSCs) under control condition and in presence of the $G_{A B A_{A}}$ receptor 11 blocker Gabazine (GBZ) with its corresponding time-course effect.

12 (D) Time course effect of WIN $(5 \mu \mathrm{M})$ on striatonigral olPSCs in slices derived 13 from $\mathrm{WT}, C B_{1}-\mathrm{KO}$ and $\mathrm{DN} 22-C B_{1}-\mathrm{KI}$ mice.

14 (E) Plots of normalized olPSCs with representative traces before and after WIN 15 treatment and summary of the average change of oIPSCs relative to baseline.

16 (F) Cataleptic, and (G) antinociceptive effect of systemic THC (10mg/kg i.p.) or 17 WIN (3mg/kg i.p.), respect to vehicle in WT and DN22-CB $-\mathrm{CI}$ mice 


\section{Figure 4. Striatonigral $\mathrm{mtCB}_{1}$ receptor signaling.}

2 (A) Schematic representation of the $\mathrm{CB}_{1}$ or $\mathrm{DN22}-\mathrm{CB}_{1}$ rescue-approach in $\mathrm{D}_{1}$ -

$3 \mathrm{CB}_{1}-\mathrm{KO}$ mice. STR, striatum; $\mathrm{SNr}$, substantia nigra pars reticulata; $\mathrm{mtCB}{ }_{1}$,

4 mitochondrial $\mathrm{CB}_{1}$ receptor; $\mathrm{pmCB}_{1}$, plasma membrane $\mathrm{CB}_{1}$ receptor.

5 (B) Representative immunofluorescence pictures of $\mathrm{CB}_{1}$ or $\mathrm{DN}_{22}-\mathrm{CB}_{1}$ rescue in 6 the $\mathrm{SNr}$ of $\mathrm{D}_{1}-\mathrm{CB}_{1}-\mathrm{KO}$ mice. Green, $\mathrm{CB}_{1}$ positive signal; Blue, DAPI nuclear 7 counterstaining. Scale bar $250 \mu \mathrm{m}$.

8 (C) Relative quantification of $\mathrm{CB}_{1}$ receptor immunofluorescence $\mathrm{D}_{1}-C B_{1}-\mathrm{KO}$ 9 mice after $\mathrm{CB}_{1}$ or $\mathrm{DN22}-\mathrm{CB}_{1}$ rescue in the $\mathrm{SNr}$.

10 (D) Effect of WIN $(1 \mu \mathrm{M})$ on mitochondrial respiration (oxygen consumption rate, $11 \mathrm{OCR}$ ) in $\mathrm{SN}$ homogenates form $\mathrm{WT}, \mathrm{D}_{1}-\mathrm{CB}_{1}-\mathrm{KO}$ control mice, and $\mathrm{CB}_{1}$ or 12 DN22-CB 1 rescued in the striatonigral circuit (see above $\boldsymbol{A}$ and $\boldsymbol{B}$ ).

13 (E) Cataleptic effect of THC (10mg/kg i.p.) in WT, $\mathrm{D}_{1}-C B_{1}-\mathrm{KO}$ control mice, and $14 \mathrm{CB}_{1}$ or $\mathrm{DN}_{22}-\mathrm{CB}_{1}$ rescued in the striatonigral circuit (see above $\boldsymbol{A}$ and $\boldsymbol{B}$ ).

15 (F) Effect of WIN $(1 \mu \mathrm{M})$ on mitochondrial respiration (oxygen consumption rate, $16 \mathrm{OCR}$ ) in $\mathrm{SN}$ homogenates pre-treated with vehicle or the SAC blocker $\mathrm{KH} 7$ $17(5 \mu \mathrm{M})$.

18 ( $\mathbf{G}$ and $\mathbf{H})$ Effects of intra-SNr administration of sAC blocker $\mathrm{KH} 7(2 \mu \mathrm{g})$ on the 19 (G) cataleptic, and (H) antinociceptive effect of systemic THC (10mg/kg i.p.) 20 respect to vehicle treated mice. 
1 (I) Effect of WIN $(1 \mu \mathrm{M})$ on mitochondrial respiration (oxygen consumption rate,

$2 \mathrm{OCR}$ ) in $\mathrm{SN}$ homogenates form $\mathrm{D}_{1}$-Cre mice injected in the striatum with control

3 (Ctr) virus or Cre-dependent mt-sAC expressing virus.

4 (J) Cataleptic, and (K) antinociceptive effects of systemic THC (10mg/kg i.p.)

5 respect to vehicle in $\mathrm{D}_{1}$-Cre mice injected with either control (Ctr) or Cre-

6 dependent mt-sAC expressing virus in the striatum.

7 (L) Cataleptic, and (M) antinociceptive effect of systemic THC (10mg/kg i.p.)

8 respect to vehicle in $\mathrm{D}_{1}$-Cre mice injected with either control (Ctr) or Cre-

9 dependent PKA-CA or MLS-PKA-CA expressing virus in the striatum.

10 (N) Effect of WIN $(1 \mu \mathrm{m})$ on mitochondrial respiration (oxygen consumption rate,

$11 \mathrm{OCR}$ ) in $\mathrm{SN}$ homogenates from $\mathrm{D}_{1}$-Cre mice injected in the striatum with control

12 virus or Cre-dependent PKA-CA or MLS-PKA-CA vectors. 


\section{SUPPLEMENTARY FIGURE LEGENDS}

2 Figure $\mathbf{S 1}$ (related to main Figure 1). Cannabinoid-induced

3 antinociception, but not catalepsy, relies on activation of striatonigral

$4 \quad \mathrm{pmCB}_{1}$ and regulation of Substance-P/NK $\mathrm{N}_{1}$ receptor activity.

5 (A) SNr correct (hit) and misplaced (no-hit) cannula placements verified by

6 infusion of skyblue toluidine solution followed by brain slicing and neutral red

7 counterstaining. Representative histological analysis (top) and schematic

8 representations (bottom, "hit" green dots, "no-hit" red dots) of the injection sites

9 in the SNr.

10 (B) Effects of correct "hit" and misplaced "no-hit" intra-SNr administration of the

11 cell permeable $\mathrm{CB}_{1}$ antagonist AM251 on the hypolocomotor effect of systemic

$12 \mathrm{THC}(10 \mathrm{mg} / \mathrm{kg}$ i.p.) respect to vehicle treated mice.

13 (C) Schematic for striatonigral or striatopallidal $\mathrm{CB}_{1}$ receptor deletion and 14 representative pictures of viral injection sites. Green signal, striatal (STR) 15 expression of AAV-FRT-iCre-EGFP. Blue signal, AAV-retro-FLP-BLFP or AAV16 retro-BLFP expression in the globus pallidus (GPe) or in the substantia nigra 17 reticulata $(\mathrm{SNr})$.

18 (D) Representative micrograph (left) and relative quantification (right) of $C B_{1} / D_{1}$ 19 and $\mathrm{CB}_{1} / \mathrm{D}_{2}$ co-expressing cells in the striatum of mice with striatopallidal (ST$20 \mathrm{GP}-\mathrm{CB}_{1}-\mathrm{KO}$ ) or striatonigral (ST-SN-CB$\left.-\mathrm{KO}\right) \mathrm{CB}_{1}$ receptor deletion compared 21 to control littermates. ec: external capsule. ns: non-statistically different. Scale 22 bar, $50 \mu \mathrm{m}$. 
1 (E) Hypolocomotor effect of systemic THC (10mg/kg i.p.) respect to vehicle in

2 mice with striatopallidal (ST-GP-CB$-\mathrm{CO}$ ) or striatonigral (ST-SN-CB $-\mathrm{KO}$ ) $\mathrm{CB}_{1}$

3 receptor deletion compared to control littermates.

4 (F-G) Effects of i.p. administration of the $\mathrm{NK}_{1}$ receptor agonist GR73632 (75

$5 \mu \mathrm{g} / \mathrm{kg}$ ) on the cataleptic (F) and antinociceptive (G) effects of systemic THC

$6 \quad(10 \mathrm{mg} / \mathrm{kg}$ i.p.) respect to vehicle treated mice.

7 (H) Left: Schematics of the Substance-P (SP) "sniffer cell" system. Co-

8 expression of human $\mathrm{NK}_{1}$ receptor $\left(\mathrm{hNK}_{1} \mathrm{R}\right)$ and GCaMP6s in HEK293T cells

9 facilitates detection of SP-induced calcium increases reflected by increased

10 GCaMP6s fluorescence. Center: fluorescence micrographs of representative

$11 \mathrm{SP}$ "sniffer cells" co-expressing $\mathrm{hNK}_{1} \mathrm{R}$-mCherry and GCaMP6s, and line-scan

12 fluorescence quantification indicating membrane localization of $h N K_{1} R$. Right:

13 representative fluorescence micrographs and kinetic trace of SP "sniffer cells" at

14 baseline (time =0s) and following stimulation with 10nM SP (time=180s) added

15 to the perfusion chamber following a 60 s baseline recording. Dose response to

$16 \mathrm{SP}$ in the same settings (bottom right) quantified as the change in GCaMP6s

17 fluorescence normalized to baseline fluorescence $(\Delta \mathrm{F} / \mathrm{F} 0)$ with increasing doses

18 of SP. The EC50 for "sniffer cells" to SP was $5.088 \mathrm{nM}$.

19 (I) GCaMP6 response to different doses of SP in presence of $\mathrm{NK}_{1} \mathrm{R}$ or in its 20 absence, indicating the specificity of the "sniffer cell" response.

21 (J) Left: traces of GCaMP6 fluorescence variation $(\Delta \mathrm{F} / \mathrm{F} 0)$ from sniffer cells 22 expressing only GCaMP6 or both GCaMP6/NK 1 R in the absence (Vehicle) and 23 in the presence of the $\mathrm{NK}_{1} \mathrm{R}$ blocker $\mathrm{CP} 122721$ (CP) when electrical stimulation 24 (gray bars) of the striatonigral pathway is applied. Right: summary bar graphs 
1 comparing means $\pm \mathrm{SE}$ values of $\Delta \mathrm{F}$ induced by electrical stimulation in all

2 sniffer cells responding and imaged over the SNr in Vehicle and CP conditions

3 (K) GCaMP6 fluorescence changes $(\Delta F)$ after electrical stimulation in control 4 condition, after vehicle and $5 \mu \mathrm{M}$ WIN on the same cells.

5 (L) Induction of calcium increase by SP in presence of $5 \mu \mathrm{M}$ WIN in vitro.

6 (M) Representative traces of light evoked inhibitory post-synaptic currents 7 (olPSCs) in the $\mathrm{SNr}$ of $\mathrm{D}_{1}$-Cre mice injected in the striatum with rAAV-DIO-

8 ChrmisonR as explained in Figure 1L. Note the presence of small olPSCs 9 induced by blue light application using during calcium imaging. 
1 Figure S2 (related to main Figure 2). Functional localization of $\mathrm{CB}_{1}$

2 receptors at mitochondrial membranes within the SNr.

3 (A) Immunogold detection of $\mathrm{CB}_{1}$ receptor by electron microscopy in WT and

$4 \mathrm{CB}_{1}-\mathrm{KO}$ mice in SNr. White arrows, plasma membrane gold particles; pink

5 arrows, mitochondrial gold particles; scale bar: $500 \mathrm{~nm}$.

6 (B) Schematic representation of the strategy employed for the generation of

7 DN22- $C B_{1}-\mathrm{KI}$ mouse line. LHA: left homology arm; RHA, right homology arm.

8 (C) Top left: $q R T-P C R$ analysis of $\mathrm{CB}_{1}$ mRNA in different brain regions from

9 WT, DN22- $C B_{1}-\mathrm{KI}$ and $C B_{1}-\mathrm{KO}$ mice. AMY, amygdala; HYP, hypothalamus;

10 STR, striatum; HPC, hippocampus; AON, anterior olfactory nucleus; PFC,

11 prefrontal cortex. n.d., not detected Top right and bottom: immunofluorescence

12 detection and representative images of $\mathrm{CB}_{1}$ receptor in the brain of WT vs

13 DN22- $C B_{1}-\mathrm{KI}$ mice $\left(C B_{1}-\mathrm{KO}\right.$ mice are shown as antibody negative control).

14 CA1, hippocampal region; SNr, substantia nigra pars reticulata; STR, striatum;

$15 \mathrm{MC}$, motor cortex; AON, anterior olfactory nucleus; PFC, prefrontal cortex; CRB, 16 cerebellum.

17 (D) Immunogold detection of $\mathrm{CB}_{1}$ receptor by electron microscopy in WT and 18 DN22- $C B_{1}-\mathrm{KI}$ mice in SNr. White arrows, plasma membrane gold particles; pink 19 arrows, mitochondrial gold particles; scale bar: $500 \mathrm{~nm}$.

20 (E) Representative autoradiograms of brain sections from basal, $1 \mu \mathrm{M}$ and 10 $21 \mu \mathrm{M}$ WIN-stimulated $\left[{ }^{35} \mathrm{~S}\right] \mathrm{GTP \gamma}$ S binding in WT mice.

22 (F) Relative quantification of WIN-mediated $\left[{ }^{35}\right.$ S]GTPYS over basal level at $1 \mu \mathrm{M}$ 23 (left) and $10 \mu \mathrm{M}$ (right) doses in WT and DN22-CB $-\mathrm{KI}$ mice. SNr, substantia 24 nigra reticulata; STR, striatum; PFC, prefrontal cortex; OB, olfactory bulb; HYP, 
1 hypothalamus; GPe, external globus pallidus; HPC, hippocampus; CB,

2 cerebellum; BLA, basolateral amygdala; AON, anterior olfactory nucleus; NAC,

3 nucleus accumbens.

4 (G) Representative autoradiograms of brain sections from WT, DN22-CB $1-\mathrm{KI}$ 5 and $\mathrm{CB}_{1}-\mathrm{KO}$ mice incubated with [ ${ }^{3 \mathrm{H}}$ ] CP55.940.

6 (H) Relative quantification of bound $\left.{ }^{3 \mathrm{H}}\right]$ CP55.940 in WT, DN22- ${ }^{-B_{1}-\mathrm{KI} \text { and }}$ $7 \quad \mathrm{CB}_{1}-\mathrm{KO}$ slices. SNr, substantia nigra pars reticulata; STR, striatum; PFC, 8 prefrontal cortex; OB, olfactory bulb; HYP, hypothalamus; GPe, external globus 9 pallidus; HPC, hippocampus; $\mathrm{CB}$, cerebellum; BLA, basolateral amygdala; 10 AON, anterior olfactory nucleus; NAC, nucleus accumbens.

11 (I) Representative trace of mitochondrial respiration in a substantia nigra 12 preparation from $\mathrm{WT}$, DN22- $C B_{1}-\mathrm{KI}$ and $C B_{1}-\mathrm{KO}$ mice. Substrates are malate, pyruvate and glutamate. The inhibitory effect of WIN was observed when the respiration was coupled to ATP synthesis via the addition of Adenosine 15 diphosphate (ADP, see Table S1). 
2 Figure S3 (related to main Figure 3). $\mathrm{MtCB}_{1}$ receptors and their signaling

3 mediate the cataleptic effect of cannabinoids in the striatonigral circuits.

4 (A) Body weight (top panel) and muscular strength (measured by grid 5 suspension test, bottom panel) of WT and DN22-CB $-\mathrm{KI}$ mice.

6 (B) Daily home cage locomotor activity of WT and DN22-CB $-\mathrm{KI}$ mice. Grey box $7 \quad$ indicate the night phase.

8 (C) Daily voluntary wheel running of WT and DN22-CB $-\mathrm{KI}$ mice. Grey box 9 indicate the night phase.

10 (D) Time course plot showing elPSCs amplitude before and after 3s 11 depolarization (-70 to $0 \mathrm{mV}$ grey line) in hippocampal slices obtained from WT 12 and $\mathrm{DN} 22-C B_{1}-\mathrm{KI}$ mice.

13 (E) Representative traces of elPSCs before and after 3s depolarization (-70 to 0 $14 \mathrm{mV}$ ) in $\mathrm{WT}$ and $\mathrm{DN22}-\mathrm{CB}_{1}-\mathrm{KI}$ mice and averaged reduction of elPSCs 15 amplitude respect to baseline recorded during 3 sweeps after depolarization.

16 (F) Average paired pulse ratio (PPR) after optogenetic stimulation of 17 striatonigral terminals in WT and DN22-CB $-\mathrm{KI}$ mice.

18 (G) Traces of GCaMP6 fluorescence variation $(\Delta F / F 0)$ from sniffer cells in the 19 absence (Vehicle) and in the presence of WIN when electrical stimulation (gray 20 bars) of the striatonigral pathway in slices from DN22-CB $-\mathrm{KI}$ mice is applied.

21 Plots are from the same cells in both conditions. Right: summary bar graphs 22 comparing means \pm SEM values of $\Delta F / F 0$ induced by electrical stimulation in all 
1 sniffer cells responding and imaged over the SNr in Vehicle and WIN conditions

2 in DN22- $\mathrm{CB}_{1}-\mathrm{KI}$ mice.

3 (H) Effects of intra-SNr administration of the cell impermeable $\mathrm{CB}_{1}$ antagonist 4 Hemopressin (Hp, 22ng) on the antinociceptive effect of systemic THC 5 (10mg/kg i.p.) in DN22-CB $-\mathrm{Cl}$ mice.

6 (I) Effects of i.p. administration of the $\mathrm{NK}_{1}$ receptor agonist GR73632 $(75 \mu \mathrm{g} / \mathrm{kg})$

7 on the antinociceptive effect of systemic THC (10mg/kg i.p.) respect to vehicle 8 in DN22- $C B_{1}-\mathrm{KI}$ mice.

9 (J) Correlation between $\mathrm{CB}_{1}$ fluorescence intensity in $\mathrm{SNr}$ (X axis) and 10 immobility in the bar test induced by $\mathrm{THC}\left(\mathrm{Y}\right.$ axis) in $\mathrm{D}_{1}-C B_{1}-\mathrm{KO}$ mice injected 11 with rAAV-DIO-CB 1 (black dots) or with rAAV-DIO-DN22-CB 1 (grey dots) in the 12 striatum.

13 (K) Effect of WIN $(1 \mu \mathrm{M})$ on mitochondrial respiration (oxygen consumption rate, $14 \mathrm{OCR})$ in SN homogenates pre-treated with vehicle or GR736321 $(1 \mu \mathrm{M})$.

15 (L) Representative immunofluorescence of the mitochondrial protein TOMM20 16 and HA in Hela cells expressing pcDNA or mt-sAC. Scale bar: $10 \mu \mathrm{m}$.

17 (M) Representative pictures of HA-tag immunostaining in the dorsal striatum of $18 \mathrm{D}_{1}$-Cre mice injected with control or Cre-dependent mt-sAC AAV. Scale bar $19100 \mu \mathrm{m}$.

20 (N) Western blotting for HA-tag, endogenous SAC, tubulin and Tomm20 after 21 immuno-magnetic isolation of striatal mitochondria (Mito) compared to total cell 
1 lysate $(T C L)$ from $D_{1}$-Cre mice injected with control or Cre-dependent mt-sAC

$2 \quad A A V$ in the dorsal striatum.

3 (0) Western blotting for HA-tag and endogenous SAC in SN homogenates 4 (used for mitochondrial respiration, see Figure 4I) from $D_{1}$-Cre mice injected 5 with control or Cre-dependent mt-sAC AAV in the dorsal striatum.

6 (P) Representative immunofluorescence and co-localization analysis of the 7 mitochondrial protein TOMM20 and Myc in Hela cells expressing pcDNA, PKA-

8 CA or MLS-PKA-CA. Scale bar: $10 \mu \mathrm{m}$. And Trypsin sensitivity assay (right).

9 (Q) Western blotting for Myc-tag, endogenous PKA, tubulin and Tomm20 after 10 immuno-magnetic isolation of striatal mitochondria (Mito) compared to total cell 11 Iysate (TCL) from $D_{1}$-Cre mice injected with control or Cre-dependent PKA-CA 12 or MLS-PKA-CA AAVs in the dorsal striatum.

13 (R) Western blotting for myc-tag in SN homogenates (used for mitochondrial 14 respiration, see Figure $\mathbf{4 N}$ ) from $D_{1}$-Cre mice injected with control or Cre15 dependent PKA-CA or MLS-PKA-CA AAVs in the dorsal striatum. 
1 Figure S4. Proposed mechanisms for the subcellular specificity of

2 behavior control by $\mathrm{CB}_{1}$ receptors in striatonigral circuits.

3 At striatonigral terminals, activation of pmCB1 triggers inhibition of cytosolic 4 PKA, which in turn results in a reduction of Substance-P release and 5 subsequent decrease of pain perception. In the same terminals, activation of

$6 \mathrm{mtCB}_{1}$ is responsible of motor impairment, by decreasing the release of GABA 7 on SNr neurons trough inhibition of mitochondrial activity. 
1 Table S1. Characterization of Mitochondrial respiration in SN extracts

$2 \mathrm{Cl}$ L, ComplexI Leak; $\mathrm{Cl}$ p, Complexl OXPHOS; $\mathrm{Cl} \& \mathrm{Cll}$ p, Complexl and

3 Complexll OXPHOS; CII p, Complexll OXPHOS; ROX, Residual Oxigen

4 Consumption.

5 Table S2. Statistical analysis. Related to Figure 1-4.

6 Table S3. Statistical analysis. Related to Figure S1-S3.

7 


\section{REFERENCES}

2 Bellocchio, L., Lafenetre, P., Cannich, A., Cota, D., Puente, N., Grandes, P.,

3 Chaouloff, F., Piazza, P., and Marsicano, G. (2010). Bimodal control of

4 stimulated food intake by the endocannabinoid system. Nature Neuroscience

5 13, 281-283.

6 Bellocchio, L., Ruiz-Calvo, A., Chiarlone, A., Cabanas, M., Resel, E., Cazalets,

7 J.R., Blazquez, C., Cho, Y.H., Galve-Roperh, I., and Guzman, M. (2016).

8 Sustained Gq-Protein Signaling Disrupts Striatal Circuits via JNK. The Journal

9 of neuroscience : the official journal of the Society for Neuroscience 36, 106111010624.

11 Benard, G., Massa, F., Puente, N., Lourenco, J., Bellocchio, L., Soria-Gomez,

12 E., Matias, I., Delamarre, A., Metna-Laurent, M., Cannich, A., et al. (2012).

13 Mitochondrial $\mathrm{CB}(1)$ receptors regulate neuronal energy metabolism. Nature 14 neuroscience $15,558-564$.

15 Boccella, S., Marabese, I., Guida, F., Luongo, L., Maione, S., and Palazzo, E. 16 (2020). The Modulation of Pain by Metabotropic Glutamate Receptors 7 and 8 17 in the Dorsal Striatum. Curr Neuropharmacol 18, 34-50.

18 Borgelt, L.M., Franson, K.L., Nussbaum, A.M., and Wang, G.S. (2013). The 19 pharmacologic and clinical effects of medical cannabis. Pharmacotherapy 33, $20 \quad 195-209$.

21 Borgkvist, A., and Fisone, G. (2007). Psychoactive drugs and regulation of the 22 cAMP/PKA/DARPP-32 cascade in striatal medium spiny neurons. Neuroscience 23 and biobehavioral reviews 31, 79-88. 
1 Borsook, D., Upadhyay, J., Chudler, E.H., and Becerra, L. (2010). A key role of

2 the basal ganglia in pain and analgesia--insights gained through human

3 functional imaging. Mol Pain 6, 27.

4 Bradford, M.M. (1976). A rapid and sensitive method for the quantitation of

5 microgram quantities of protein utilizing the principle of protein-dye binding.

6 Analytical Biochemistry 72, 248-254.

7 Brown, R.E. (2019). Review of Franz Joseph Gall: Naturalist of the mind,

8 visionary of the brain. Hist Psychol 22, 374-379.

9 Bucko, P.J., Lombard, C.K., Rathbun, L., Garcia, I., Bhat, A., Wordeman, L., 10 Smith, F.D., Maly, D.J., Hehnly, H., and Scott, J.D. (2019). Subcellular drug 11 targeting illuminates local kinase action. Elife 8.

12 Busquets-Garcia, A., Bains, J., and Marsicano, G. (2018). CB1 Receptor 13 Signaling in the Brain: Extracting Specificity from Ubiquity. 14 Neuropsychopharmacology : official publication of the American College of 15 Neuropsychopharmacology 43, 4-20.

16 Chazalon, M., Paredes-Rodriguez, E., Morin, S., Martinez, A., Cristovao17 Ferreira, S., Vaz, S., Sebastiao, A., Panatier, A., Boue-Grabot, E., Miguelez, C., 18 and Baufreton, J. (2018). GAT-3 Dysfunction Generates Tonic Inhibition in 19 External Globus Pallidus Neurons in Parkinsonian Rodents. Cell Rep 23, 1678201690.

21 Chen, W., Ennes, H.S., McRoberts, J.A., and Marvizon, J.C. (2018). 22 Mechanisms of mu-opioid receptor inhibition of NMDA receptor-induced 23 substance $P$ release in the rat spinal cord. Neuropharmacology $128,255-268$. 
1 Chomczynski, P., and Sacchi, N. (1987). Single-step method of RNA isolation

2 by acid guanidinium thiocyanate-phenol-chloroform extraction. Anal Biochem $3162,156-159$.

4 Choo, Y.S. (2004). Mutant huntingtin directly increases susceptibility of

5 mitochondria to the calcium-induced permeability transition and cytochrome c

6 release. Human Molecular Genetics 13, 1407-1420.

7 Clapper, J.R., Moreno-Sanz, G., Russo, R., Guijarro, A., Vacondio, F., Duranti,

8 A., Tontini, A., Sanchini, S., Sciolino, N.R., Spradley, J.M., et al. (2010).

9 Anandamide suppresses pain initiation through a peripheral endocannabinoid 10 mechanism. Nat Neurosci 13, 1265-1270.

11 Cohen, K., Weizman, A., and Weinstein, A. (2019). Positive and Negative 12 Effects of Cannabis and Cannabinoids on Health. Clin Pharmacol Ther 105, $13 \quad 1139-1147$.

14 Creighton, J. (2011). Targeting therapeutic effects: subcellular location matters. 15 Focus on "Pharmacological AMP-kinase activators have compartment-specific 16 effects on cell physiology". Am J Physiol Cell Physiol 301, C1293-1295.

17 Darmani, N.A., and Pandya, D.K. (2000). Involvement of other 18 neurotransmitters in behaviors induced by the cannabinoid CB1 receptor 19 antagonist SR 141716A in naive mice. J Neural Transm (Vienna) 107, 931-945. 20 Deniau, J.M., Mailly, P., Maurice, N., and Charpier, S. (2007). The pars 21 reticulata of the substantia nigra: a window to basal ganglia output. Progress in 22 brain research 160, 151-172.

23 Donvito, G., Nass, S.R., Wilkerson, J.L., Curry, Z.A., Schurman, L.D., Kinsey, 24 S.G., and Lichtman, A.H. (2018). The Endogenous Cannabinoid System: A 25 Budding Source of Targets for Treating Inflammatory and Neuropathic Pain. 
1 Neuropsychopharmacology : official publication of the American College of

2 Neuropsychopharmacology 43, 52-79.

3 Dubreucq, S., Koehl, M., Abrous, D.N., Marsicano, G., and Chaouloff, F. (2010).

$4 \quad$ CB1 receptor deficiency decreases wheel-running activity: consequences on

5 emotional behaviours and hippocampal neurogenesis. Exp Neurol 224, 106-

6113.

7 Dwivedi, Y., and Pandey, G.N. (2008). Adenylyl cyclase-cyclicAMP signaling in

8 mood disorders: role of the crucial phosphorylating enzyme protein kinase A.

9 Neuropsychiatr Dis Treat 4, 161-176.

10 Eichel, K., and von Zastrow, M. (2018). Subcellular Organization of GPCR

11 Signaling. Trends Pharmacol Sci 39, 200-208.

12 Fernandez-Ruiz, J., Moreno-Martet, M., Rodriguez-Cueto, C., Palomo-Garo, C.,

13 Gomez-Canas, M., Valdeolivas, S., Guaza, C., Romero, J., Guzman, M., 14 Mechoulam, R., and Ramos, J.A. (2011). Prospects for cannabinoid therapies in 15 basal ganglia disorders. Br J Pharmacol 163, 1365-1378.

16 Francisco, A., Engel, D.F., Figueira, T.R., Rogerio, F., de Bem, A.F., and 17 Castilho, R.F. (2020). Mitochondrial $\operatorname{NAD}(P)(+)$ Transhydrogenase is Unevenly 18 Distributed in Different Brain Regions, and its Loss Causes Depressive-like 19 Behavior and Motor Dysfunction in Mice. Neuroscience 440, 210-229.

20 Freeze, B.S., Kravitz, A.V., Hammack, N., Berke, J.D., and Kreitzer, A.C. 21 (2013). Control of basal ganglia output by direct and indirect pathway projection 22 neurons. The Journal of neuroscience : the official journal of the Society for 23 Neuroscience 33, 18531-18539. 
1 Garcia, C., Palomo-Garo, C., Gomez-Galvez, Y., and Fernandez-Ruiz, J.

2 (2016). Cannabinoid-dopamine interactions in the physiology and

3 physiopathology of the basal ganglia. Br J Pharmacol 173, 2069-2079.

4 Garcia, G.C., Bartol, T.M., Phan, S., Bushong, E.A., Perkins, G., Sejnowski,

5 T.J., Ellisman, M.H., and Skupin, A. (2019). Mitochondrial morphology provides

6 a mechanism for energy buffering at synapses. Sci Rep 9, 18306.

7 Giuffrida, A., and Seillier, A. (2012). New insights on endocannabinoid

8 transmission in psychomotor disorders. Prog Neuropsychopharmacol Biol

9 Psychiatry 38, 51-58.

10 Griebel, G., Stemmelin, J., and Scatton, B. (2005). Effects of the cannabinoid

11 CB1 receptor antagonist rimonabant in models of emotional reactivity in

12 rodents. Biological Psychiatry 57, 261-267.

13 Guedouari, H., Daigle, T., Scorrano, L., and Hebert-Chatelain, E. (2017). Sirtuin

145 protects mitochondria from fragmentation and degradation during starvation.

15 Biochimica et Biophysica Acta (BBA) - Molecular Cell Research 1864, 169-176.

16 Gutierrez-Rodriguez, A., Bonilla-Del Rio, I., Puente, N., Gomez-Urquijo, S.M.,

17 Fontaine, C.J., Egana-Huguet, J., Elezgarai, I., Ruehle, S., Lutz, B., Robin,

18 L.M., et al. (2018). Localization of the cannabinoid type-1 receptor in subcellular

19 astrocyte compartments of mutant mouse hippocampus. Glia 66, 1417-1431.

20 Häring, M., Kaiser, N., Monory, K., and Lutz, B. (2011). Circuit Specific

21 Functions of Cannabinoid CB1 Receptor in the Balance of Investigatory Drive 22 and Exploration. PLoS ONE 6, e26617.

23 Hebert-Chatelain, E., Desprez, T., Serrat, R., Bellocchio, L., Soria-Gomez, E.,

24 Busquets-Garcia, A., Pagano Zottola, A.C., Delamarre, A., Cannich, A., Vincent, 
1 P., et al. (2016). A cannabinoid link between mitochondria and memory. Nature $2539,555-559$.

3 Heimann, A.S., Gomes, I., Dale, C.S., Pagano, R.L., Gupta, A., de Souza, L.L.,

4 Luchessi, A.D., Castro, L.M., Giorgi, R., Rioli, V., et al. (2007). Hemopressin is 5 an inverse agonist of CB1 cannabinoid receptors. Proceedings of the National 6 Academy of Sciences of the United States of America 104, 20588-20593.

7 Ibsen, M.S., Connor, M., and Glass, M. (2017). Cannabinoid CB1 and CB2

8 Receptor Signaling and Bias. Cannabis Cannabinoid Res 2, 48-60.

9 Ilouz, R., Lev-Ram, V., Bushong, E.A., Stiles, T.L., Friedmann-Morvinski, D., 10 Douglas, C., Goldberg, J.L., Ellisman, M.H., and Taylor, S.S. (2017). Isoform11 specific subcellular localization and function of protein kinase $A$ identified by 12 mosaic imaging of mouse brain. Elife 6 .

13 Jimenez-Blasco, D., Busquets-Garcia, A., Hebert-Chatelain, E., Serrat, R., 14 Vicente-Gutierrez, C., Ioannidou, C., Gomez-Sotres, P., Lopez-Fabuel, I., 15 Resch-Beusher, M., Resel, E., et al. (2020). Glucose metabolism links astroglial 16 mitochondria to cannabinoid effects. Nature 583, 603-608.

17 Johnson, M.B., Young, A.D., and Marriott, I. (2016). The Therapeutic Potential 18 of Targeting Substance P/NK-1R Interactions in Inflammatory CNS Disorders. 19 Front Cell Neurosci 10, 296.

20 Kanellopoulos, A.K., Mariano, V., Spinazzi, M., Woo, Y.J., McLean, C., Pech, 21 U., Li, K.W., Armstrong, J.D., Giangrande, A., Callaerts, P., et al. (2020). Aralar 22 Sequesters GABA into Hyperactive Mitochondria, Causing Social Behavior 23 Deficits. Cell 180, 1178-1197 e1120. 
1 Kano, M., Ohno-Shosaku, T., Hashimotodani, Y., Uchigashima, M., and

2 Watanabe, M. (2009). Endocannabinoid-mediated control of synaptic

3 transmission. Physiol Rev 89, 309-380.

4 Klapoetke, N.C., Murata, Y., Kim, S.S., Pulver, S.R., Birdsey-Benson, A., Cho,

5 Y.K., Morimoto, T.K., Chuong, A.S., Carpenter, E.J., Tian, Z., et al. (2014).

6 Independent optical excitation of distinct neural populations. Nat Methods 11, $7 \quad 338-346$.

8 Knight, R.T. (2007). Neuroscience. Neural networks debunk phrenology.

9 Science 316, 1578-1579.

10 Koch, M., Varela, L., Kim, J.G., Kim, J.D., Hernandez-Nuno, F., Simonds, S.E.,

11 Castorena, C.M., Vianna, C.R., Elmquist, J.K., Morozov, Y.M., et al. (2015).

12 Hypothalamic POMC neurons promote cannabinoid-induced feeding. Nature $13519,45-50$.

14 Lahuna, O., and Jockers, R. (2018). [Mitochondrial signaling of G protein15 coupled receptors]. Biol Aujourdhui 212, 21-26.

16 Lemberger, T., Parlato, R., Dassesse, D., Westphal, M., Casanova, E., Turiault, 17 M., Tronche, F., Schiffmann, S.N., and Schutz, G. (2007). Expression of Cre 18 recombinase in dopaminoceptive neurons. BMC Neurosci 8, 4.

19 Lever, I.J., and Malcangio, M. (2002). CB(1) receptor antagonist SR141716A 20 increases capsaicin-evoked release of Substance $P$ from the adult mouse 21 spinal cord. Br J Pharmacol 135, 21-24.

22 Livak, K.J., and Schmittgen, T.D. (2001). Analysis of relative gene expression 23 data using real-time quantitative PCR and the 2(-Delta Delta $C(T)$ ) Method.

24 Methods 25, 402-408. 
1 Makrecka-Kuka, M., Krumschnabel, G., and Gnaiger, E. (2015). High-

2 Resolution Respirometry for Simultaneous Measurement of Oxygen and

3 Hydrogen Peroxide Fluxes in Permeabilized Cells, Tissue Homogenate and

4 Isolated Mitochondria. Biomolecules 5, 1319-1338.

5 Marsicano, G., Goodenough, S., Monory, K., Hermann, H., Eder, M., Cannich,

6 A., Azad, S.C., Cascio, M.G., Gutierrez, S.O., van der Stelt, M., et al. (2003).

7 CB1 cannabinoid receptors and on-demand defense against excitotoxicity.

8 Science 302, 84-88.

9 Marsicano, G., and Kuner, R. (2008). Anatomical distribution of receptors, 10 ligands and enzymes in the brain and the spinal cord: circuitries and 11 neurochemistry. In Cannabinoids and the brain, A. Kofalvi, ed. (New York: 12 Springer), pp. 161-202.

13 Martin, J.L., Gadegbeku, B., Wu, D., Viallon, V., and Laumon, B. (2017).

14 Cannabis, alcohol and fatal road accidents. PloS one 12, e0187320.

15 Martinez, A., Macheda, T., Morgese, M.G., Trabace, L., and Giuffrida, A. 16 (2012). The cannabinoid agonist WIN55212-2 decreases L-DOPA-induced PKA 17 activation and dyskinetic behavior in 6-OHDA-treated rats. Neurosci Res 72 , $18 \quad 236-242$.

19 Metna-Laurent, M., Mondesir, M., Grel, A., Vallee, M., and Piazza, P.V. (2017).

20 Cannabinoid-Induced Tetrad in Mice. Curr Protoc Neurosci 80, 959 51-59 59 2110.

22 Monory, K., Blaudzun, H., Massa, F., Kaiser, N., Lemberger, T., Schutz, G., 23 Wotjak, C.T., Lutz, B., and Marsicano, G. (2007). Genetic dissection of 24 behavioural and autonomic effects of Delta(9)-tetrahydrocannabinol in mice. 25 PLoS biology 5, e269. 
1 Nadal, X., La Porta, C., Andreea Bura, S., and Maldonado, R. (2013).

2 Involvement of the opioid and cannabinoid systems in pain control: New

3 insights from knockout studies. European Journal of Pharmacology 716, 1424157.

5 Niswender, C.M., Willis, B.S., Wallen, A., Sweet, I.R., Jetton, T.L., Thompson, 6 B.R., Wu, C., Lange, A.J., and McKnight, G.S. (2005). Cre recombinase7 dependent expression of a constitutively active mutant allele of the catalytic 8 subunit of protein kinase A. Genesis 43, 109-119.

9 Oliveira da Cruz, J., Busquets-Garcia, A., Zhao, Z., Varilh, M., Lavanco, G., 10 Bellocchio, L., Robin, L., Cannich, A., Julio-Kalajzić, F., Lesté-Laserre,T., 11 Maitre, M., Drago, F., Marsicano, G., Soria-Gomez, E. (2020). Specific 12 Hippocampal Interneurons Shape Consolidation of Recognition Memory. Cell 13 Reports. 32(7): 108046. doi: 10.1016/j.celrep.2020.108046

14 Oshita, K., Inoue, A., Tang, H.B., Nakata, Y., Kawamoto, M., and Yuge, O. 15 (2005). $\mathrm{CB}(1)$ cannabinoid receptor stimulation modulates transient receptor 16 potential vanilloid receptor 1 activities in calcium influx and substance $P$ 17 Release in cultured rat dorsal root ganglion cells. J Pharmacol Sci 97, 377-385. 18 Pagano Zottola , A.C., Soria-Gomez, E., Bonilla-del-Río, I., Muguruza, C., 19 Terral, G., Robin, L.M., Oliveira da Cruz, J.F., Redon, B., Lesté-Lasserre, T., 20 Tolentino-Cortes, T Puente, N., Barreda-Gómez, G Chaouloff, F., Callado, L.F., 21 Grandes, P., Marsicano, G., Bellocchio, L. (2020). A new mutant mouse model 22 lacking mitochondrial-associated $\mathrm{CB} 1$ receptor. Biorxiv.

23 Pautrat, A., Rolland, M., Barthelemy, M., Baunez, C., Sinniger, V., Piallat, B., 24 Savasta, M., Overton, P.G., David, O., and Coizet, V. (2018). Revealing a novel 
1 nociceptive network that links the subthalamic nucleus to pain processing. ELife

$27, \mathrm{e} 36607$.

3 Paxinos, G., and Franklin, K.B.J. (2001). The Mouse Brain in Stereotaxic

4 Coordinates (S. Diego (USA): Academic Press).

5 Pertwee, R.G. (2001). Cannabinoid receptors and pain. Progress in 6 neurobiology 63, 569-611.

7 Prashad, S., and Filbey, F.M. (2017). Cognitive motor deficits in cannabis users.

8 Curr Opin Behav Sci 13, 1-7.

9 Puente, N., Bonilla-Del Río, I., Achicallende, S., Nahirney, P.C., and Grandes, 10 P. (2019). High-resolution Immunoelectron Microscopy Techniques for 11 Revealing Distinct Subcellular Type 1 Cannabinoid Receptor Domains in Brain. 12 Bioprotocol 9.

13 Qi, G., Mi, Y., and Yin, F. (2019). Cellular Specificity and Inter-cellular 14 Coordination in the Brain Bioenergetic System: Implications for Aging and 15 Neurodegeneration. Front Physiol 10, 1531.

16 Rajendran, L., Knolker, H.J., and Simons, K. (2010). Subcellular targeting 17 strategies for drug design and delivery. Nat Rev Drug Discov 9, 29-42.

18 Rangaraju, V., Calloway, N., and Ryan, T.A. (2014). Activity-driven local ATP 19 synthesis is required for synaptic function. Cell 156, 825-835.

20 Ray, A.P., Chebolu, S., Ramirez, J., and Darmani, N.A. (2009). Ablation of least 21 shrew central neurokinin NK1 receptors reduces GR73632-induced vomiting. 22 Behavioral neuroscience 123, 701-706.

23 Redon, B., Violleau, C., Georges, F., Marsicano, G., and Chaouloff, F. (2020). 24 The ergogenic impact of the glucocorticoid prednisolone does not translate into 25 increased running motivation in mice. Psychoneuroendocrinology 111, 104489. 
1 Rozenfeld, R., and Devi, L.A. (2008). Regulation of CB1 cannabinoid receptor

2 trafficking by the adaptor protein AP-3. FASEB journal : official publication of the

3 Federation of American Societies for Experimental Biology 22, 2311-2322.

4 Ruehle, S., Remmers, F., Romo-Parra, H., Massa, F., Wickert, M., Wortge, S.,

5 Haring, M., Kaiser, N., Marsicano, G., Pape, H.C., and Lutz, B. (2013).

6 Cannabinoid CB1 Receptor in Dorsal Telencephalic Glutamatergic Neurons:

7 Distinctive Sufficiency for Hippocampus-Dependent and Amygdala-Dependent

8 Synaptic and Behavioral Functions. The Journal of neuroscience : the official

9 journal of the Society for Neuroscience 33, 10264-10277.

10 Sales-Carbonell, C., Rueda-Orozco, P.E., Soria-Gomez, E., Buzsaki, G., 11 Marsicano, G., and Robbe, D. (2013). Striatal GABAergic and cortical 12 glutamatergic neurons mediate contrasting effects of cannabinoids on cortical 13 network synchrony. Proceedings of the National Academy of Sciences of the 14 United States of America 110, 719-724.

15 Simpson, D. (2005). Phrenology and the neurosciences: contributions of F. J. 16 Gall and J. G. Spurzheim. ANZ J Surg 75, 475-482.

17 Skalhegg, B.S., and Tasken, K. (2000). Specificity in the cAMP/PKA signaling 18 pathway. Differential expression, regulation, and subcellular localization of 19 subunits of PKA. Front Biosci 5, D678-693.

20 Soria-Gomez, E., Bellocchio, L., Reguero, L., Lepousez, G., Martin, C., 21 Bendahmane, M., Ruehle, S., Remmers, F., Desprez, T., Matias, I., et al. 22 (2014). The endocannabinoid system controls food intake via olfactory 23 processes. Nature neuroscience 17, 407-415.

24 Steiner, H., Bonner, T.I., Zimmer, A.M., Kitai, S.T., and Zimmer, A. (1999). 25 Altered gene expression in striatal projection neurons in CB1 cannabinoid 
1 receptor knockout mice. Proceedings of the National Academy of Sciences of

2 the United States of America 96, 5786-5790.

3 Steinhoff, M.S., von Mentzer, B., Geppetti, P., Pothoulakis, C., and Bunnett,

4 N.W. (2014). Tachykinins and their receptors: contributions to physiological

5 control and the mechanisms of disease. Physiol Rev 94, 265-301.

6 Szabo, B., Wallmichrath, I., Mathonia, P., and Pfreundtner, C. (2000).

7 Cannabinoids inhibit excitatory neurotransmission in the substantia nigra pars

8 reticulata. Neuroscience 97, 89-97.

9 Taylor, A.M., Becker, S., Schweinhardt, P., and Cahill, C. (2016). Mesolimbic 10 dopamine signaling in acute and chronic pain: implications for motivation, 11 analgesia, and addiction. Pain 157, 1194-1198.

12 Terral, G., Busquets-Garcia, A., Varilh, M., Achicallende, S., Cannich, A., 13 Bellocchio, L., Bonilla-Del Río, I., Massa, F., Puente, N., Soria-Gomez, E., et al. 14 (2019). CB1 Receptors in the Anterior Piriform Cortex Control Odor Preference 15 Memory. Current Biology 29, 2455-2464.e5.

16 Vallee, M., Vitiello, S., Bellocchio, L., Hebert-Chatelain, E., Monlezun, S., 17 Martin-Garcia, E., Kasanetz, F., Baillie, G.L., Panin, F., Cathala, A., et al. 18 (2014). Pregnenolone can protect the brain from cannabis intoxication. Science $19343,94-98$.

20 Valsecchi, F., Konrad, C., and Manfredi, G. (2014). Role of soluble adenylyl 21 cyclase in mitochondria. Biochim Biophys Acta 1842, 2555-2560.

22 Vos, M., Lauwers, E., and Verstreken, P. (2010). Synaptic mitochondria in 23 synaptic transmission and organization of vesicle pools in health and disease. 24 Front Synaptic Neurosci 2, 139. 
1 Wilson, R.I., Kunos, G., and Nicoll, R.A. (2001). Presynaptic specificity of

2 endocannabinoid signaling in the hippocampus. Neuron 31, 453-462.

3 Woodhams, S.G., Chapman, V., Finn, D.P., Hohmann, A.G., and Neugebauer,

4 V. (2017). The cannabinoid system and pain. Neuropharmacology 124, 1055120.

6 Zaelzer, C., Gizowski, C., Salmon, C.K., Murai, K.K., and Bourque, C.W.

7 (2018). Detection of activity-dependent vasopressin release from neuronal

8 dendrites and axon terminals using sniffer cells. J Neurophysiol 120, 1386-

91396.

10 Zhao, Z., Soria-Gomez, E., Varilh, M., Covelo, A., Julio-Kalajzic, F., Cannich, 11 A., Castiglione, A., Vanhoutte, L., Duveau, A., Zizzari, P Beyeler, A., Cota, D., 12 Bellocchio, L., Busquets-Garcia, A., Marsicano, G. (2020). A novel cortical 13 mechanism for top-down control of water intake. Curr Biol 30, 4789-4798.

14 Zhou, F.M. (2016). The Substantia Nigra Pars Reticulata. In Handbook of 15 Behavioral Neuroscience, (Elsevier), pp. 293-316. 

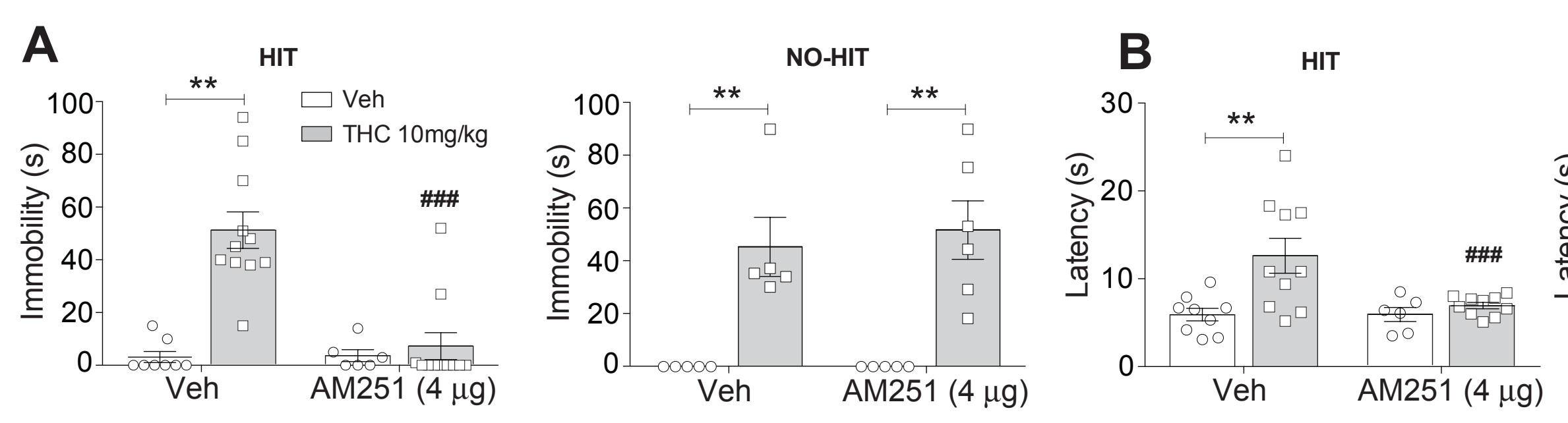

Figure 1
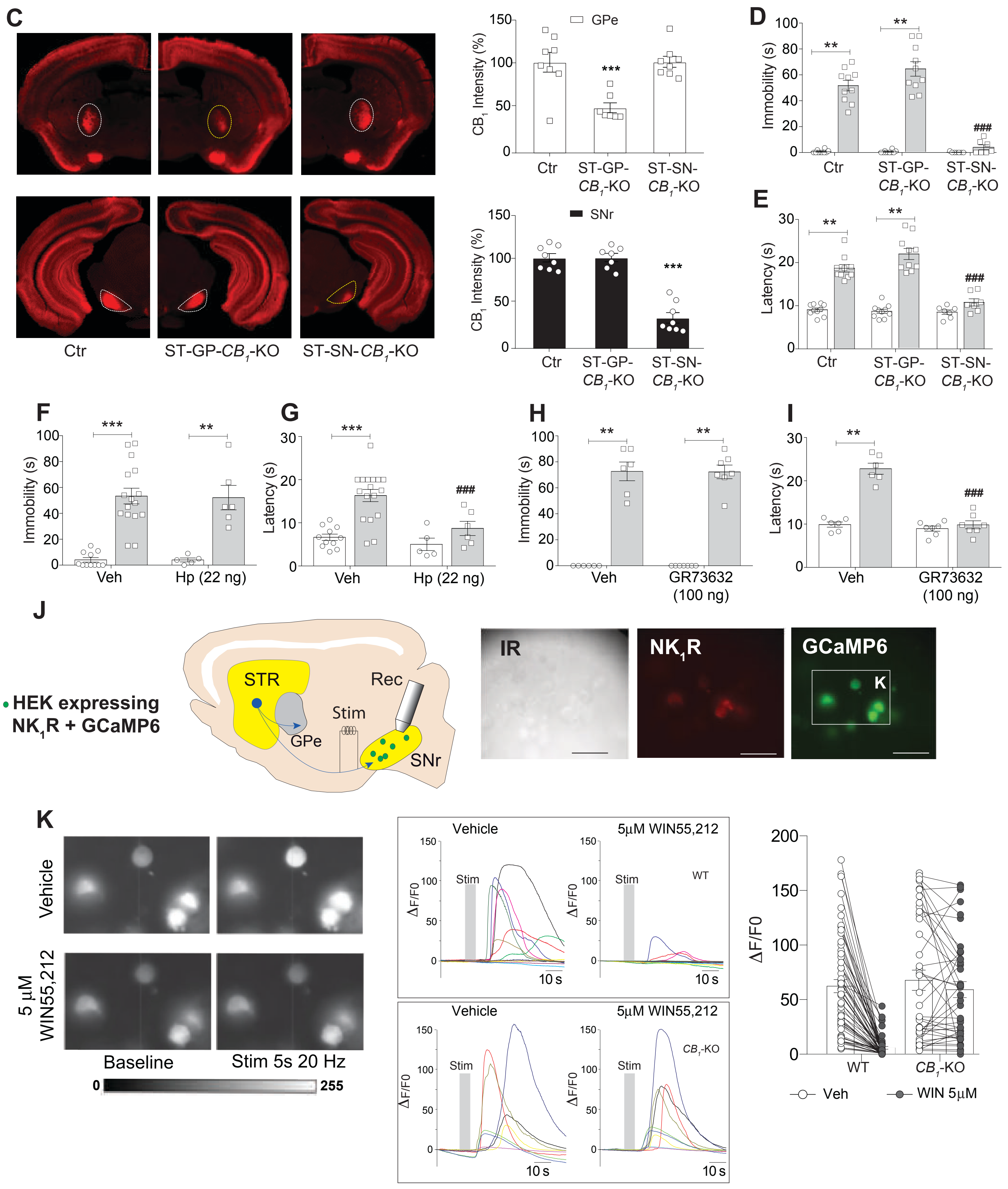

$\mathbf{L}$

AAV-DIO-ChrimsonR in $D_{1}$-Cre mice
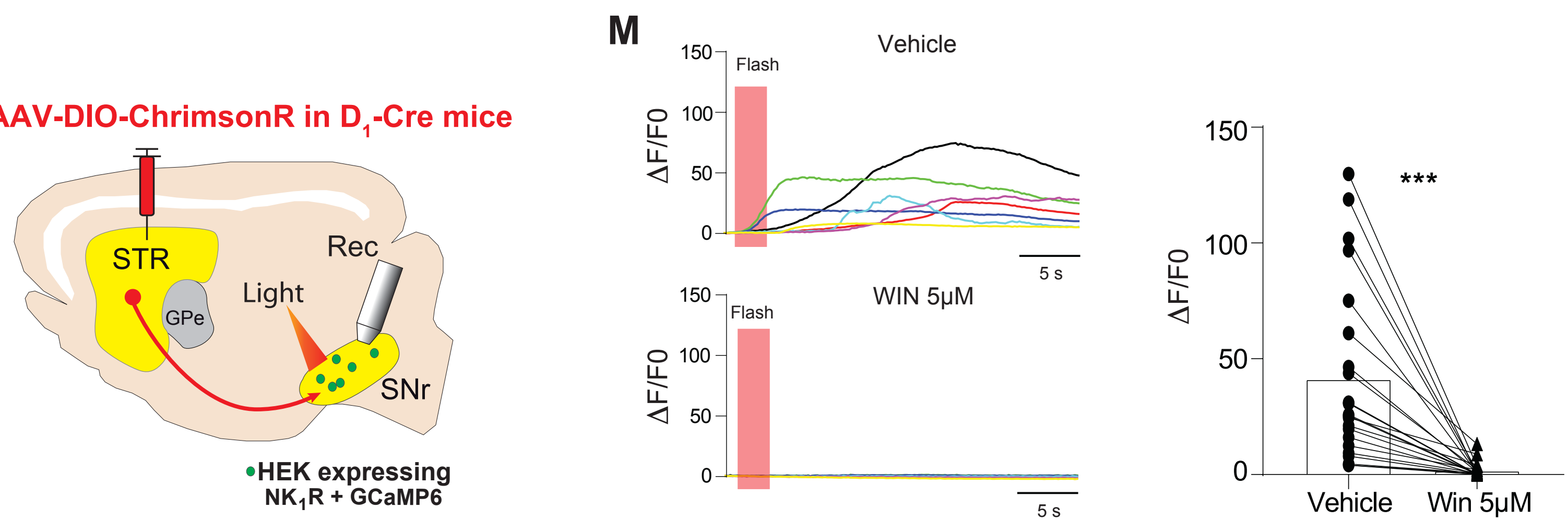
Figure 3
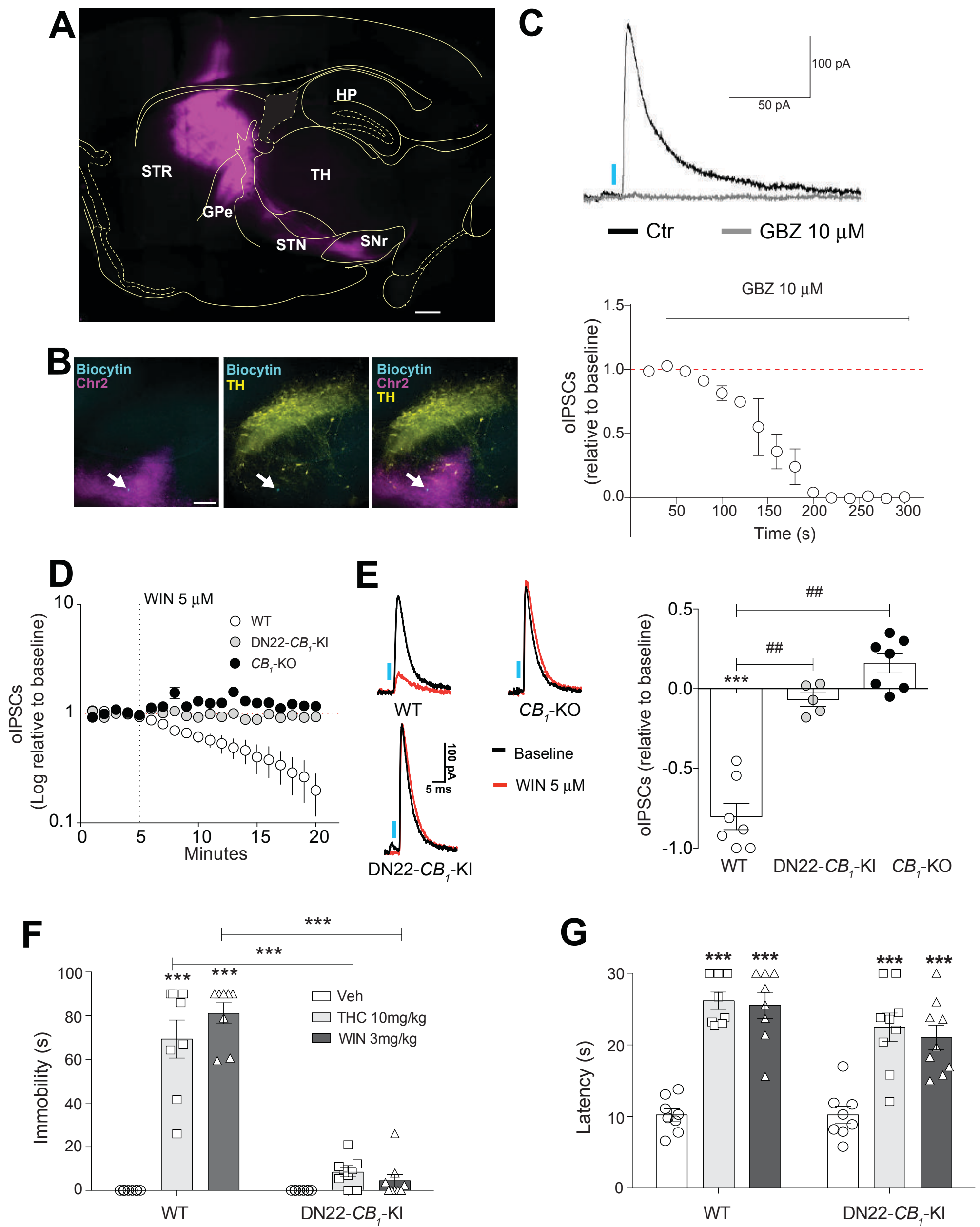
Figure 4

A

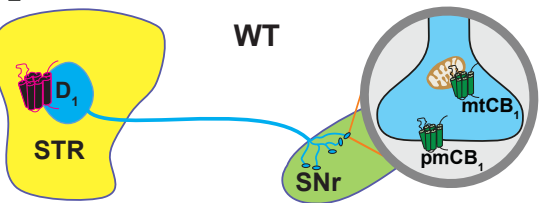

AAV-DIO-CB,

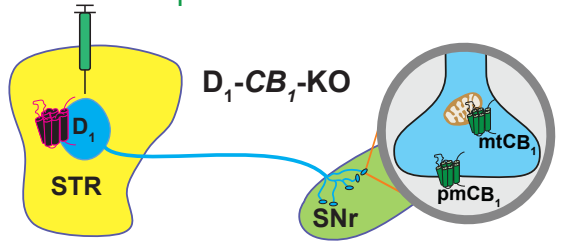

C

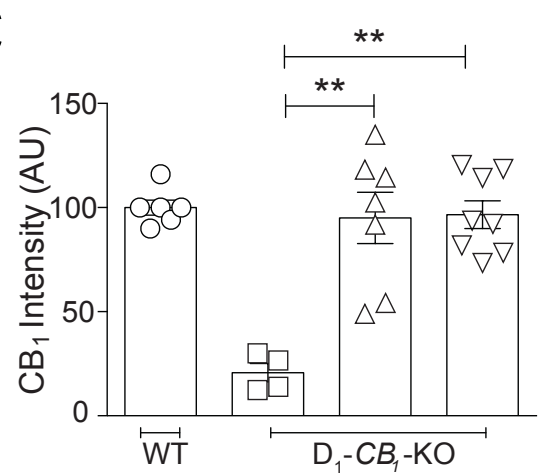

DIO-Ctr +

$\mathrm{DIO}_{-\mathrm{CB}_{1}}$ -

$\mathbf{F}$
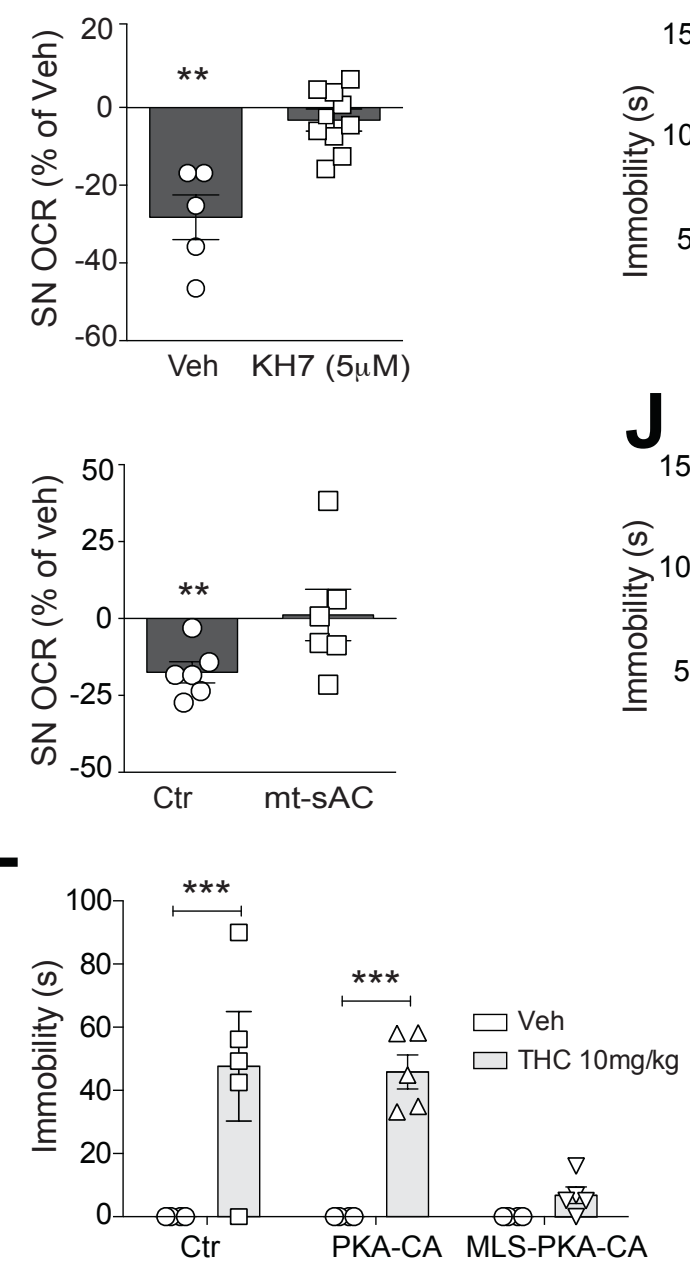

AAV-DIO-DN22-CB 1

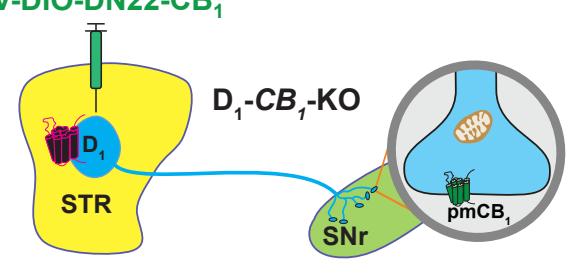

D

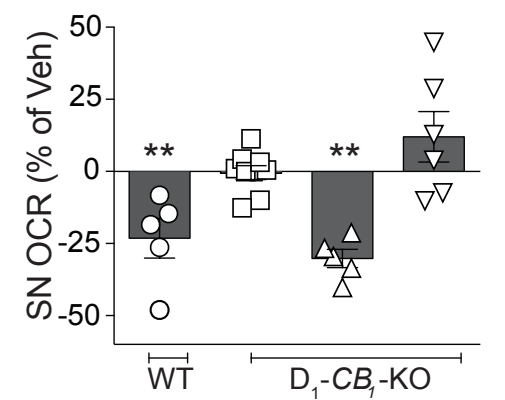

DIO-Ctr + $\mathrm{DIO}_{-\mathrm{CB}_{1} \text { - }}$

DIO-DN22 -
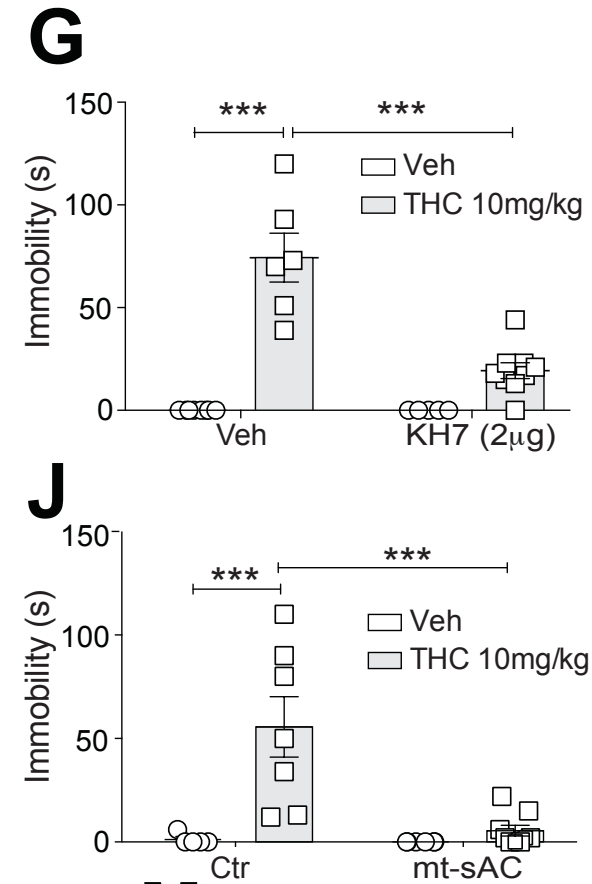

M

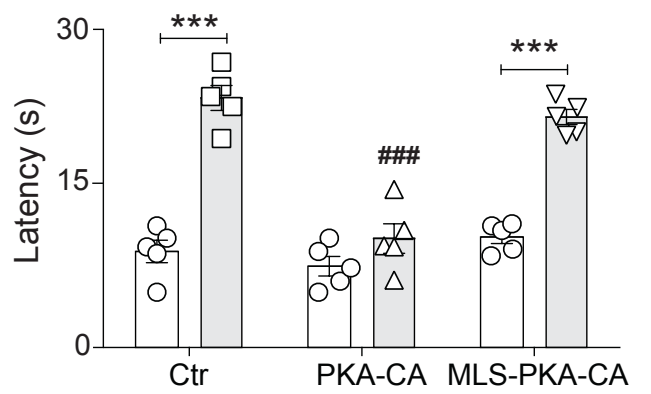

WT

$\mathrm{D}_{1}-C B_{1}-\mathrm{KO}$

$\mathrm{D}_{1}-\mathrm{CB}_{1}-\mathrm{KO}$

$\mathrm{CB}_{1}$

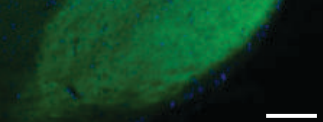

E
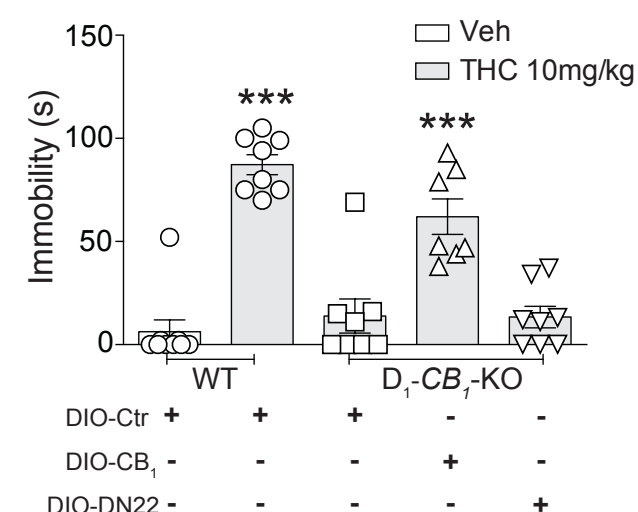

H
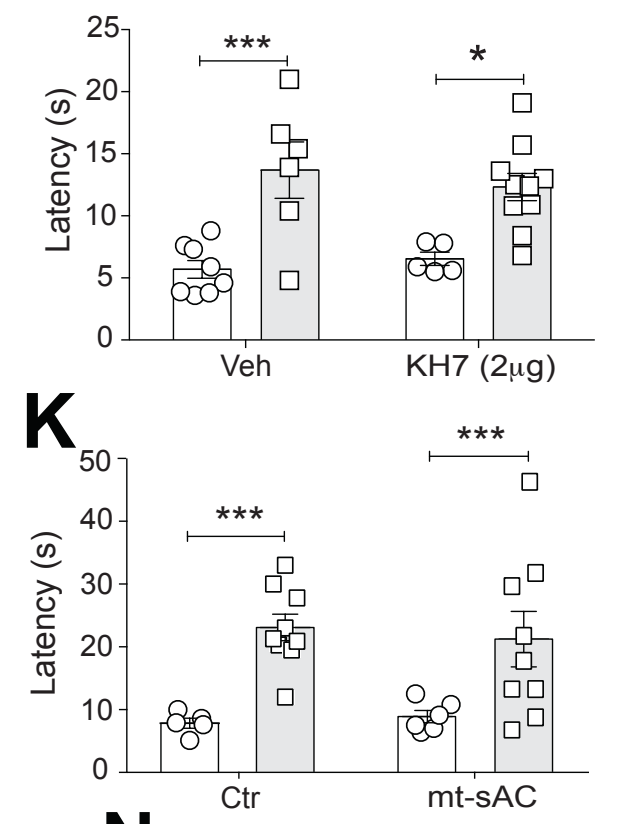

N

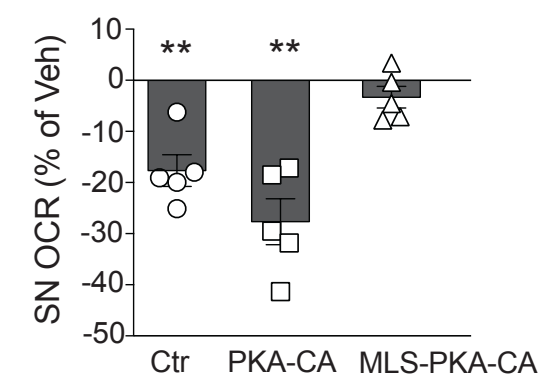


A

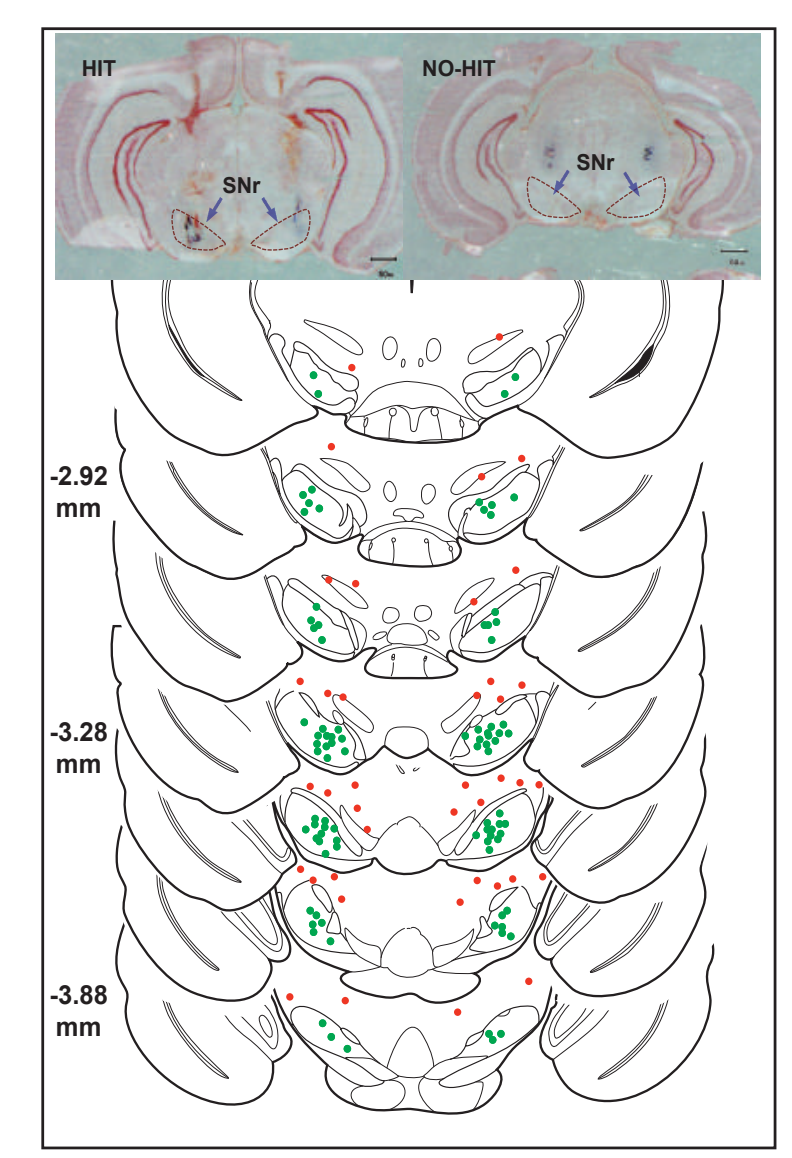

B
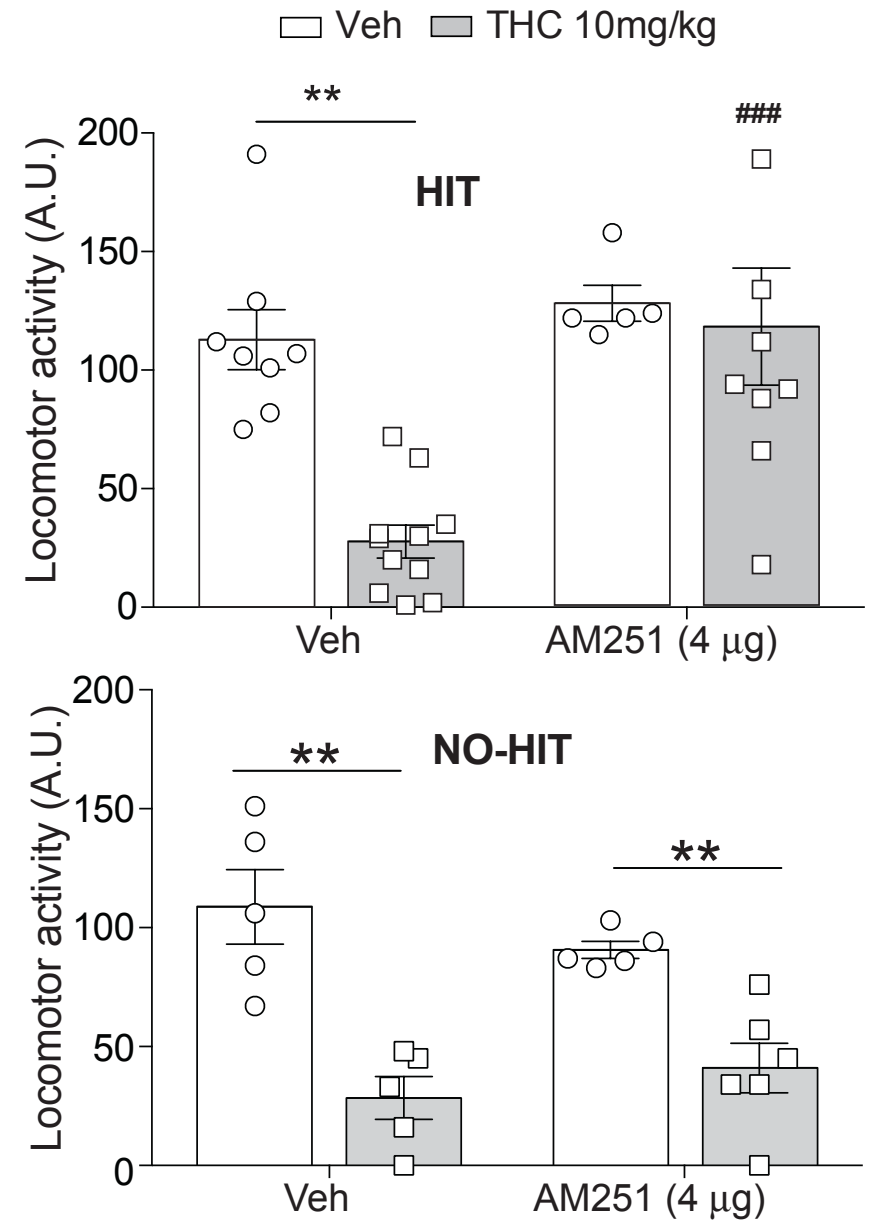

C

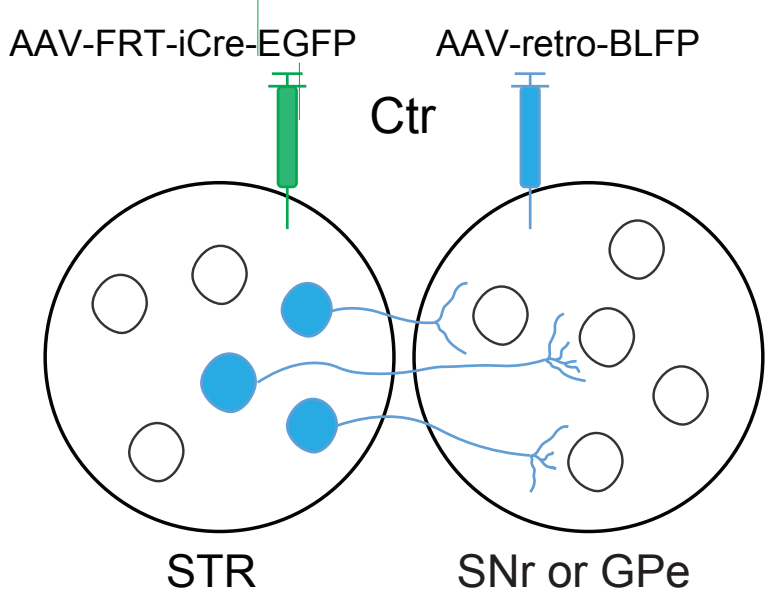

AAV-FRT-iCre-EGFP AAV-retro-FLP-BLFP

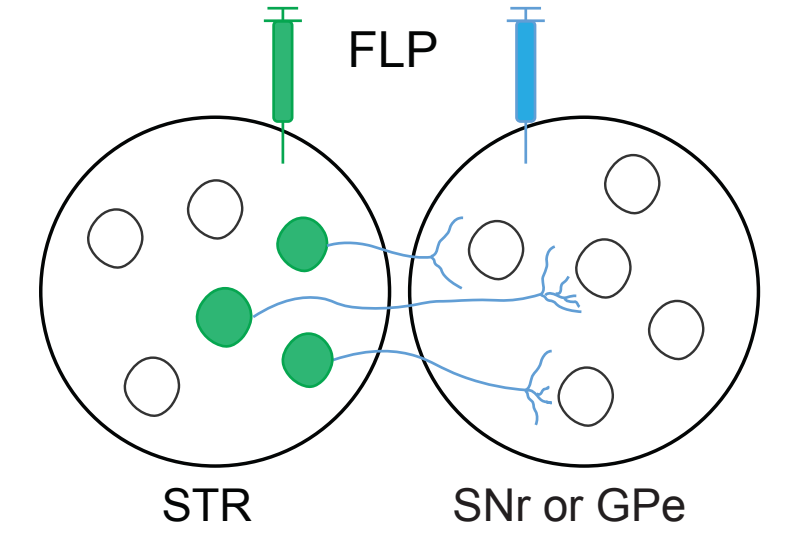

Figure S1
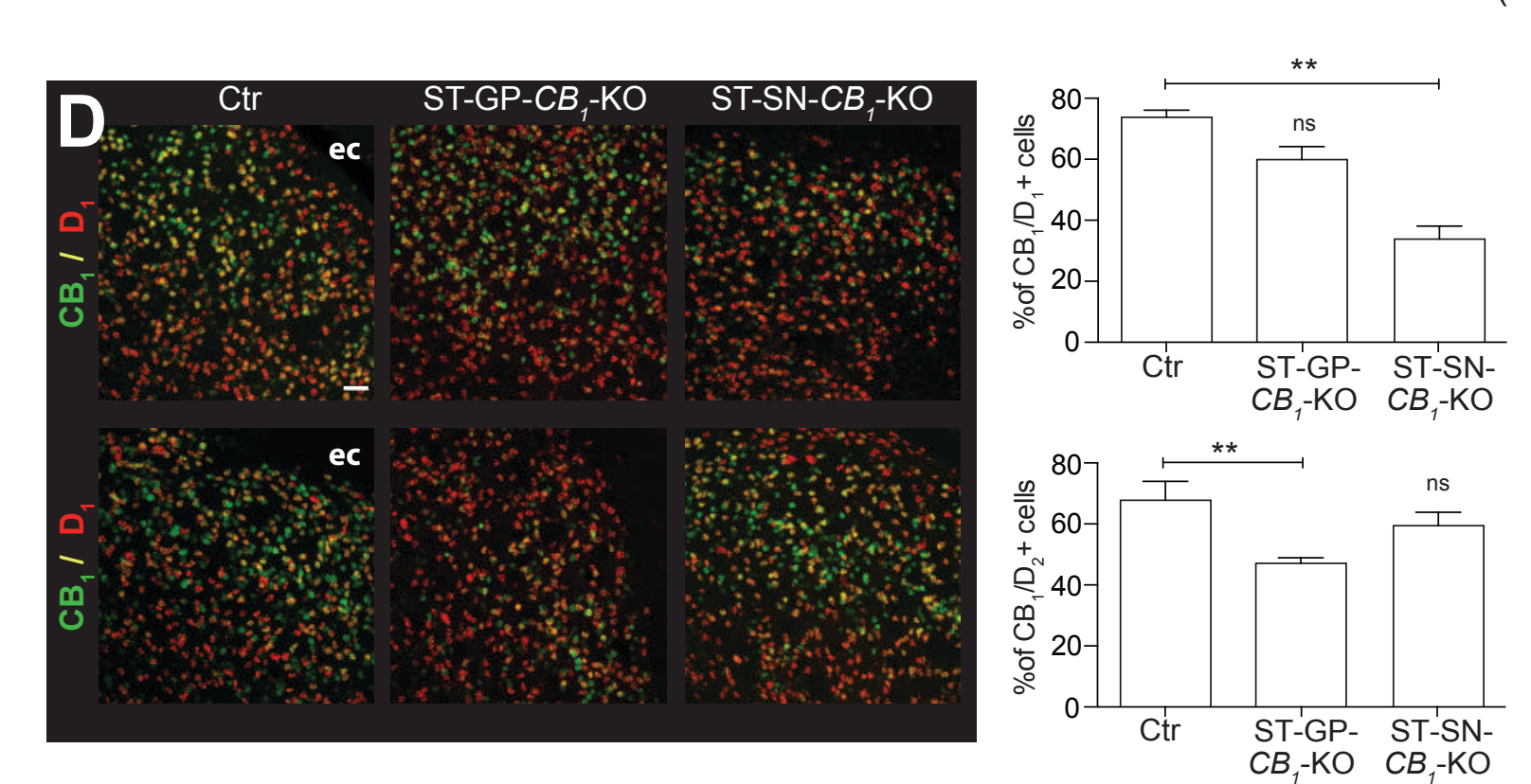

E

$\mathbf{F}$

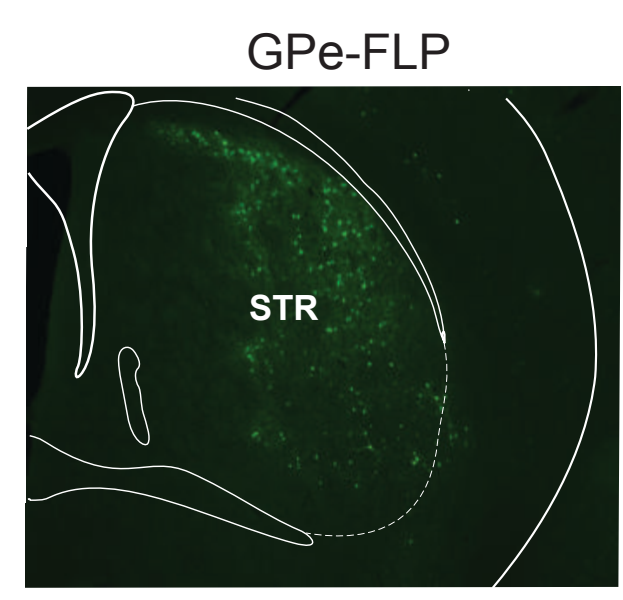

SNr-FLP

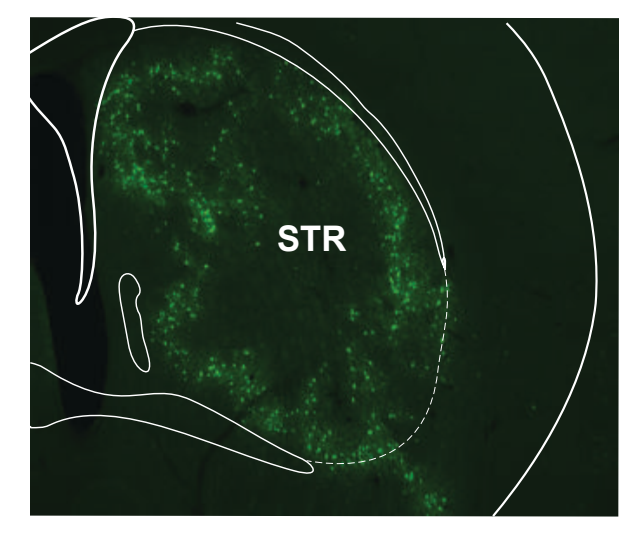

ST-GP-CB - KO

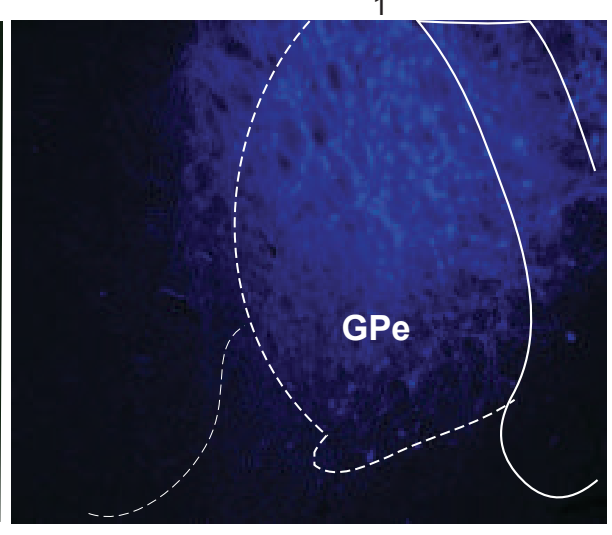

ST-SN-CB - KO
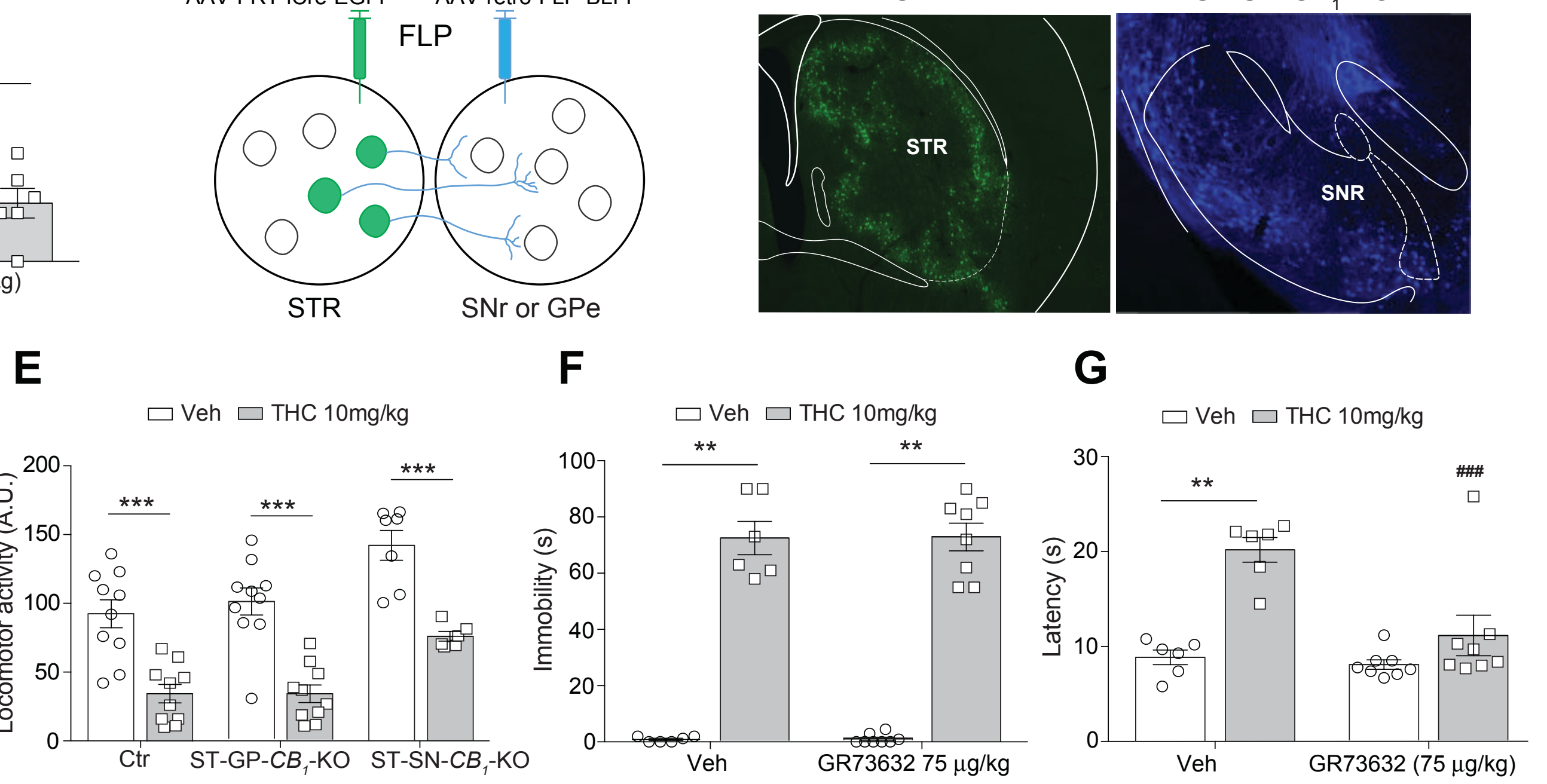

H SP "Sniffer Cell" System
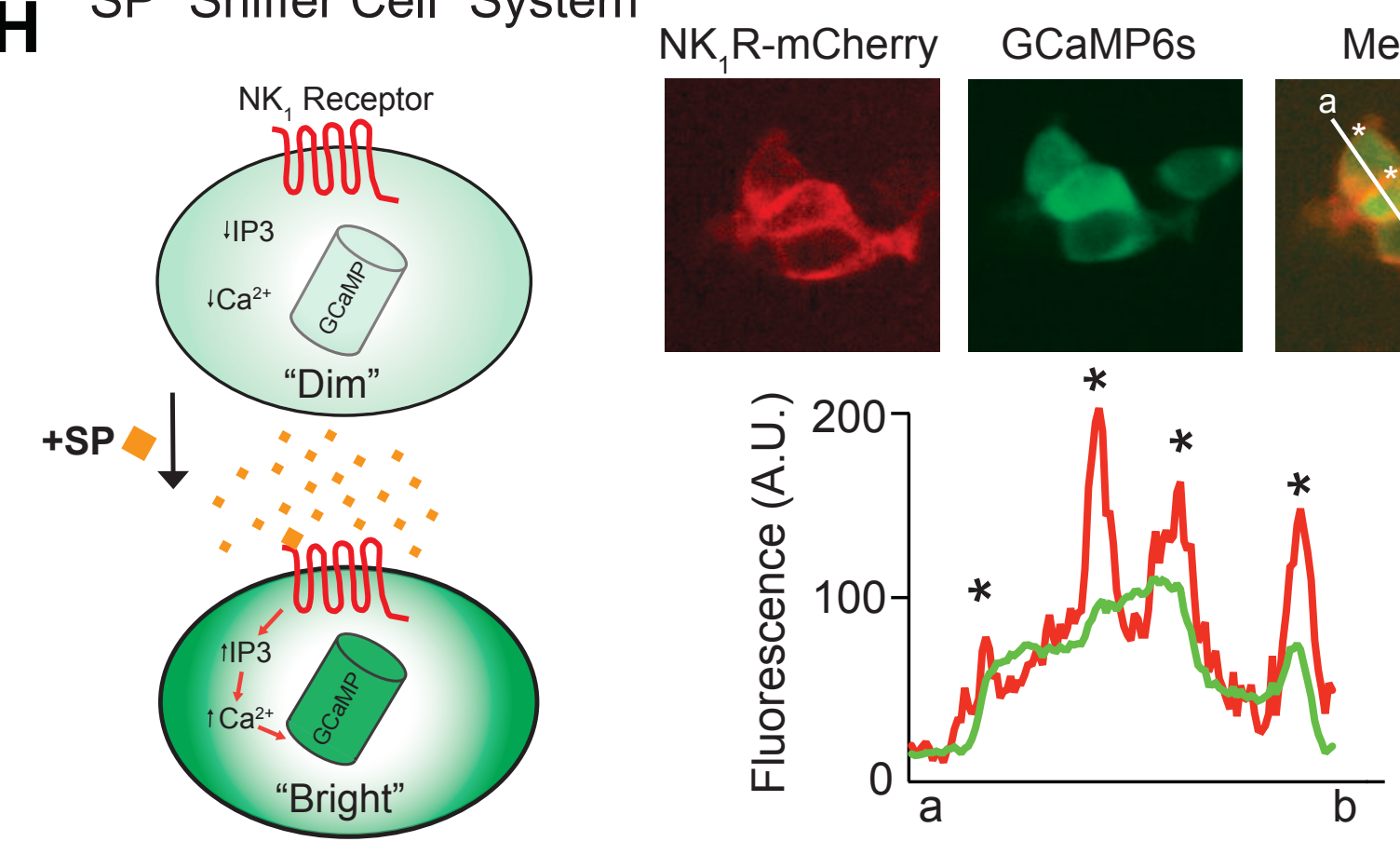

$J$
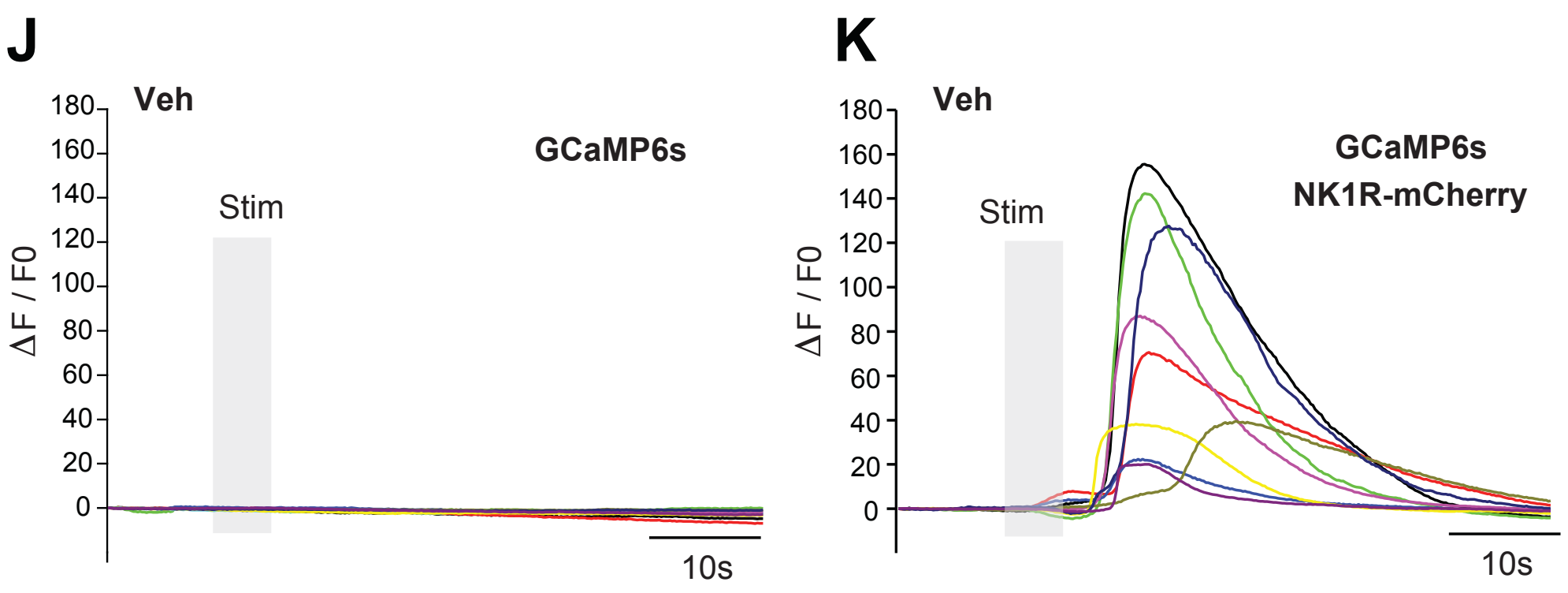
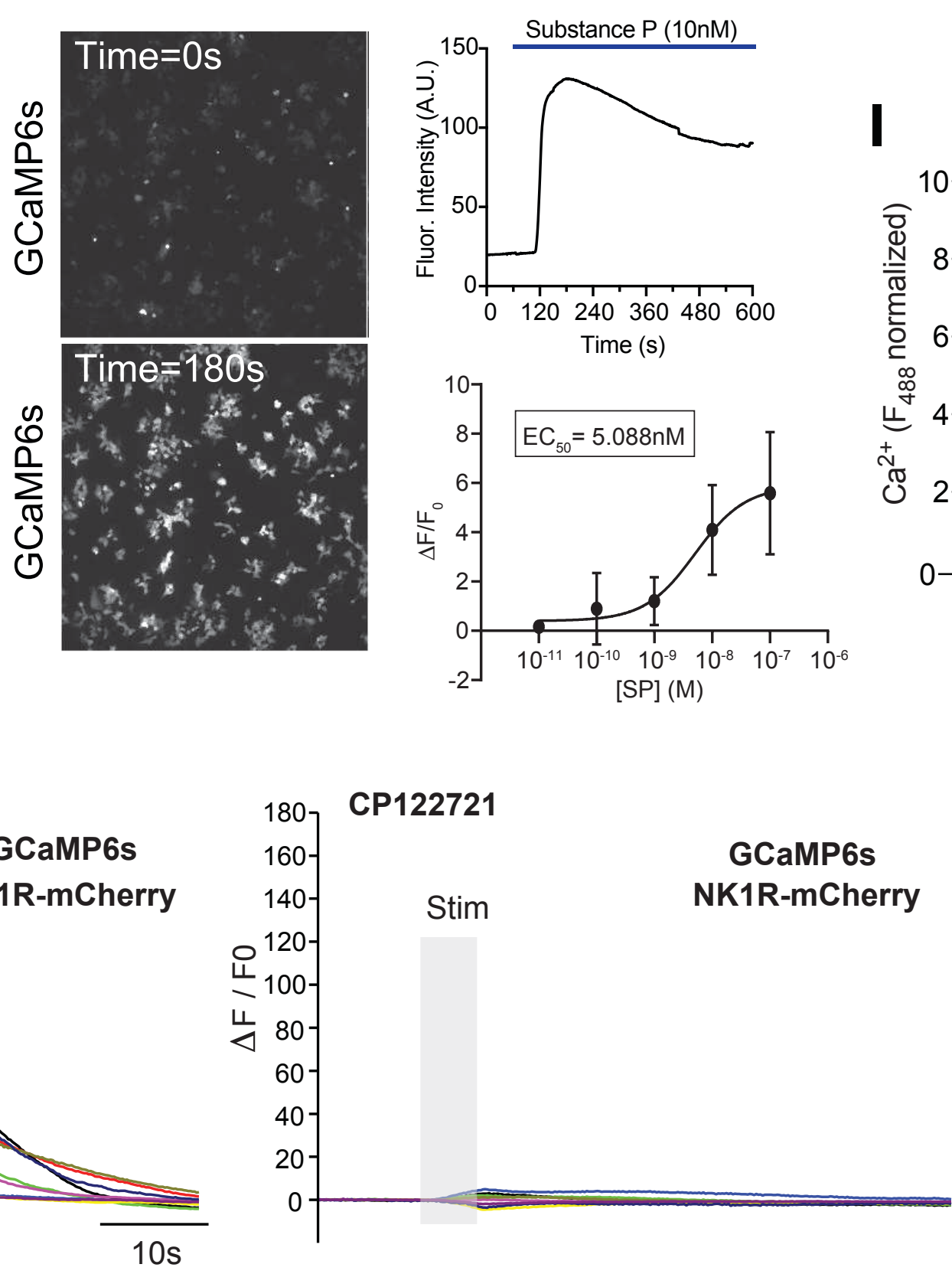

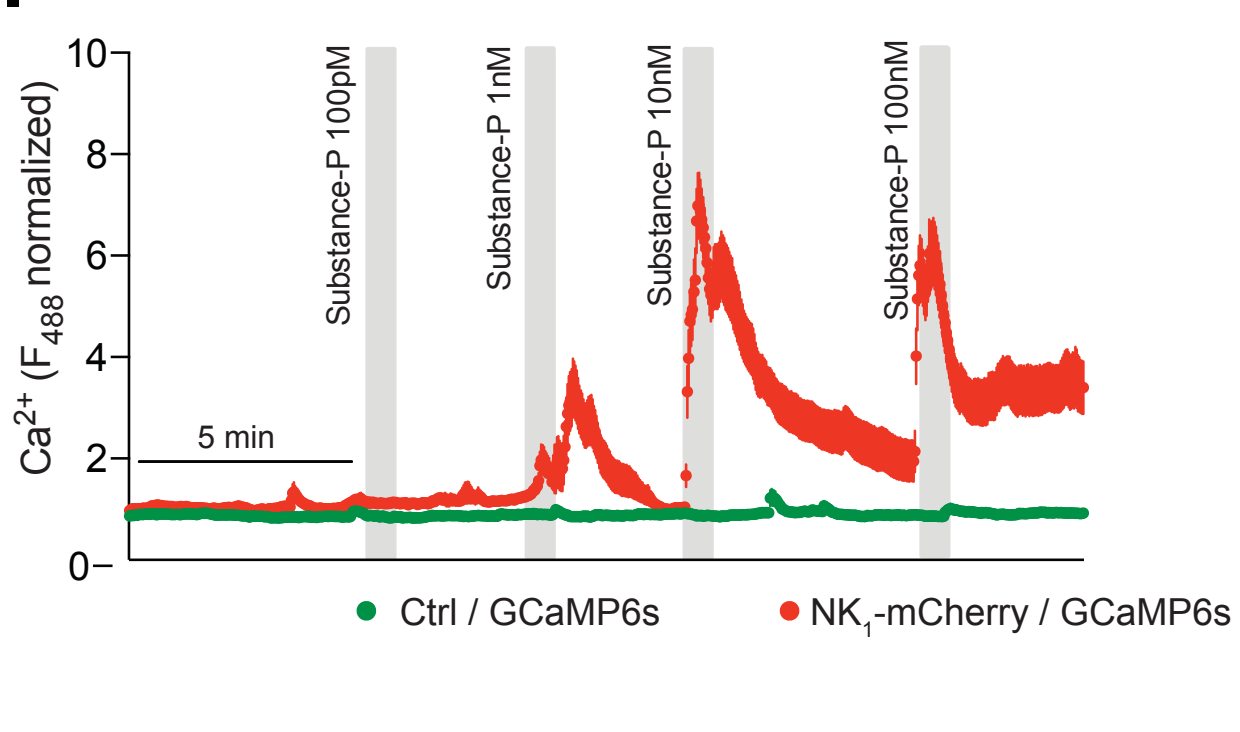

$\mathbf{L}$

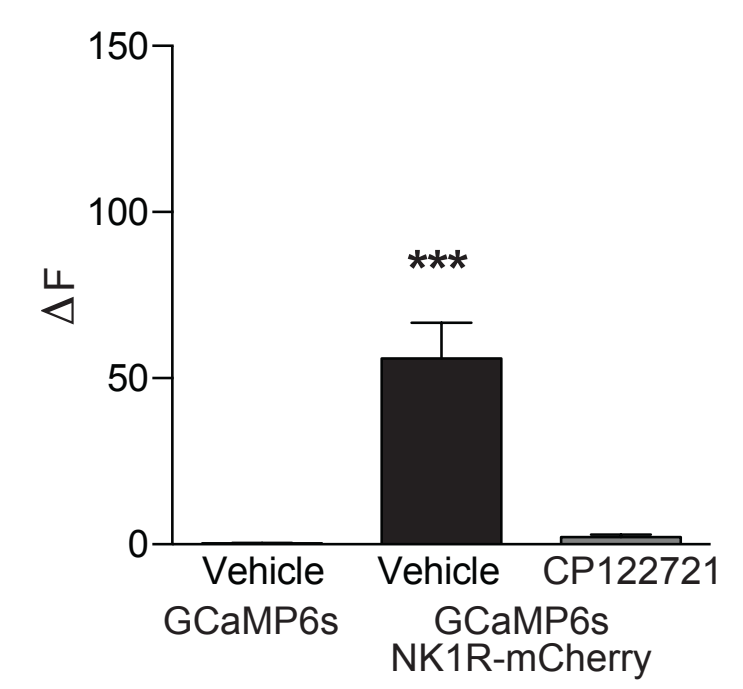

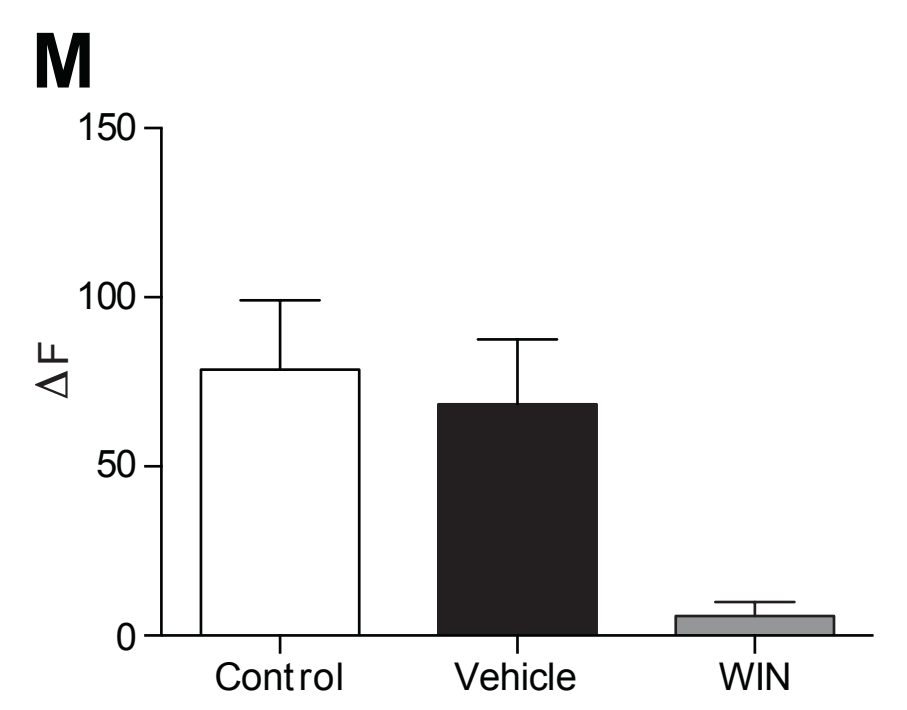
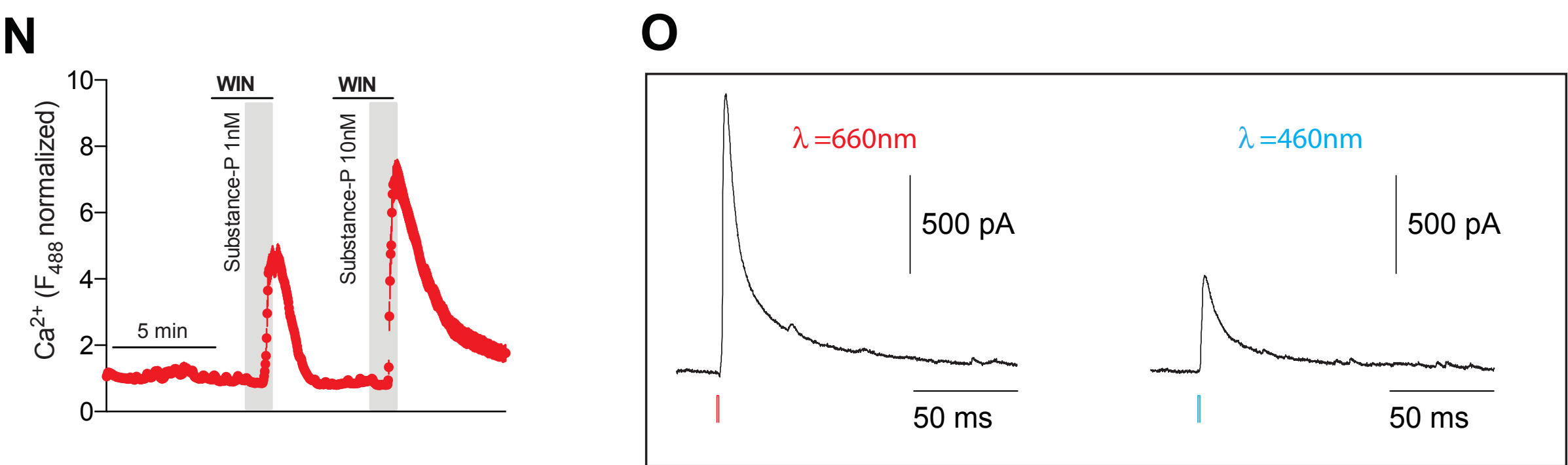
A

\section{Figure S2}
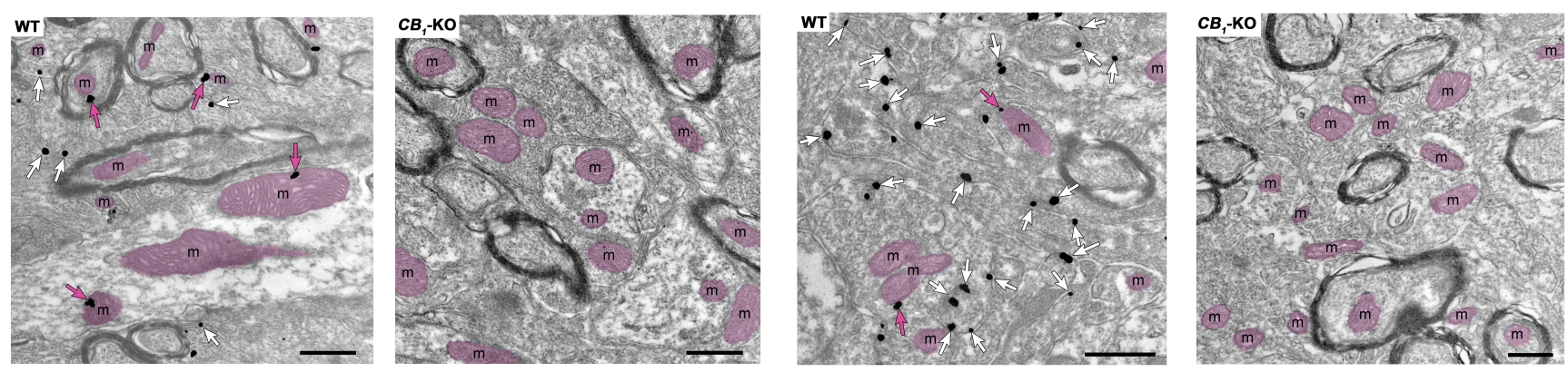

B
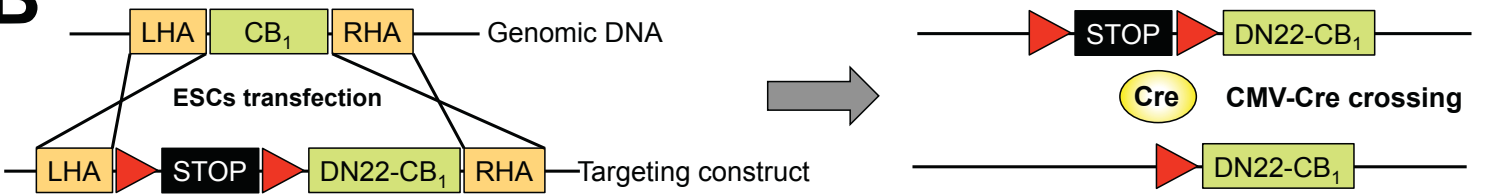

STOP-DN22-CB
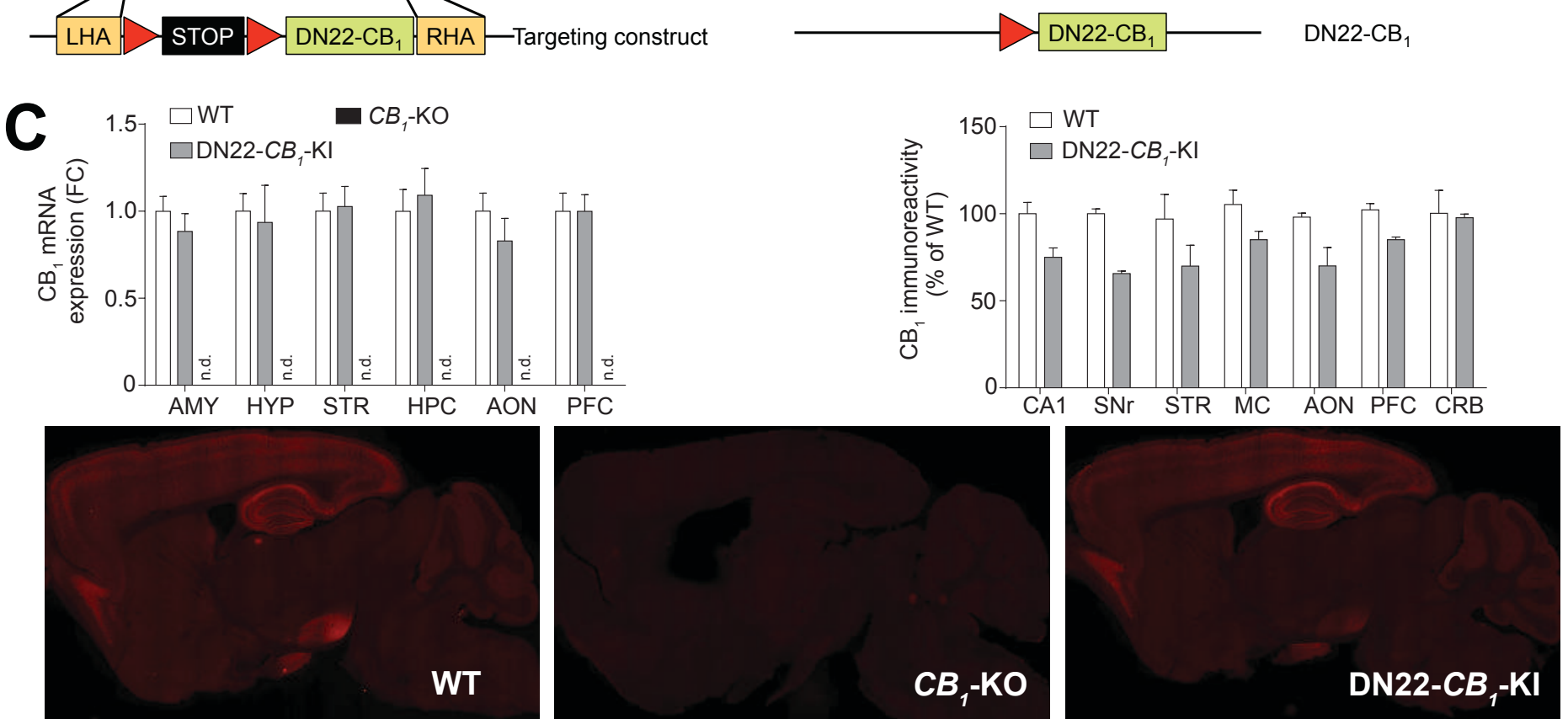

D
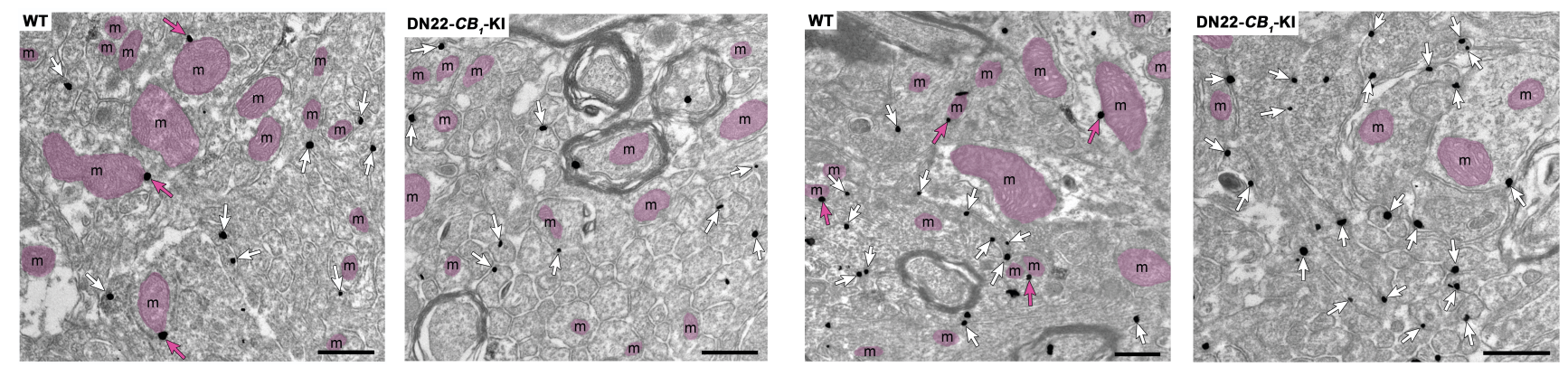
Figure S2 (cont)

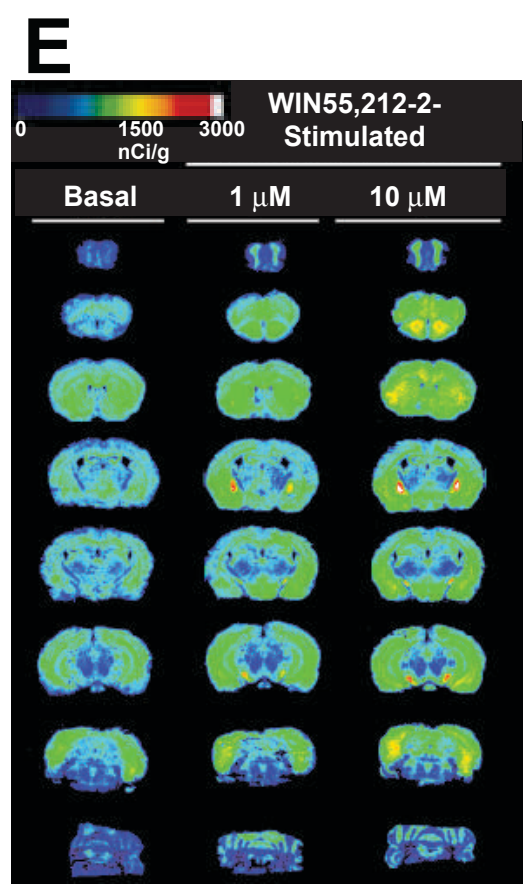

G

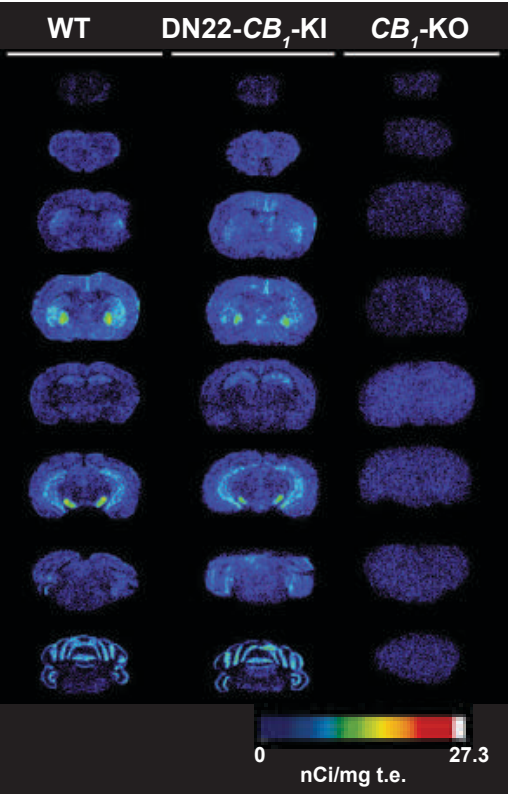

$\mathbf{F}$

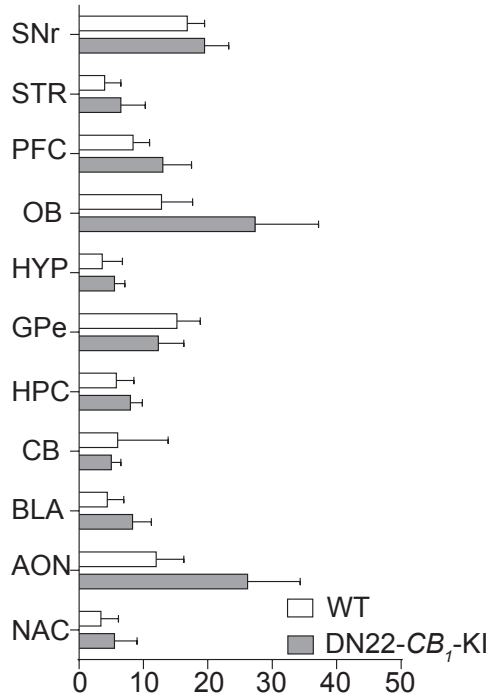

[ $\left.{ }^{35} \mathrm{~S}\right] \mathrm{GTP} \gamma \mathrm{S}$ bound

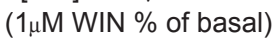

\section{H}

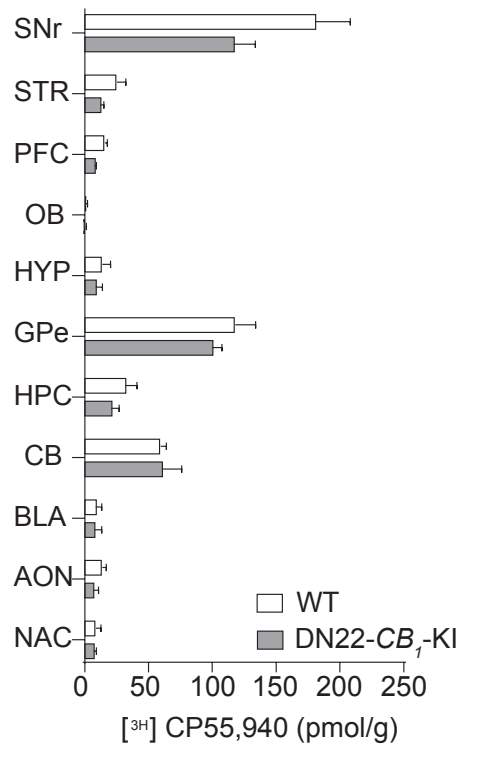

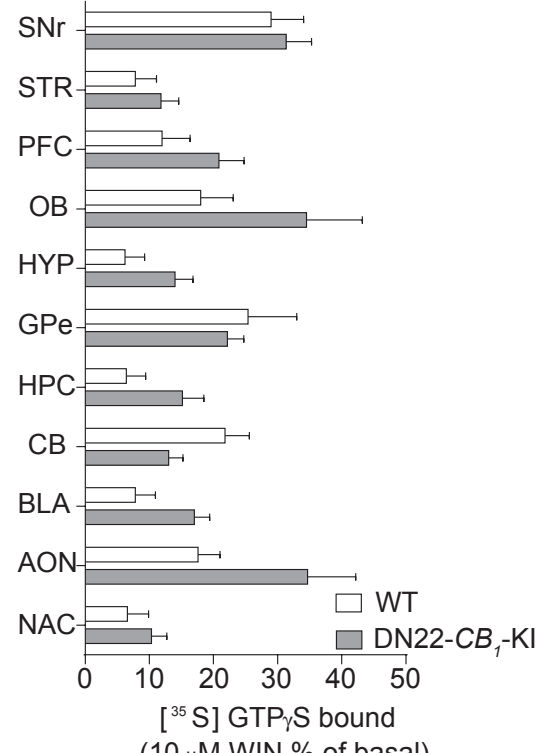

(10 $\mu \mathrm{M}$ WIN \% of basal)

\section{I}
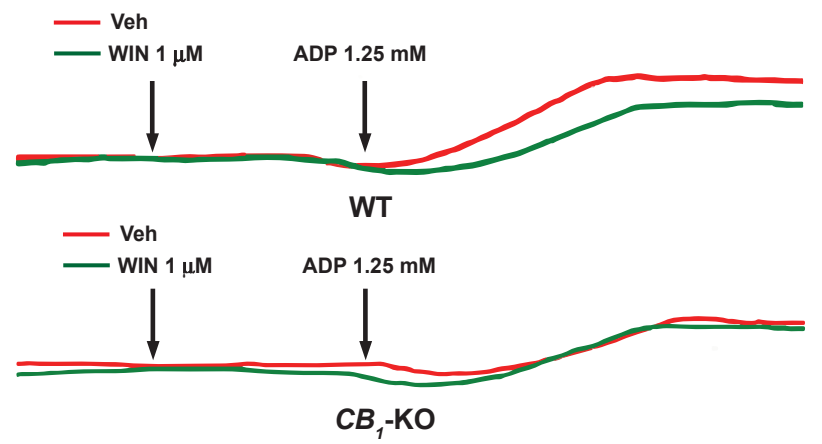

- Veh

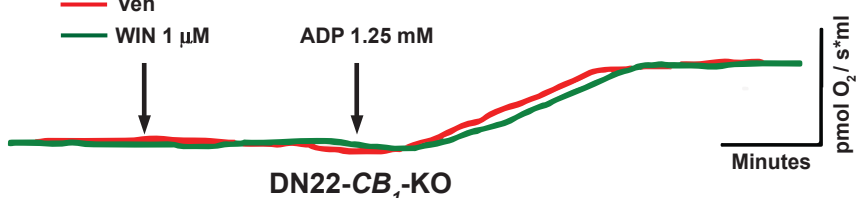


Figure S3

A

DN22-CB, $-\mathrm{Kl}=\square$ 吅品罗 口

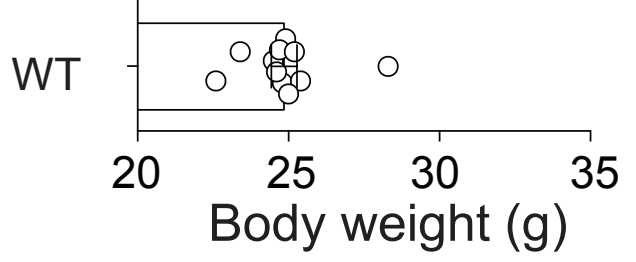

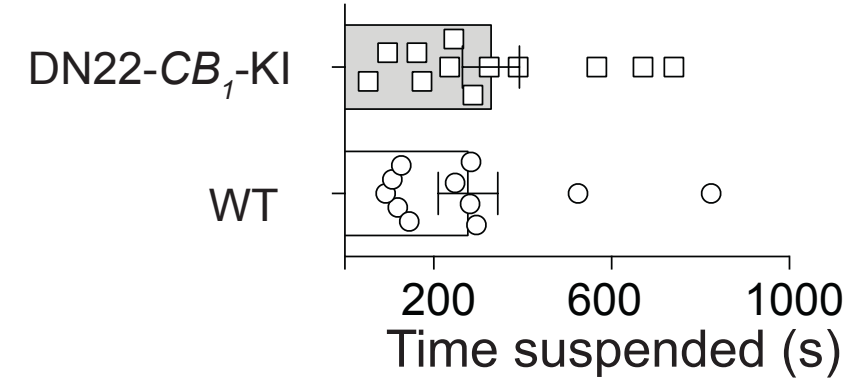

D

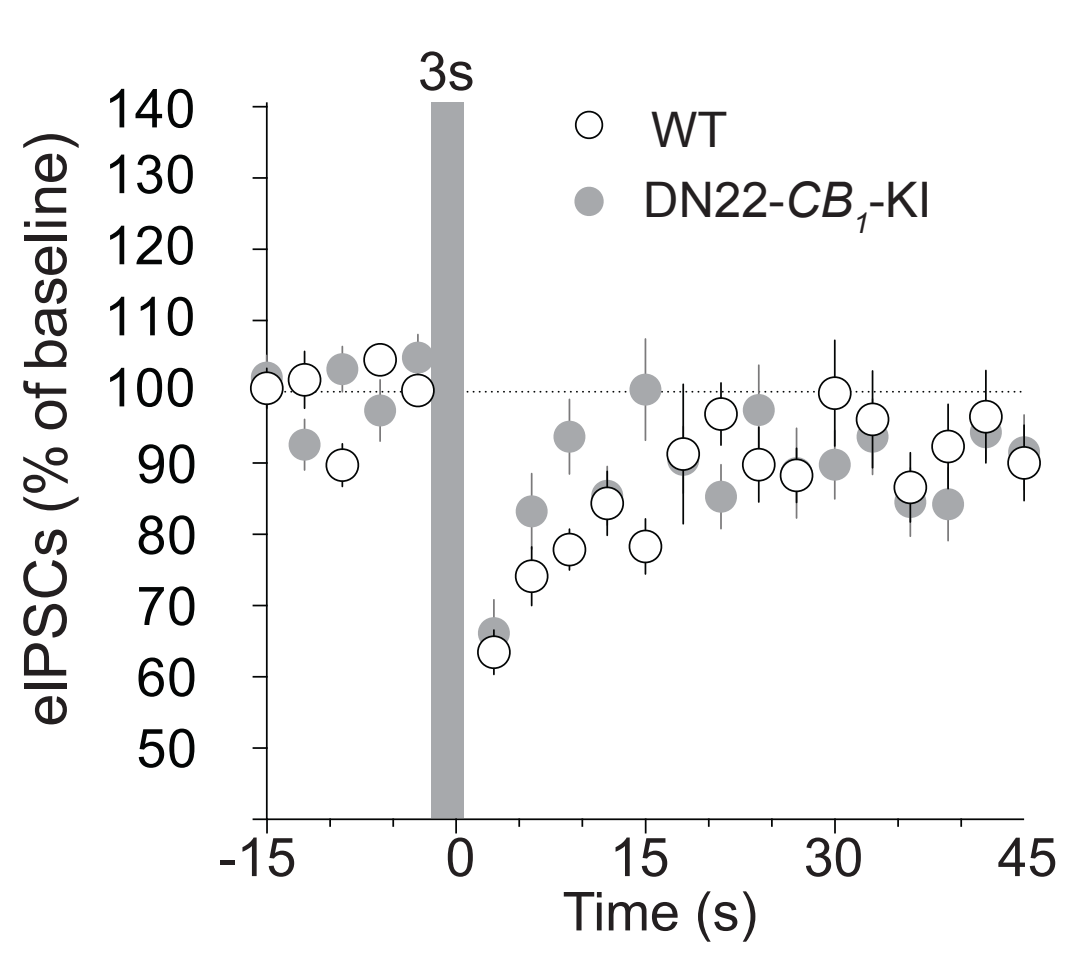

F

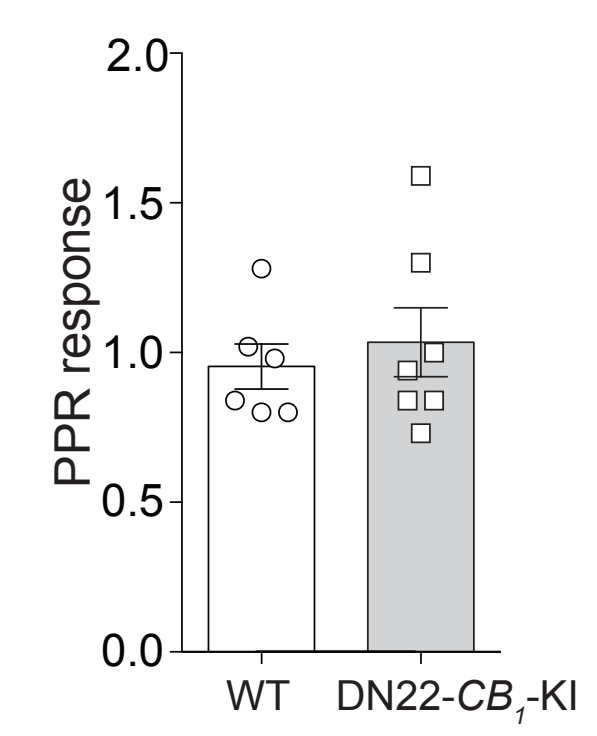

H

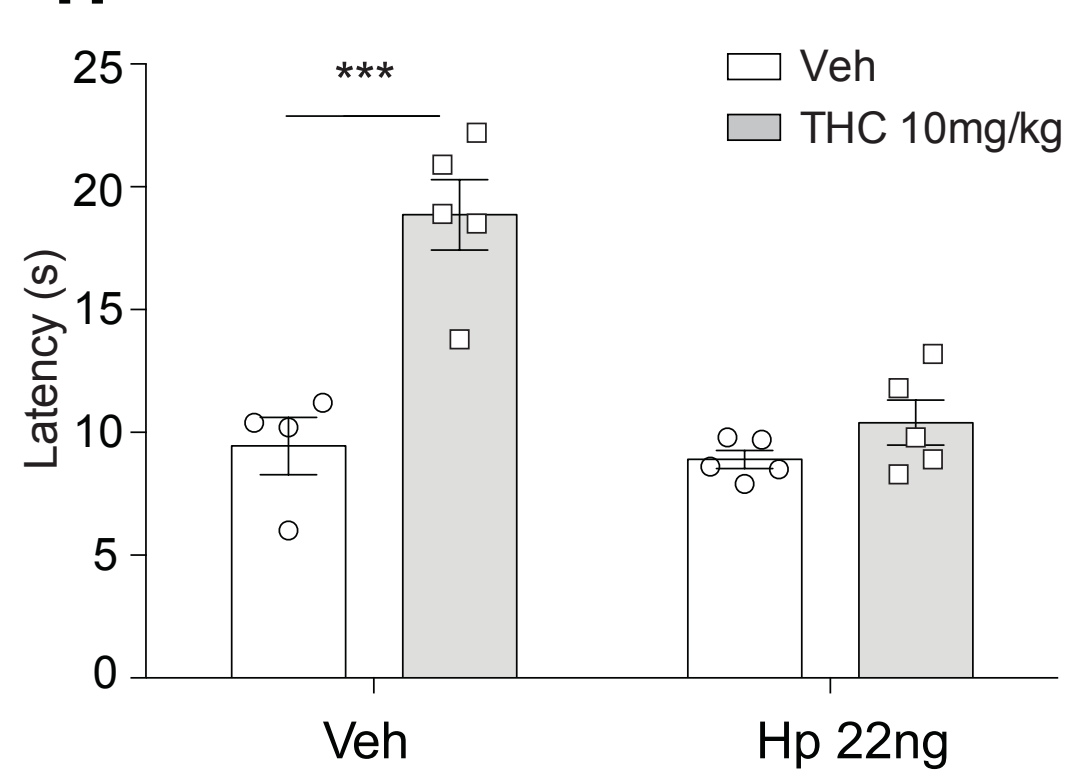

B

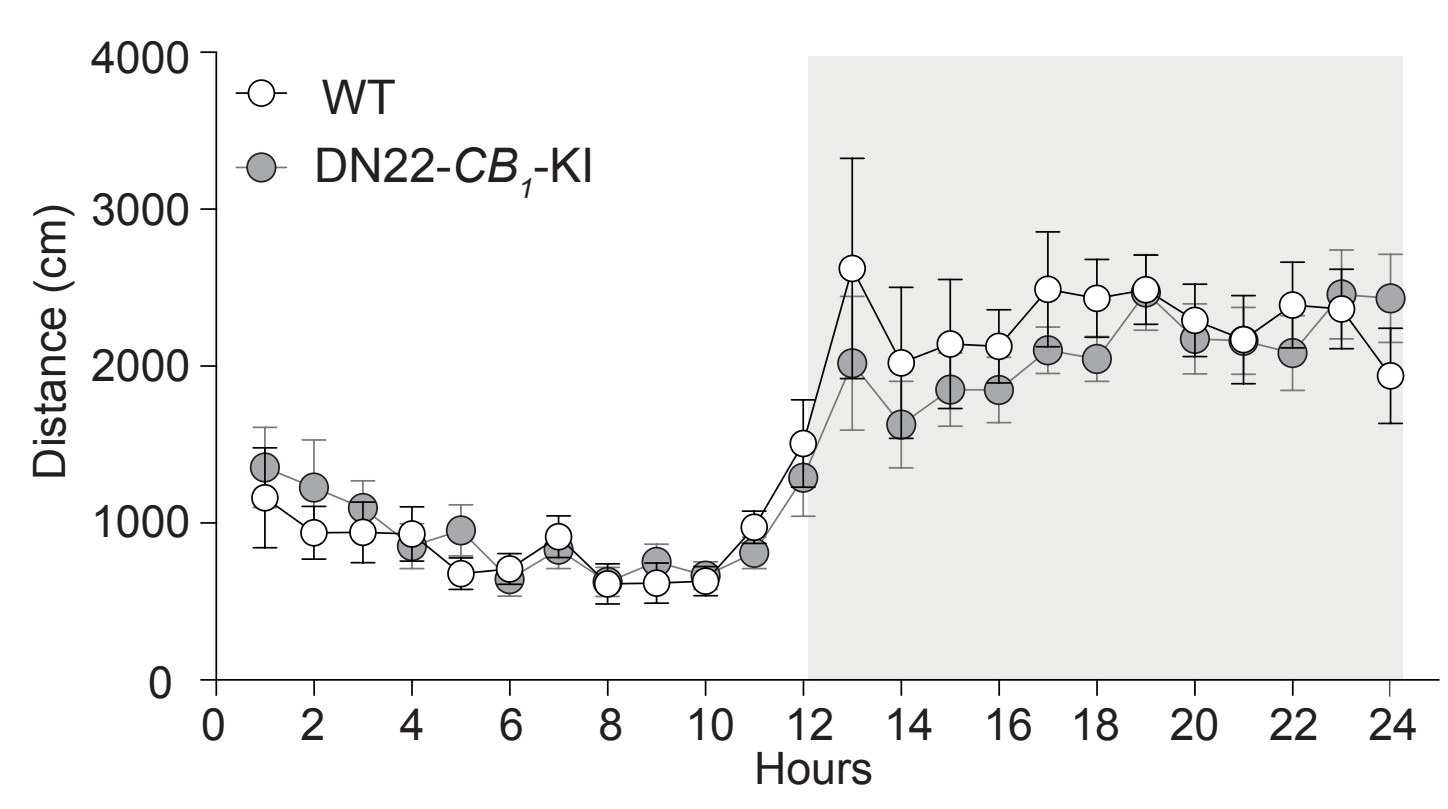

E

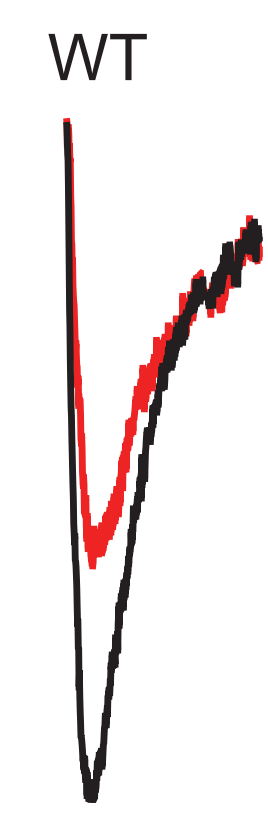

$\mathrm{DN} 22-\mathrm{CB}_{1}-\mathrm{KI}$
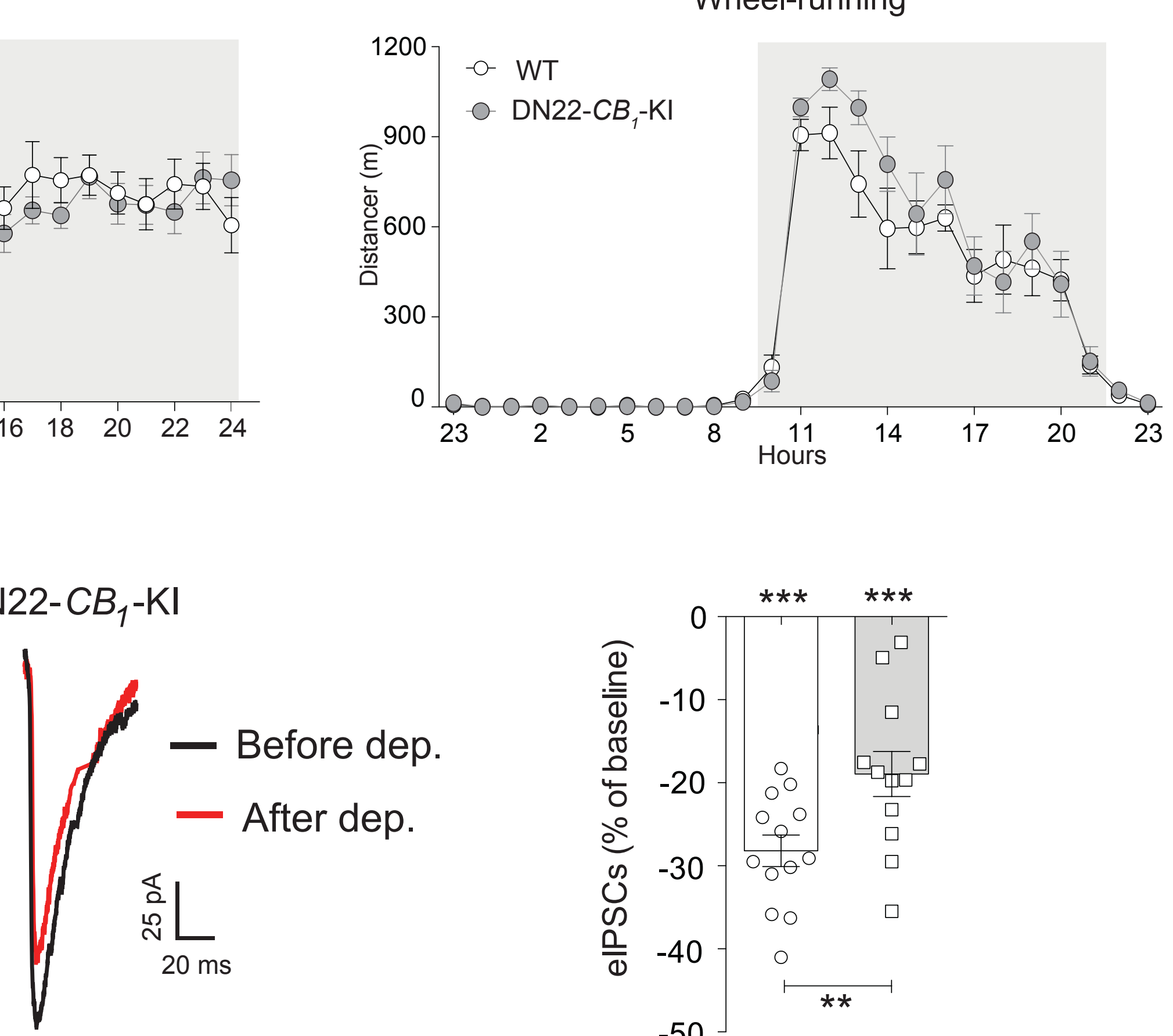

I

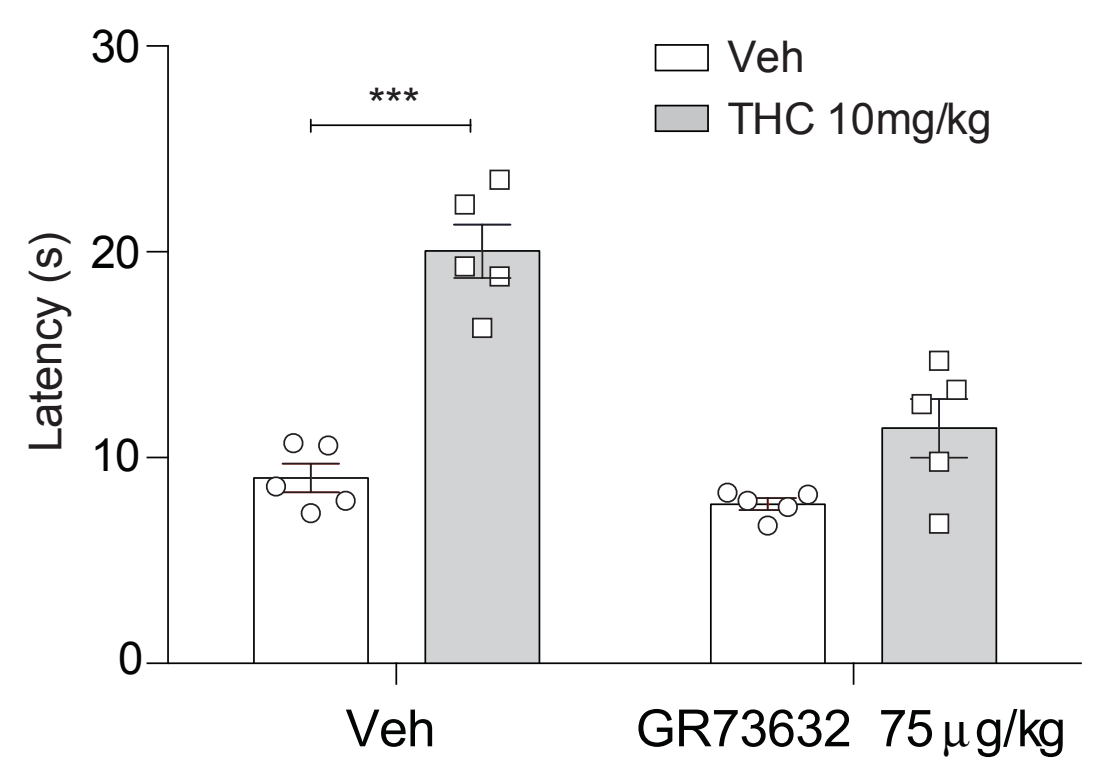

G
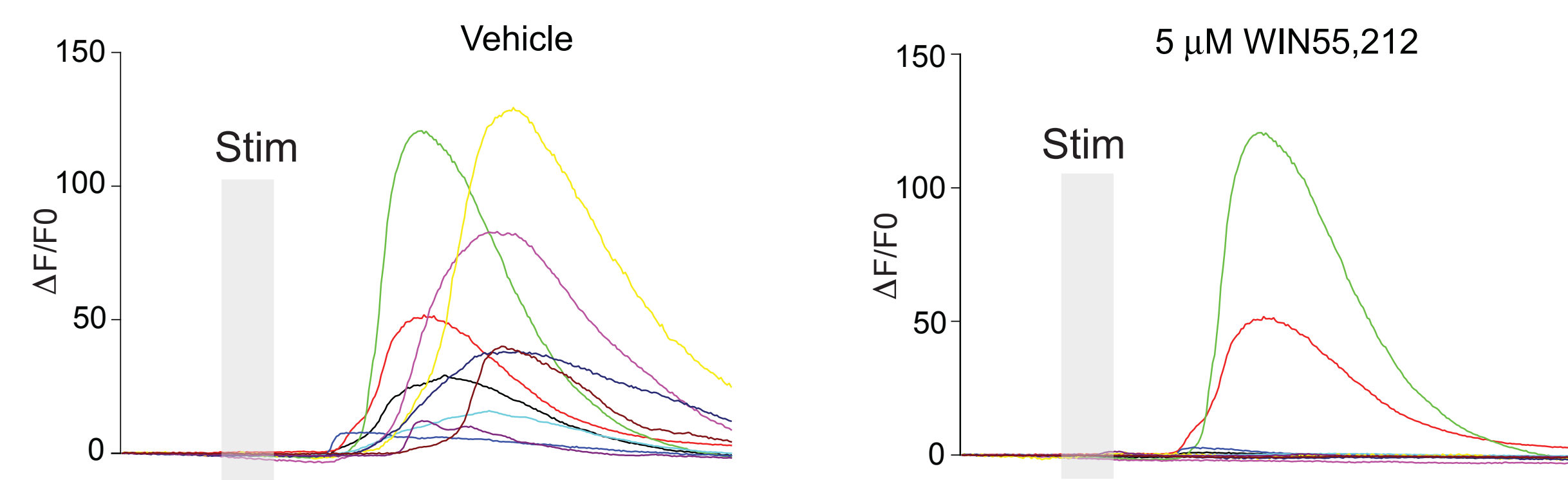

$10 \mathrm{~s}$

J

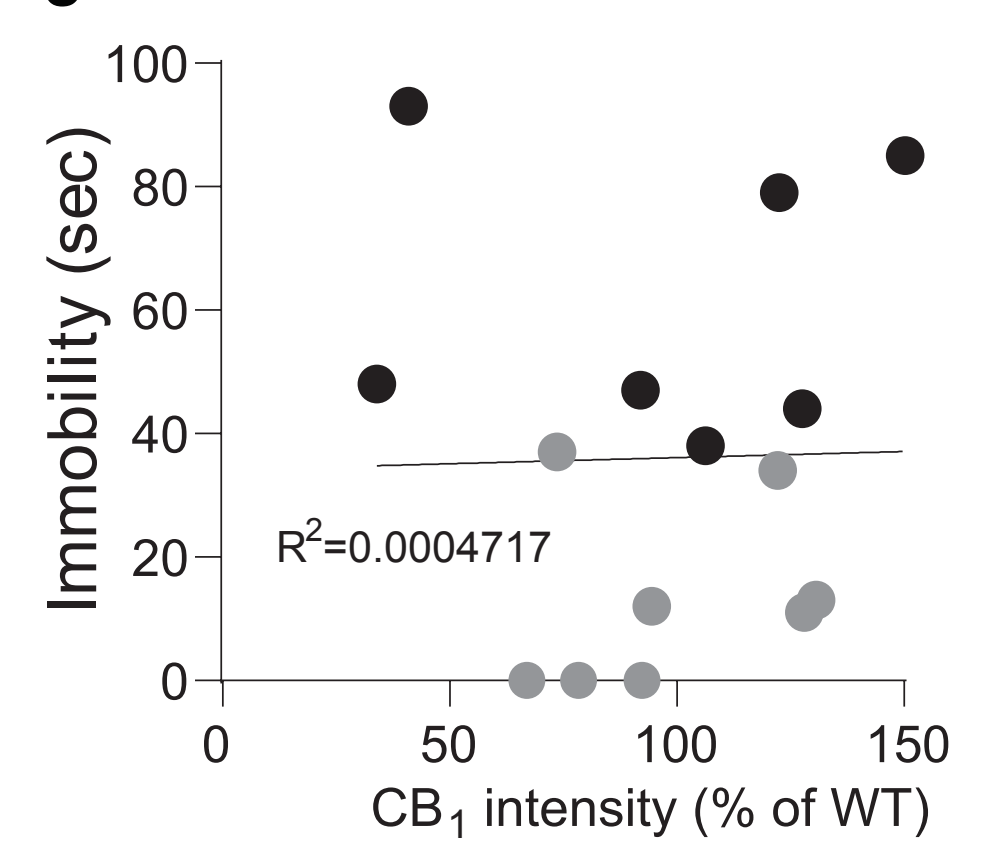

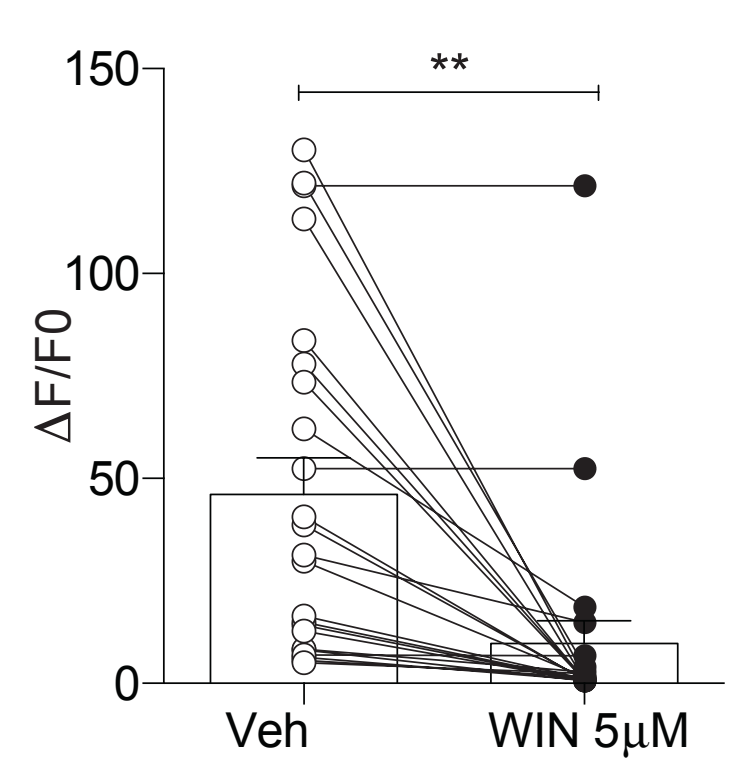

K

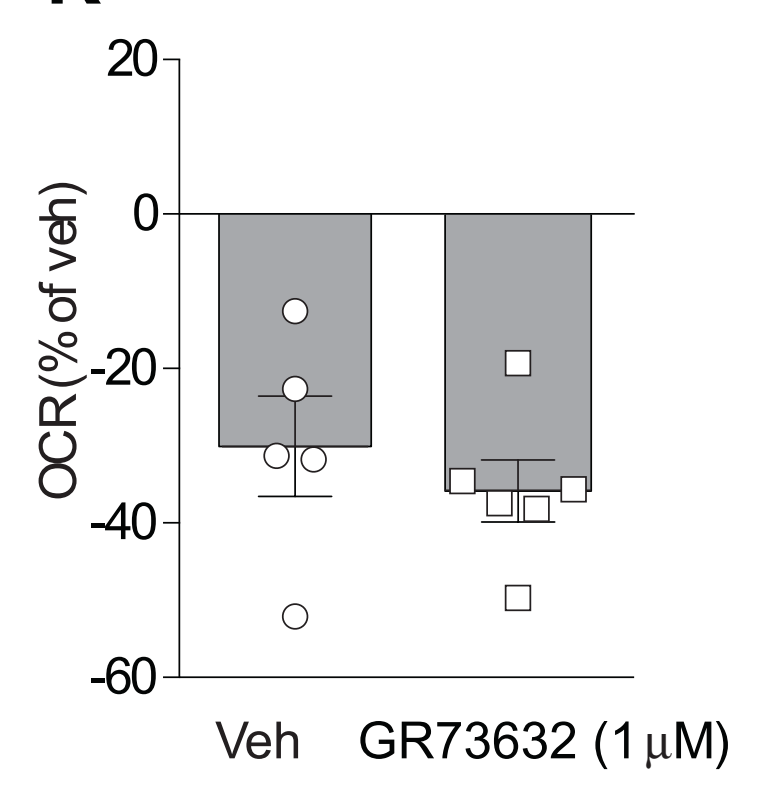


Figure S3 (cont)

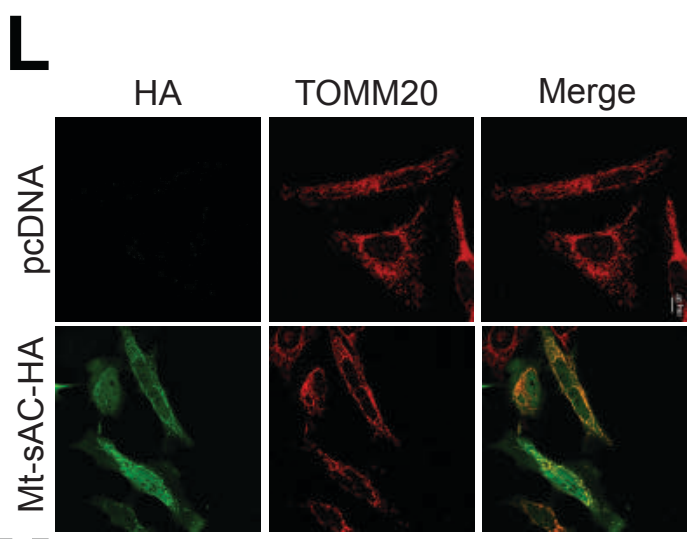

M Dapi / Ha-tag
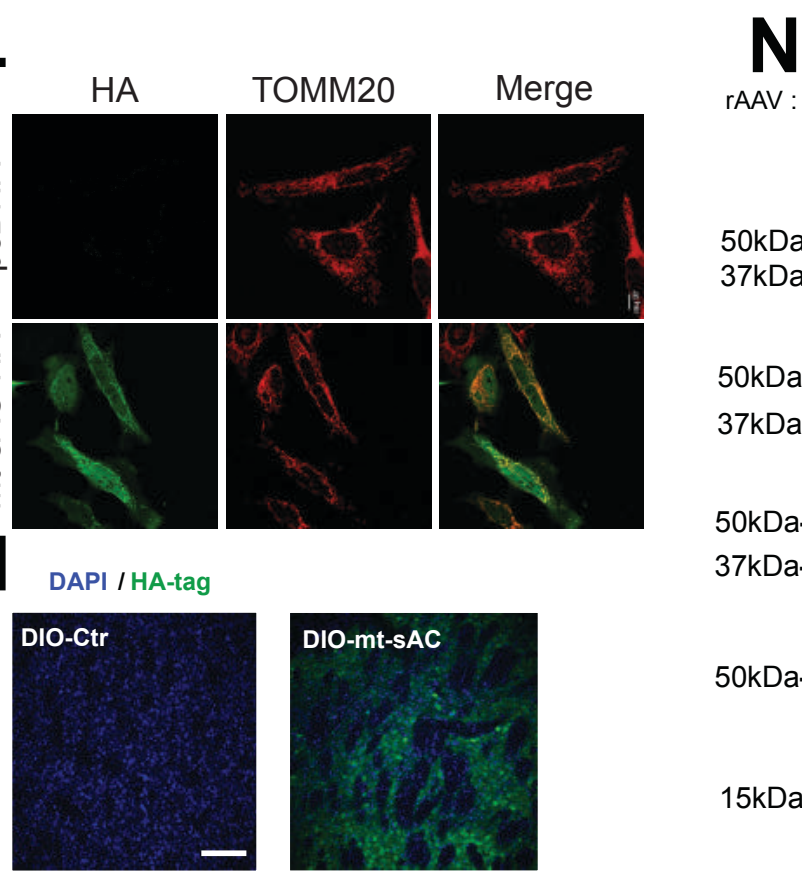

rAAV :

Ctr mt-sAC-HA

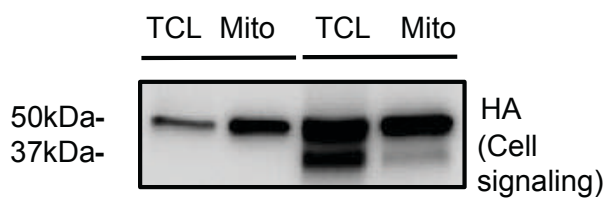

rAAV : Ctr mt-sAC

$50 \mathrm{kDa}-$

$37 \mathrm{kDa}-$
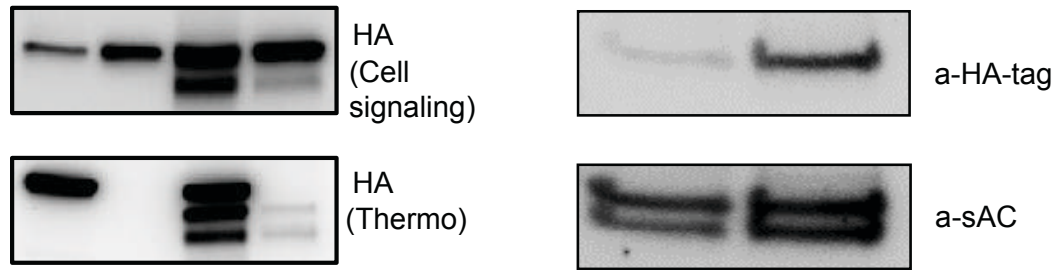

$50 \mathrm{kDa}-$

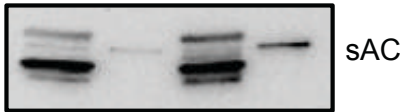

$50 \mathrm{kDa}-$

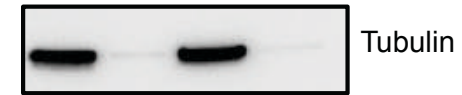

$15 k D a-$

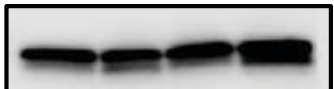

Tomm20

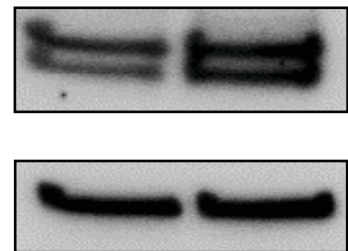

a-sAC

a-Tubulin
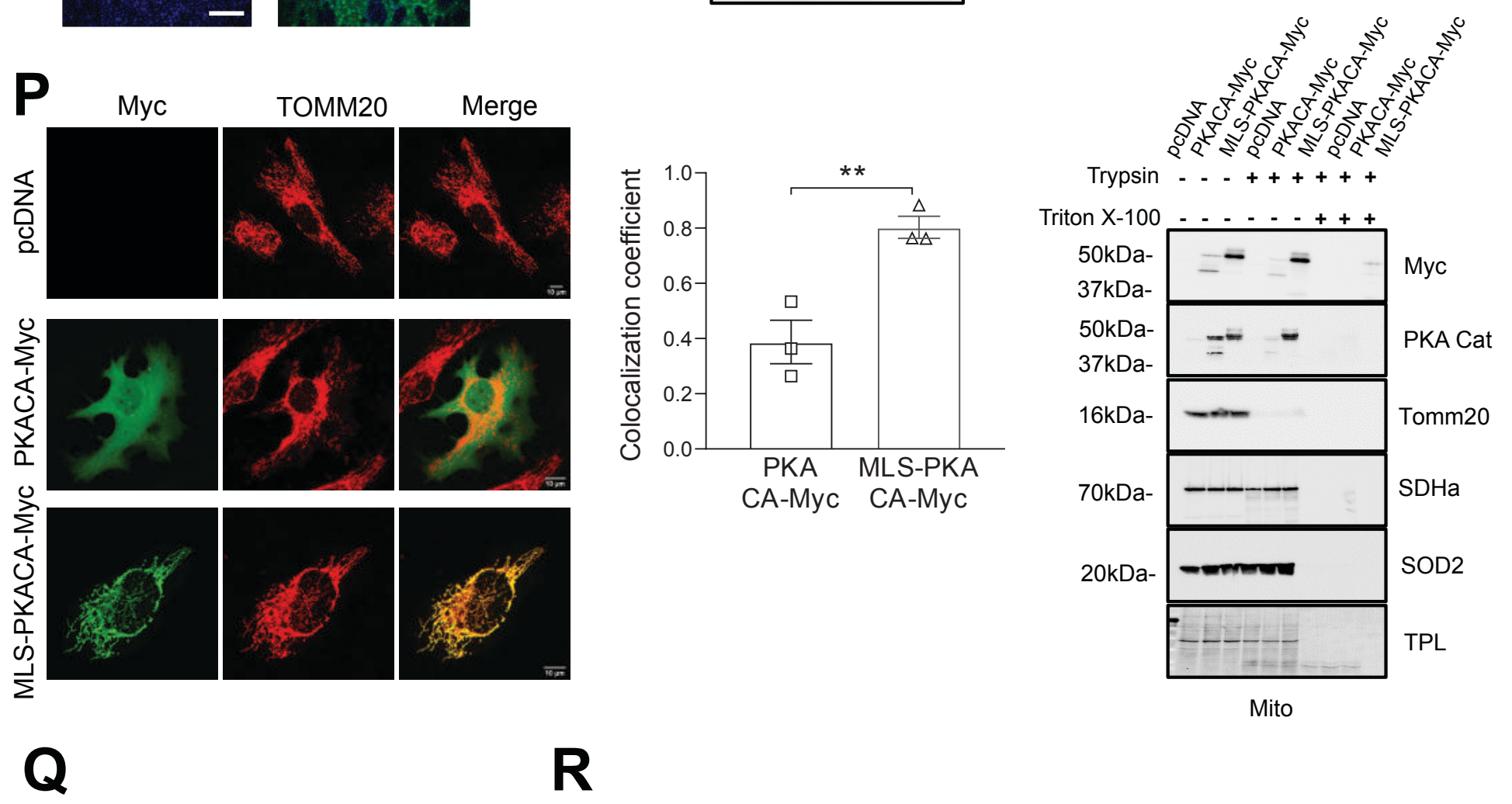

$\mathbf{R}$

rAAV : Ctrl PKA-CA MLS-PKA-CA
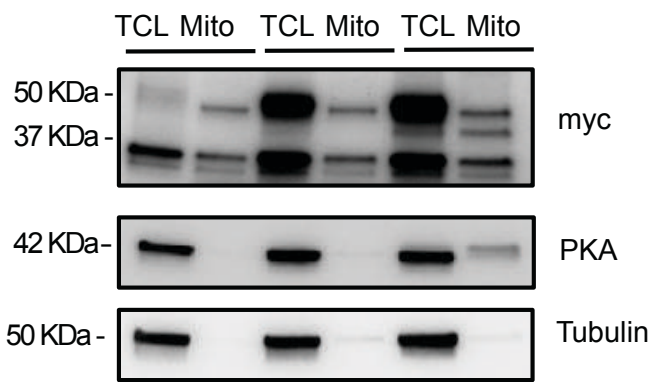

$15 \mathrm{KDa}-$

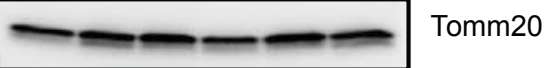

rAAV : Ctr PKA-CA MLS-PKA-CA

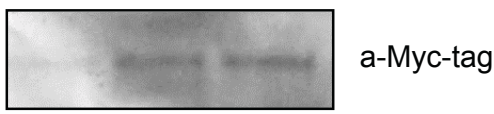

a-Tubulin 
Figure S4

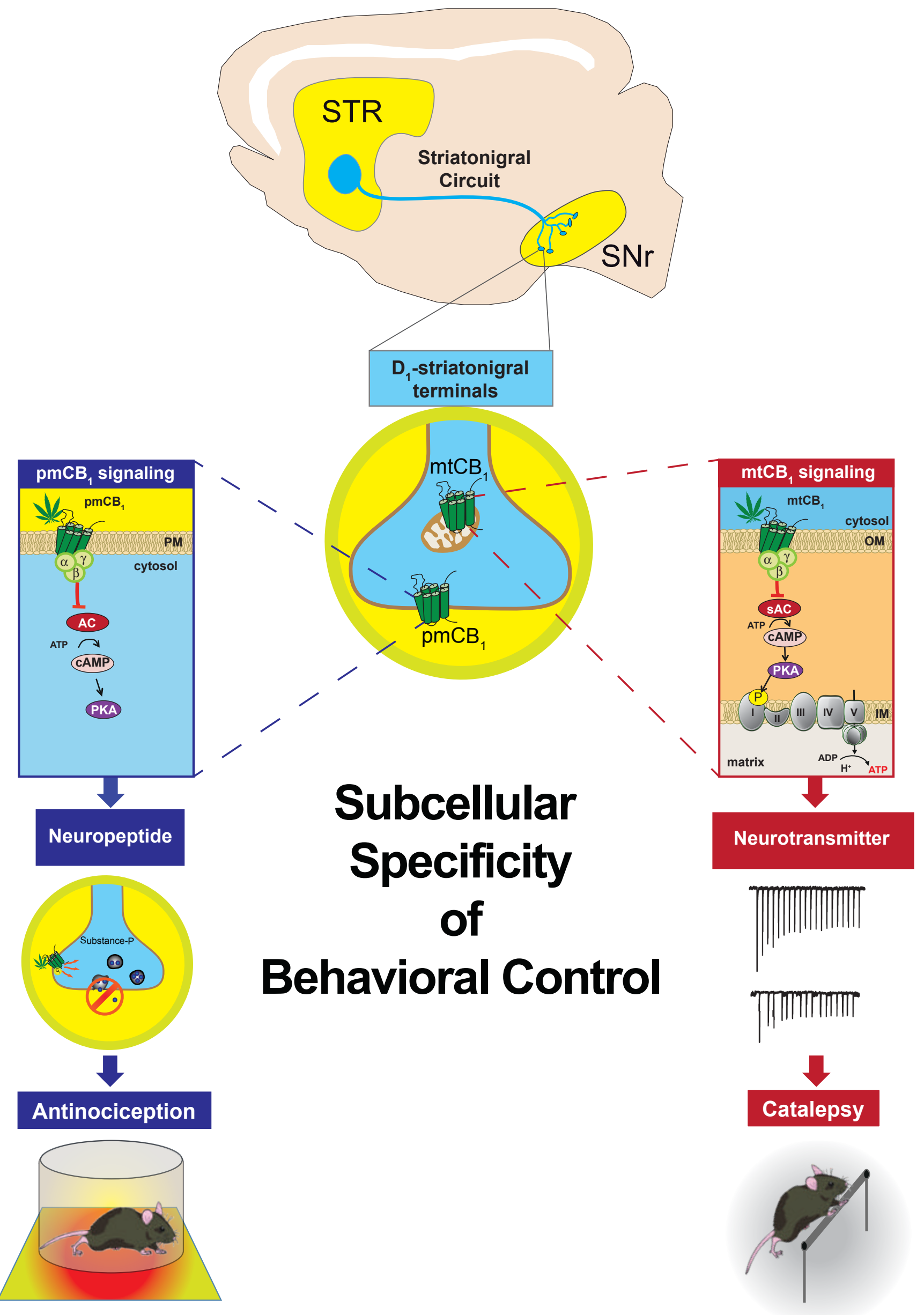

